
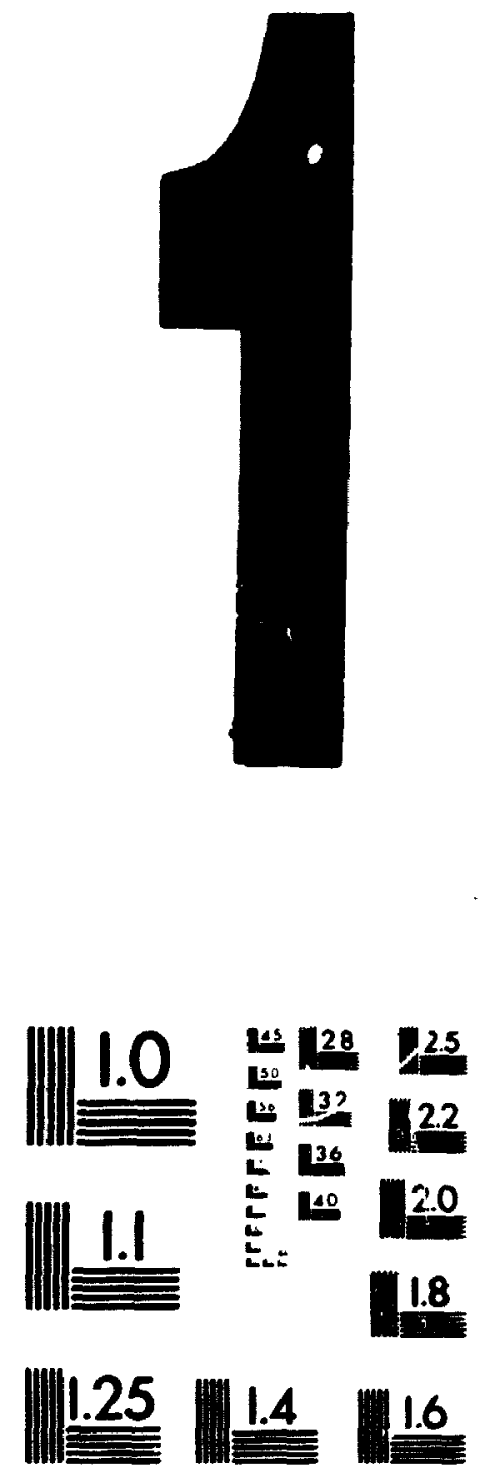

MICROCOPY RESOLUTION TEST CHART NATIONAL BUREAU OF STANDARDS

STANDART REFERENCE MATERIAL 1010 (ANSI and ISC TEST CHART No 2, 
National Library

of Canada

Acquisitions and

Bibliographic Services Branch

395 Welington Street

Onawa. Onlano

KIA ONA
Bibliotheque nationale

du Canada

Direction des acquisitions et

des services bibliographiques

395. ne Wellington

Onawa (Onlario)

\section{NOTICE}

AVIS

La qualité de cette microforme dépend grandement de la qualité de la thèse soumise au microfilmage. Nous avons tout fait pour assurer une qualité supérieure de reproduction.

S'il manque des pages, veuillez communiquer avec l'université qui a conféré le grade.

La qualité d'impression de certaines pages peut laisser à désirer, surtout si les pages originales ont été dactylographiées à l'aide d'un ruban usé ou si l'université nous a fait parvenir une photocopie de qualité inférieure.

La reproduction, même partielle, de cette microforme est soumise à la Loi canadienne sur le droit d'auteur, SRC. 1970, c. C-30, et ses amendements subséquents.
Reproduction in full or in part of this microform is governed by the Canadian Copyright Act, R.S.C. 1970, c. C-30, and subsequent amendments.
Some pages may have indistinct print especially if the original pages were typed with a poor typewriter ribbon or if the university sent us an inferior photocopy.

The quality of this microform is heavily dependent upon the quality of the original thesis submitted for microfilming. Every effort has been made to ensure the highest quality of reproduction possible.

If pages are missing, contact the university which granted the degree. 


\title{
DEVELOPMENT AND EVALUATION OF A HIGH VOLTAGE SUPPLY UNIT FOR ELECTRGRHEOLOGICAL FLUID DAMPERS
}

\author{
by \\ Murray Al-n Sturk, B.Eng. \\ A thesis submitted to \\ the Faculty of Graduate Studies and Resemain \\ in partial fulfilment of \\ the requirements for the degree of \\ Master of Engineering
}

\author{
Ottawa-Carleton Institute \\ for Mechanical and Aerospace Engineering \\ Department of Mechanical and Aerospace Engineering \\ Carleton University \\ Ottawa, Ontario
}

September 1993

(- Copyright Murray Sturk, 1993 
National Library

of Canada

Acquisitions and

Bibliographic Services Branch

395 Wellington Sineet

Otlawa, Oniario

KIA ONA
Bibliotheque nationale

du Canada

Direction des acquisitions et

des services bibliographiques

395, nue Wollington

Oltema (Onterio)

K1A ONA

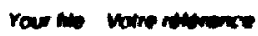

Our nowe nemenes
The author has granted an irrevocable non-exclusive licence allowing the National Library of Canada to reproduce, loan, distribute or sell copies of his/her thesis by any means and in any form or format, making this thesis available to interested persons.
L'auteur a accordé une licence irrévocable et non exclusivé permettant à la Bibliotheque nationale du Canada de reproduire, prêter, distribuer ou vendre des coples de sa these de quelque manière et sous quelque forme que ce soit pour mettre des exemplaires de cette thèse à la disposition des personnes intéressées.

L'auteur conserve la propriété du drolt d'auteur qui protège sa these. Ni la thèse ni des extraits substantiels de celle-cl ne dolvent être imprimés ou autrement reproduits sans son autorisation.

ISBN $\quad 0-315-89864-X$ 
Nom Murray A. Stur !

Dissertation Abstrocts In hernational is arranged by broad, general subject calegories. Please select the one subject which most nearty describes tha content of your dissertation. Enter the corresponding four-digit code in the spoces provided.

Autamotive Encinering

sunket TaM

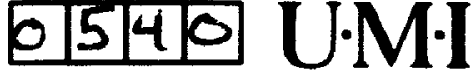

Sunvect CODE

\section{Subinet Congories}

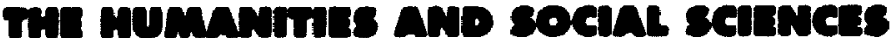

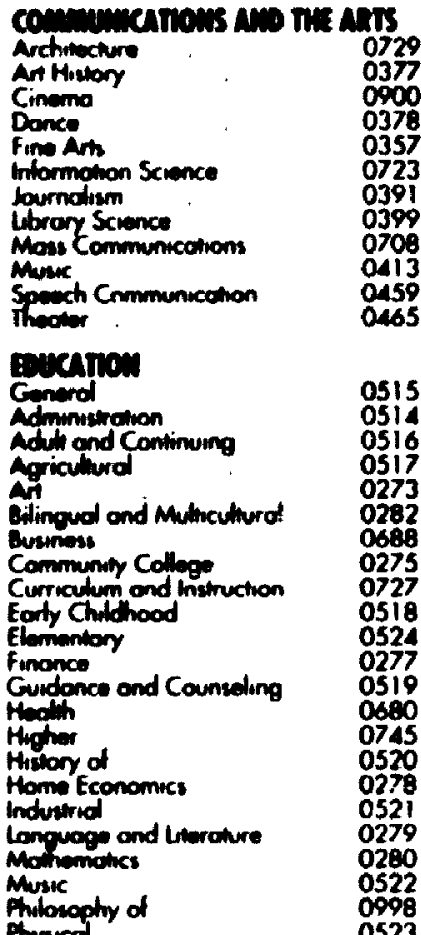

Psychology

Rooding

Sciences

Secondory

Sociol Sciences

Socrology of

Speciol

Teocher Irauning

Technology

Tess ond hoosurements

Vocotionol

\section{umeunes, unatres an} ineusics

Longugose

Ancrent

Modern

Lineroture

General

Compordive

Modievol

Modern

Africar

Amoricon

Aston

Conodion (English)

Conodion (French)

English

Germonic

Lotin Americon

Middle Eostern

Romonce

Slavic and East Europeon

0679

0289

0290

0401

0294

0295

0316

0591

0305

0352

0355

0312

0312

0313

0523 mosonit, narem an Minotosr

Philosophy

Religyor.

Biblical Studies

Clergy.

Hastory of

Philosophy of

Theology.

\section{soan sojuct}

Americon Studes

Anthropology

Anchoedogr

Culurol

Business Administrotion

Gemerol

Accounting

Bonking

Monogement

Morketing

Conodion Studies

Economics

Aanerol

Commerce-Business

Commerce

Finonse

History

theor

folklore

Geogrophy

Gerontology

History

Generol
0422

0318

0321

0319

0320

0469

0323

032

0326
0327

0327

0310

0272

0770
0454

0338

0385

0501

0503

0505

050

Os09

0510

0358

0360

0351

0578

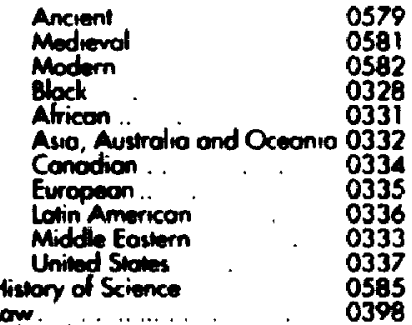

Politicol Science.

\section{Generol}

Inmenational low ond

Relotions

Public Admunistrotion

Recreation

Socioloory

General

$\begin{array}{ll}\text { Gemeral } & 0626 \\ \text { Crminology and Penology } & 0627\end{array}$

Eemogrophy ond Rocrol Studies 0631

individual and family

Shudiss

Indusuriol and Labor

Relotions

Public and Sociol Wellore

Sociol Structure and

Development

Theory and Methods

Tronsportation

Urban and Regional Planning

0628

0629

0630

0700

0344

0709

0999

0453

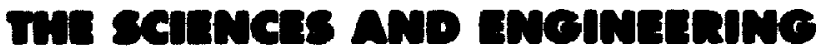

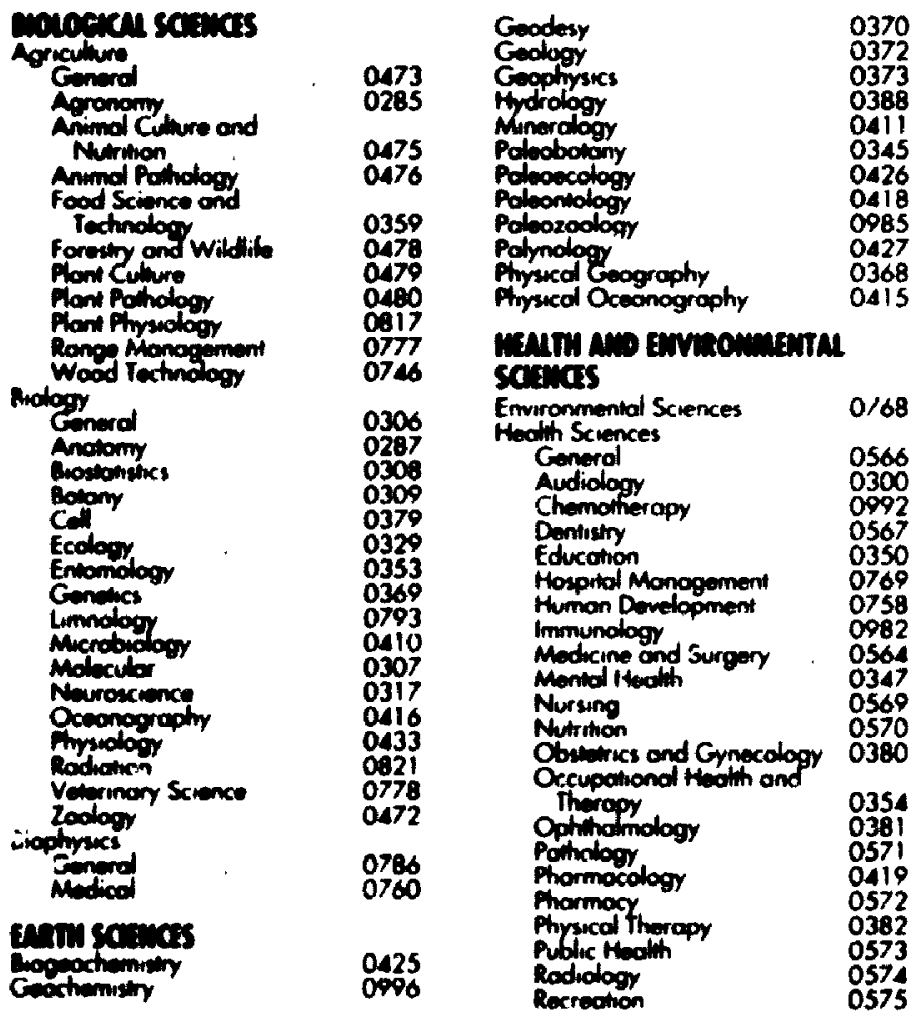

Speoch Poithology
Toxicology

Home Economics

\section{Pursecu saguas}

Pure Sciences

Chemisiny

Agrencol

Anolytical

Brochemistry

inorgonic

Nucieor

Prgonic

Phormoces

Physical

Rodiotion

Mothemotics

Physics

Generol

Astromonity and

Astrophysuc:

Almospheric Secunce

Alomic

Electronics and Electricity

Elementory Porticles and

High Energy

Fluid and Plosmo

Molecular

Nucleor

Optics

Rodiation

Solid Sidte

Stotistics

Apitind Scinnces

Aaplied Machanics

Computer Science
0460

0386

Engineering

Aorospoce

Agricuthurol

Biomedical

Chemical

Civil

Electronics and Electrical

Hoot and Thermodynomics

Hydroulic.

Industrial

Morine

Matericals Serence

Machonical

Metollurgy

Mining

Pockoging

Pockoging

Sonitary and Municipal

System Science

Goonctinology

Operotions leseorch

Plastics Tectnology

Textile Tectinology

\section{Frantesr}

Generol

Bhovorel

Development

Experimental

industrict

Personaling

Prysologecol

Psychobiology

Socid 
The undersigned recommend to the Faculty of Graduate Studies

and Research acceptance of the thesis

"DEVELOPMENT AND EVALUATION OF A HIGH VOLTAGF SUPPLY UNIT

FOR ELECTRORHEOLOGICAL DAMPERS"

submitted by Murray Alan Sturk

in partial fulfilment of the requirements for

the degree of Master of Engineering

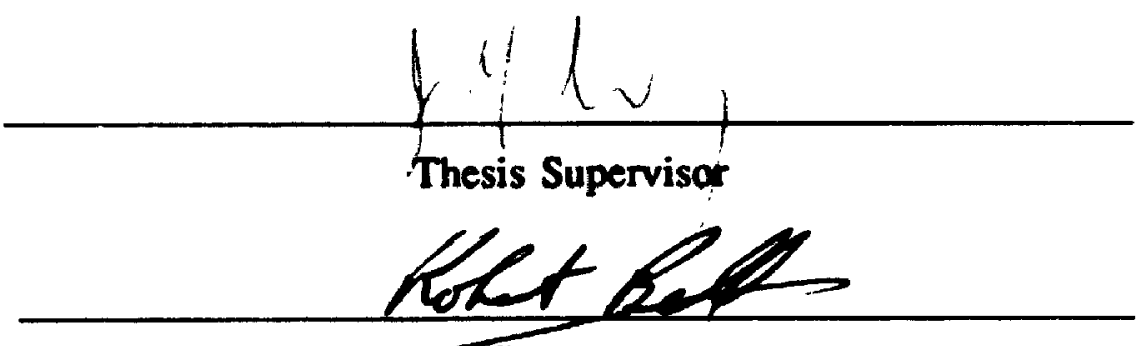

Chair, Department of Mechanical and Aerospace Engineering

Carleton University 


\begin{abstract}
The purpose of the thisis is to demonstrate that unipolar direct current pulses are effective in the control of Electrotheological Fluids, and these pulses can be simply and effectively generated by a flyback DCDC converter. The three main topics investigated in the thesis are:
\end{abstract}

1. Characterization of Electrorheological (ER) Fluids with respect to mechanical and electrical properties;

2. Development and testing of a High Voltage Supply Unit for exciting the ER fluid; and

3. Testing of the ER damper in both passive and active modes.

The main thrust of the dissertation is with regard to the development of the High Voltage Supply Unit for modulating the damping force in the ERF damper. It is shown that a simple and economical High Voltage Supply Unit can be built from a conventional automotive ignition coil. There is strong evidence that ER Fluids are easily controllable with Pulse-Width-Modulation (PWM) techniques - and that an ER damper as might exist in an automotive suspension system can be controlled. in a practical and efficient manner.

Semi-Active suspensions are intended to produce a controllable damping force to improve the ride quality of the vehicle. Two distinct Semi-Active strategies were utilized in controlling the ER damper in a closed loop system. The results are compared with similar tests performed with the ER damper in a passive mode. 


\section{ACKNOWLEDGEMENTS}

The research described in this report was conducted at the Carleton University Transport Technology Research Laboratory under the supervision of Dr. J.Y. Wong. Funding was made available from an Natural Sciences and Engineering Research Council (NSERC) grant awarded to Professor Wong. I would like to thank Dr. Wong for patiently contributing his extensive experience and knowledge to this project. I am truly grateful and honoured to be under his supervision.

I would also like to express my gratitude to Dr. X.M. Wu for his assistance and guidance throughout the course of my research activities. Dr. Wu was instrumental in organizing and conducting many of the experiments described within this report. In addition, Dr. Wu was mainly responsible for coding the control strategies into software.

I would like to thank Chris Bontolotto, who is publishing his Master's Thesis on the theological properties of ER fluids, for providing all the Couette flow (shear stress versus shear rate) information and graphs.

I would like to thank Peter Manache and Mike Kelly of the Engineering Technical Centre - Electronics for their help and enlightenment in all matrers electrical.

Finally, I would like to thank Dr. D. Russeli for attending our meetings and sharing his ideas on control strategies. 


\section{TABLE OF CONTENTS}

Page

Acceptance Sheet $\ldots \ldots \ldots \ldots \ldots \ldots \ldots \ldots \ldots \ldots \ldots \ldots \ldots$ ii

Abstract $\ldots \ldots \ldots \ldots \ldots \ldots \ldots \ldots \ldots \ldots \ldots \ldots \ldots \ldots \ldots \ldots \ldots$

Acknowledgements $\ldots \ldots \ldots \ldots \ldots \ldots \ldots \ldots \ldots \ldots \ldots \ldots \ldots$ iv

Table of Contents $\ldots \ldots \ldots \ldots \ldots \ldots \ldots \ldots \ldots \ldots \ldots \ldots \ldots$

List of Tables $\ldots \ldots \ldots \ldots \ldots \ldots \ldots \ldots \ldots \ldots \ldots \ldots \ldots \ldots \ldots$

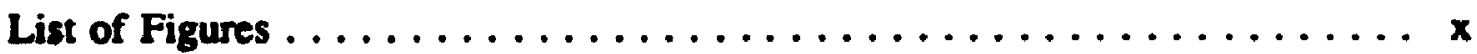

List of Symbols $\ldots \ldots \ldots \ldots \ldots \ldots \ldots \ldots \ldots \ldots \ldots \ldots \ldots \ldots \ldots$

CHAPTER I: Introduction $\ldots \ldots \ldots \ldots \ldots \ldots \ldots \ldots \ldots \ldots$

CHAPTER II: Electrorheological Fluids . . . . . . . . . . . . . 4

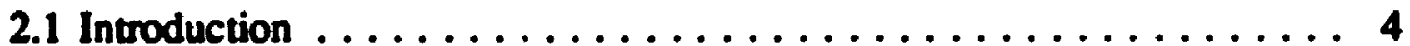

2.2 Theoretical Background $\ldots \ldots \ldots \ldots \ldots \ldots \ldots$

2.2.1 Fibrillation Theory $\ldots \ldots \ldots \ldots \ldots \ldots \ldots$

2.2.2 Electric Double Layer Polarisation . . . . . . . . . . . . . 11

2.2.3 Electro-Osmosis and Capillarity . . . . . . . . . . . . . . 14

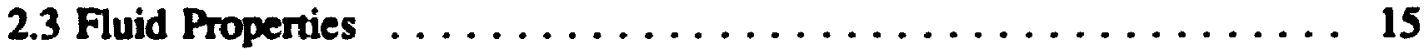

2.3.1 Bingham Flow Model . . . . . . . . . . . . . . . 15

2.3.2 Apparent Viscosity and Electroviscosity ........... 16

2.3.3 Static and Dynamic Yield Stress . . . . . . . . . . . . 20

2.3.4 Shear Ratio ........ ................. 20

2.3.5 Effect of Temperature On Shear Stress . . . . . . . . . . . . 21

2.3.6 The Role of Water In ER Fluids . . . . . . . . . . . 22

2.3.7 Particle Size $\ldots \ldots \ldots \ldots \ldots \ldots \ldots \ldots \ldots \ldots \ldots . \ldots \ldots$

2.3.8 Volume Fraction and Volume Factor ... . . . . . . . . 25

2.3.9 Tribological Aspects of ER Fuids . . . . . . . . . . . . . 27

2.3.10 Secondary ER Effects: Rheopexy and Electrophoresis . . . . . 28 
2.3.11 Summary of Mechanical Properties . . . . . . . . . . 29

2.4 Electrical Properties $\ldots \ldots \ldots \ldots \ldots \ldots \ldots \ldots \ldots \ldots \ldots$

2.4.1 Effect of Field Strength On Shear Stress .......... 30

2.4.2 Conductivity and Current Density . . . . . . . . . . 34

2.4 .3 Total Current $\ldots \ldots \ldots \ldots \ldots \ldots \ldots \ldots \ldots \ldots . \ldots 4$

2.4.4 Complex Permittivity and Dielectric Hysteresis ......... 48

2.4.5 Role of Permittivity In ER Fluids ............. 50

2.4.6 Permittivity (Dielectric Constant) Measurements . . . . . . 52

2.4.7 Dielectric Strength $\ldots \ldots \ldots \ldots \ldots \ldots \ldots \ldots \ldots \ldots 6$

2.4.8 Frequency Effects ................... 64

2.4.9 Summary of Electrical Properties . . . . . . . . . 66

CHAPTER III: High Voltage Supply Unit $\ldots \ldots \ldots \ldots \ldots \ldots \ldots \ldots 68$

3.1 Requirements of The High Voltage Power Supply ......... 68

3.2 Flyback Converter $\ldots \ldots \ldots \ldots \ldots \ldots \ldots \ldots \ldots \ldots$. 81

3.2.1 Theory of Operation $\ldots \ldots \ldots \ldots \ldots \ldots \ldots \ldots \ldots$. 81

3.2.2 Transfer Function and Voltage Gain $\ldots \ldots \ldots \ldots \ldots \ldots \ldots 85$

3.2.3 Power Supply Components . . . . . . . . . . . . 89

3.2.3.1 Transformer . . . . . . . . . . . . . . . . 90

3.2.3.2 Switching Transistor $\ldots \ldots \ldots \ldots \ldots \ldots \ldots \ldots 98$

3.2.3.3 Integrated Circuit Regulator $\ldots \ldots \ldots \ldots \ldots \ldots \ldots 101$

3.2.3.4 Diode . . . . . . . . . . . . . . . . . 103

3.2.4 Parasitic Components . . . . . . . . . . . . . . 103

3.2.5 Flyback Converter Operation and Performance ........ 109

3.2.5.1 Power Supply System Overview . . . . . . . . . . 109

3.2.5.2 Duty Cycle (PWM) Control $\ldots \ldots \ldots \ldots \ldots \ldots \ldots 111$

3.2.5.3 Switching Frequency $\ldots \ldots \ldots \ldots \ldots \ldots \ldots \ldots$

3.2.5.4 Response Time $\ldots \ldots \ldots \ldots \ldots \ldots \ldots \ldots \ldots \ldots 117$

3.3 Discharge Circuit $\ldots \ldots \ldots \ldots \ldots \ldots \ldots \ldots \ldots \ldots \ldots$

3.4 System Performance . . . . . . . . . . . . . . . 127 
CHAPTER IV: Electronic Controlled Suspensions $\ldots \ldots \ldots \ldots \ldots \ldots \ldots 131$

4.1 Introduction $\ldots \ldots \ldots \ldots \ldots \ldots \ldots \ldots \ldots \ldots \ldots \ldots \ldots \ldots \ldots \ldots$

4.2 Active Suspensions $\ldots \ldots \ldots \ldots \ldots \ldots \ldots \ldots \ldots \ldots \ldots \ldots \ldots$

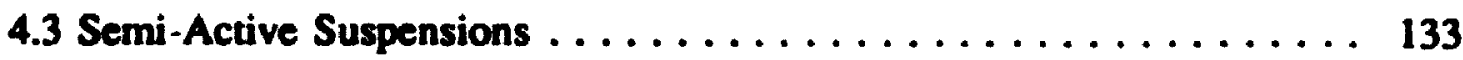

4.4 Practical Applications of Semi-Active Suspensions . . . . . . . . . 137

4.4.1 Historical Background . . . . . . . . . . . . . 137

4.4.2 Hardware Limitations . . . . . . . . . . . . . 138

4.4.3 Wheel Hop Control $\ldots \ldots \ldots \ldots \ldots \ldots \ldots \ldots \ldots \ldots$

4.4.4 Relative Feedback Control Strategies . . . . . . . . . . 143

4.4.5 Mechanical versus Electrorheological Dampers . . . . . . 147

CHAPTER V: Experimenta! Apparatus and Test Procedures ......... 150

5.1 Quarter-Car-Mode' Test Rig . . . . . . . . . . . . . 150

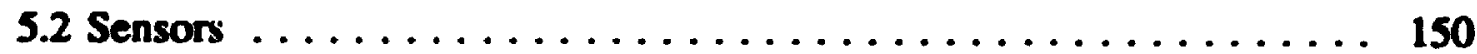

5.3 Control Strategy $\ldots \ldots \ldots \ldots \ldots \ldots \ldots \ldots \ldots \ldots \ldots \ldots 151$

5.4 Tests and Procedures $\ldots \ldots \ldots \ldots \ldots \ldots \ldots \ldots \ldots \ldots \ldots$

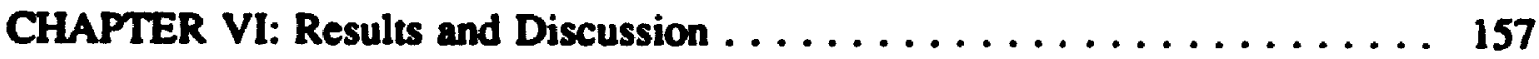

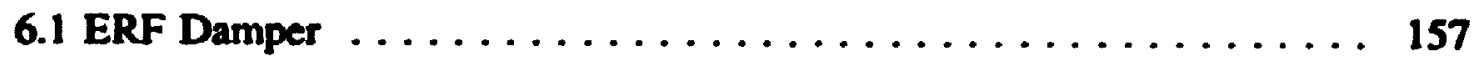

6.2 High Voltage Supply Unit $\ldots \ldots \ldots \ldots \ldots \ldots \ldots \ldots \ldots \ldots$

6.3 System Performance $\ldots \ldots \ldots \ldots \ldots \ldots \ldots \ldots \ldots \ldots \ldots$

6.3.1 Passive Control $\ldots \ldots \ldots \ldots \ldots \ldots \ldots \ldots \ldots \ldots \ldots$

6.3.2 Semi-Active Control $\ldots \ldots \ldots \ldots \ldots \ldots \ldots \ldots \ldots \ldots$

CHAPTER VII: Conclusions $\ldots \ldots \ldots \ldots \ldots \ldots \ldots \ldots \ldots \ldots \ldots$

7.1 ER Fluids $\ldots \ldots \ldots \ldots \ldots \ldots \ldots \ldots \ldots \ldots \ldots \ldots \ldots \ldots \ldots$

7.1.1 ERF 'A' $\ldots \ldots \ldots \ldots \ldots \ldots \ldots \ldots \ldots \ldots \ldots \ldots \ldots$

7.1.2 ERF 'B' $\ldots \ldots \ldots \ldots \ldots \ldots \ldots \ldots \ldots \ldots \ldots \ldots \ldots \ldots 17$

7.1.3 Alternative ER Fluids $\ldots \ldots \ldots \ldots \ldots \ldots \ldots \ldots \ldots \ldots 171$

7.2 ERF Damper $\ldots \ldots \ldots \ldots \ldots \ldots \ldots \ldots \ldots \ldots \ldots \ldots \ldots$

vii 
7.3 High Voltage Supply Unit $\ldots \ldots \ldots \ldots \ldots \ldots \ldots \ldots \ldots \ldots$

7.4 Control Strategies and System Performance ............ 174

CHAPTER VIII: Recommendations $\ldots \ldots \ldots \ldots \ldots \ldots \ldots \ldots \ldots \ldots$

8.1 ERF Damper $\ldots \ldots \ldots \ldots \ldots \ldots \ldots \ldots \ldots \ldots \ldots \ldots \ldots$

8.2 High Voltage Supply Unit $\ldots \ldots \ldots \ldots \ldots \ldots \ldots \ldots \ldots \ldots$

8.3 Control Strategies $\ldots \ldots \ldots \ldots \ldots \ldots \ldots \ldots \ldots \ldots \ldots .178$

8.4 Summary $\ldots \ldots \ldots \ldots \ldots \ldots \ldots \ldots \ldots \ldots \ldots \ldots \ldots$

References $\ldots \ldots \ldots \ldots \ldots \ldots \ldots \ldots \ldots \ldots \ldots \ldots \ldots \ldots \ldots$ 


\section{LIST OF TABLES}

TABLE DESCRIPTION

PAGE

I ERF 'A' Power Law Exponent and Constant $\ldots \ldots \ldots \ldots \ldots 42$

II ERF 'B50' Power Law Exponent and Constant ..........43

III ERF 'B100' Power Law Exponent and Constant . . . . . . . . . 44

IV Capacitance Measurements of ERF 'A' $\ldots \ldots \ldots \ldots \ldots \ldots$

V Capacitance Measurements of ERF 'B50' .............59

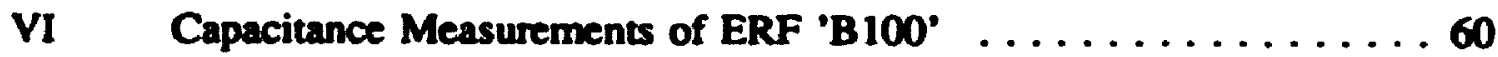

VII Relative Dielectric Constants of Two Polymers $\ldots \ldots \ldots 65$

VIII Summary of Elecurical Properties . . . . . . . . . . . . 67

IX Coil Comparison $\ldots \ldots \ldots \ldots \ldots \ldots \ldots \ldots \ldots \ldots$

$\mathbf{X} \quad$ Transistor Comparison $\ldots \ldots \ldots \ldots \ldots \ldots \ldots \ldots$ 


\section{LIST OF FIGURES}

\section{FIGURE DESCRIPTION}

1 Rotating (Couette) Viscometer Measurements of

Shear Stress versus Shear Rate for ERF 'B' . . . . . . . . . 19

2 Rotating (Couette) Viscometer Measurements of

Shear Stress versus Shear Rate for ERF 'A' $\ldots \ldots \ldots \ldots \ldots \ldots$

3 Parallel Piate Electrode Measurements of

Current Density versus Electric Field Strength for ERF 'A' . . . . . 39

4 Parallel Plate Elcutrode Measurements of

Current Density versus Electric Field Strength for ERF 'B50' . . . 40

5 Parallel Plate Electrode Measurements of

Current Density versus Electric Field Strength for ERF 'B 100' . . 41

6 Rotating (Couette) Viscosmeter Measurements of

Shear Ratio versus Temperature $\ldots \ldots \ldots \ldots \ldots \ldots \ldots \ldots$

7 Cross Sectional Yiew of Electrorheological Fluid Damper

Used In Semi-Active Saspension System Testing . . . . . . . . 63

8 Estimated Capacitance of An Electrorheological Fluid Damper

With Fixed Length and Diameter But Varying Number of Cylinders . 77

9 Estimated Electrostatic Energy Storage of An Electrorheological

Fluid Damper With Fixed Length, Diameter and Electric Field

Strength But Varying Number of Cylinders . . . . . . . . 78

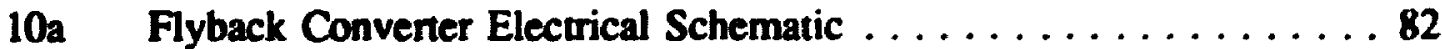

10b Simplified Equivalent Model $\ldots \ldots \ldots \ldots \ldots \ldots \ldots \ldots \ldots$

11 Output Voltage, Primary Current and Voltage Gain versus Duty Cycle For Coil No.1 . . . . . . . . . . . 112

12 Output Voltage versus Duty Cycle For Coil No.1

At Various Switching Frequencies . . . . . . . . . . . 114

13 Output Voltage versus Duty Cycle For Coil No.2

At Various Switching Frequencies $\ldots \ldots \ldots \ldots \ldots \ldots \ldots \ldots$ 
14 Output Voltage Across 100 pF ERF Fluid Using Coil No.1

Showing Effective Rise Time and Discharge Time

of High Voltage Supply Unit and Discharge Circuit . . . . . . . 119

15 Output Voltage Across ERF Damper Using Coil No1

Showing Effective Rise Time and Discharge Time

of High Voltage Supply Unit and Discharge Circuit $\ldots \ldots \ldots \ldots 122$

16 Output Voltage Across 450 pF Capacitor Using Coil No.1

Showing Effective Rise Time and Discharge Time

of High Voltage Supply Unit and Discharge Circuit $\ldots \ldots \ldots \ldots 123$

17 (1stput Voltage Across 770 pF Capacitor Using Coil No.1

Showing Effective Rise Time and Discharge Time

of High Voltage Supply Unit and Discharge Circuit ........ 124

18 Output Voltage Across ERF Damper Using Coil No.2

Showing Effective Rise Time and Discharge Time

of High Voltage Supply Unit and Discharge Circuit . . . . . . 125

19 Measured Sprung Mass Acceleration of

The Semi-Active Suspension System

Before and After the Application of High Voltage $\ldots \ldots \ldots \ldots 128$

20 Representative Output Voltage and Commanded or

Desired Voltage For the Semi-Active Suspension System . . . . . 130

21 Diagremmatical Sketch of Semi-Active Suspension System

Showing Instrumentation, Sprung Mass, Unsprung Mass and

Electroheological Fluid Damper . . . . . . . . . . . 145

22 Experimental Semi-Active Suspension System

Incorporating Electrotheological Fluid Damper . . . . . . . 146

23 Relative Displacement and Relative Velocity of

Semi-Active Suspension System, and Commandod Damping Ratio,

Before and After Application of ON-OFF Control $\ldots \ldots \ldots \ldots 155$ 
24 Relative Displacement and Relative Velocity of

Semi-Active Suspension System, and Commanded Damping Ratio,

Before and After Application of Continuous Control . . . . . . . 156

25 Damping Force versus Relative Velocity

Showing Variation of Damping Force Before and

After Application of High Voltage (Passive Control) . . . . . 158

26 Comparison of Simulated and Experimental Results For the Sprung

Mass Transmissibility Using Both Theoretical Levels of Damping

Ratio and Experimental Levels of Constant Applied Voltage . . . . 165

27 Experimental Results of the Transmissibility of the Sprung

Mass Using Both Passive (Fixed Voltage) and Semi-Active Control

Including ON-OFF and Continuous Semi-Active Control . . . . . 168

28 Experimental Results of the Dynamic Tire Deflection

Using Both Passive (Fixed Voltage) and Semi-Active Control

Including ON-OFF and Continuous Semi-Active Control . . . . . . 169

29 Effective Damping Ratio For the Electrorheological

Fluid Damper versus Frequency $\ldots \ldots \ldots \ldots \ldots \ldots \ldots \ldots$ 


\section{LIST OF SYMBOLS}

SYMBOL DEFINITION

a .......... gain factor

B ........... complex dipolar coefficient

$\zeta \ldots \ldots \ldots$ damping ratio

$\dot{\gamma} \ldots \ldots \ldots$ shear rate

$\Delta \eta \ldots \ldots \ldots$ electroviscosity

o.......... conductivity

$\sigma^{\prime} \ldots \ldots \ldots \ldots$ equivalent conductivity

E $\ldots \ldots \ldots \ldots$ permittivity

$\varepsilon_{0} \ldots \ldots \ldots \ldots$ absolute permittivity of air $\left(8.854 \times 10^{-12} \mathrm{C}^{2} \mathrm{~N}^{-1} \mathrm{~m}^{-2}\right)$

$\varepsilon \ldots \ldots \ldots \ldots$ permittivity of the fluid medium

E $\ldots \ldots \ldots \ldots$ relative permittivity or dielectric constant

n . . . . . . absolute viscosity

$\eta_{\mathrm{A}} \ldots \ldots \ldots \ldots$ apparent viscosity

$\eta_{p} \ldots \ldots \ldots$ plastic viscosity

$\mu_{0} \ldots \ldots \ldots \ldots$ permeability of vacuum $\left(4 \pi \times 10^{-7} \mathrm{Hm}^{-1}\right)$

$\mu_{4} \ldots \ldots \ldots \ldots$ relative permeability $\left(\mu_{\mathrm{ar}}=1.0\right)$

p ......... charge density, or resistivity

$p_{\mathrm{f}} \ldots \ldots \ldots$ fluid density

$p_{p} \ldots \ldots \ldots \ldots$ particle density

t(E) $\ldots \ldots \ldots \ldots$ ER fluid yield stress in response to electric field

t. . . . . . . . static yield stress

$t_{y}, \ldots \ldots \ldots$ shear yield stress

\$......... volume fraction, or magnetic flux

$\omega \ldots \ldots \ldots$ driving radian frequency

is. ......... undamped natural frequency 
A .......... total electrode area

a ......... radius of particle or inner radius of cylinder

B . . . . . . . magnetic flux density

b ......... width of electrode or outer radius of cylinder

C . . . . . . . . capacitance, or a constaרt

C. ........ damping coefficient

C. ........ shunt capacitance

C. ......... secondary capacitance

c $\ldots \ldots \ldots \ldots$ damping coefficient

D ......... duty cycle

$D_{t} \ldots \ldots \ldots$. . . damping factor

d .......... spacing between electrodes

$d Q / d r . . . \ldots$. instantancous rate of charge transfer

$\mathrm{dV} / \mathrm{dt} \ldots \ldots \ldots$ slew rate or rate of change of voltage

E . . . . . . electric field intensity

F. ....... dipole force

$F_{0} \ldots \ldots \ldots$ force on plates with no field

$F_{c} \ldots \ldots \ldots$ control force

$F_{E R} \ldots \ldots \ldots$ force on plates with tield on

f $\ldots \ldots \ldots \ldots$ frequency

$f_{c} \ldots \ldots \ldots \ldots$ critical frequency

$f_{i}$ or $f_{\text {res }} \ldots \ldots \ldots$ resonant frequency

G . . . . . . gap width

g . . . . . . gravitational constant $\left(9.81 \mathrm{~ms}^{-2}\right)$

H . . . . . . magnetic field intensity

I or $\mathbf{i} \ldots \ldots \ldots$ current

L. . . . . . . magnetizing current

L........ peak current 
4.1, $\ldots \ldots \ldots$ secondary and primary current, respectively

J .......... current density

$J_{\text {oma }} \ldots \ldots \ldots$ conduction current density

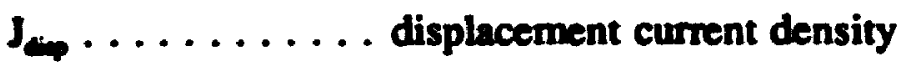

J. . . . . . . electrostatic energy

k .......... constant of proportionality

k. . . . . . . dielectric constant

$k_{1} \ldots \ldots \ldots$ relative permittivity of the silicone fluid $(2.5)$

$k_{1} \ldots \ldots \ldots \ldots$ relative permittivity of the silica particle (7.2)

k. . . . . . . spring rate

$k_{1} \ldots \ldots \ldots$ tire equivalent spring rate

L . . . . . . . length or inductance

L. ......... shunt indictance

$4 \ldots \ldots \ldots$ leakage inductance

L. . . . . p primary inductance

L......... secondary inductance

$\mathbf{N} \ldots \ldots \ldots \ldots$ number of turns

$N_{1} \ldots \ldots \ldots$ number of dipoles per unit volume

$N_{p} \ldots \ldots \ldots \ldots$ number of primary turns

$N_{s} \ldots \ldots \ldots$ number of secondary turns

n .......... an exponent

P ......... power or pressure

$P_{0} \ldots \ldots \ldots$ pressure drop with zero electric field

P. ........ charge density

$P_{\mathrm{ER}} \ldots \ldots \ldots \ldots$ pressure drop with electric ficld applied

p . . . . . . . total dipole moment

Q . . . . . . . volume flow rate

Q. ........ total charge 
$Q_{1}$ and $Q_{2} \ldots \ldots$ charge quantities

q $\ldots \ldots \ldots \ldots$ charge

R........ reluctance

$R_{1} \ldots \ldots \ldots$. load resistance

$R_{p} \ldots \ldots \ldots$ primary resistance

R. ......... secondary resistance

$R_{0}, R_{i} \ldots \ldots$ outermost and innermost radii of damper

r .......... distance between centres

$\mathbf{r}_{\mathbf{g}} \ldots \ldots \ldots \ldots$ radius of sphere

S $\ldots \ldots \ldots \ldots$ speed

T . . . . . . total switching period

tor bar ........ time on and time off, respectively

v ........... voltage

vo ......... volume

$v_{\text {. }} \ldots \ldots \ldots$ drift velocity

$v_{\star} \ldots \ldots \ldots$ direct current voltage

$v_{1} \ldots \ldots \ldots$ initial voltage

$\mathbf{v}_{\text {rel }} \ldots \ldots \ldots$ relative velocity

$v_{z} \ldots \ldots \ldots$ secondary voltage

w ......... work

$y, \dot{y} \ldots \ldots \ldots$ absolute displacement, velocity of the wheel

$2, \dot{z} \ldots \ldots \ldots$ absolute displacement, velocity respectively of the sprung mass

xvi 


\section{CHAPTER I}

\section{INTRODUCTION}

Electrorheological (ER) fluids are slurries or mixtures consisting of micron size particles of non-conducting or semi-conducting solids suspended in a liquid insulating medium and exhibiting both a marked increase in resistance to flow and also a static yield stress when subjected to a transverse electric field in the onder of 1 to $10 \mathrm{kV} / \mathrm{mm}$.

When first discovered, these slumies were termed "electroviscous" due to what was believed to be a voltage induced change in viscosity. However, as notud by Stangroom [1], the term electroviscous is inappropriate since the behaviourial change of the ER fluid when electrically stressed is not a change in viscosity but rather an increase in the force required to start and maintain movement; hence the term "rheological" which is less specific than "electroviscous". Some researchers have gone farther; Korobko and Shulman [2] have suggested the term "electrostructural" rather than "electrorheological" since there is ', vidence that optical, thermophysical, electrical and acoustic properties are changing as well as the macroscopic fluid properties. However, it is expected that the term "electrorheological" will remain in use as a term denoting the propensity of certain fluids to "stiffen" upon being subjected to electric fields in the order of 1 to $10 \mathrm{kV} / \mathrm{mm}$.

Electrotheological fluids are considered to have potential in such diverse areas as:

1. Power Transmission - clurches, brakes, couplings;

2. Vibration Isolation - dampers, engine mounts, panel stiffeners; and 
3. Robotics - linkages, pressure/motion sensors.

The primary advantages of ER Fluids are their speed of response (milliseconds) and ease of control. They have been proposed for fast hydraulic machines which will be capable of transforming low-current signals to substantial mechanical forces [3]. References [4] through [11] provide a representative cross section of the literature already published on the subject of ER applications.

The purpose of this thesis is to show how a Semi-Active suspension system can be realized using an ER fluid damper energized with Pulse-Width-Modulated DC signals. The author's main contribution to the research carried out at the Carleton Transpon Technology Research Laboratory was in the development of a High Voitage Supply Unit for the ER damper. The design and testing of this unit is the central topic of this thesis. Additional research was carried out in the following areas:

1. Electrical Properties Testing of One Starch Based and One Proprietary ER fluid;

2. Design and Testing of a Computer Controlled Suspension System; and

3. Development of a Semi-Active Control Strategy.

The bulk of the experimental research was carried out using an experimental ER damper installed in a quarter-car-model testing apparatus. A closed-loop Semi-Active Control Strategy was implemented using a PC data acquisition system and relative velocity and relative displacement feedback. Performance data in the form of sprung 
mass acceleration, suspension travel and tire dynamic deflection were recorded for both passive and Semi-Active modes. Sinusoidal road profiles ranging in frequency from 0.5 to $15 \mathrm{~Hz}$. were input to the system. 


\section{CHAPTER II}

\section{ELECTRORHEOLOGICAL FLUIDS}

\subsection{Introduction}

This chapter provides information pertining to the nature and characterietics of ER fluids. The chapter begins with a brief historical and theoretical background to ER fluids including a discussion on the possible mechanisms responsible for the ER effect. The mechanical and electrical properties are discussed from the viewpoint of other researchers as well as from the author's own experimental rescarch. The significance of the mechanical and electrical properties is related to the subject of the following chapter which describes the development of an experimental high voltage power supply.

Scientific research into viscosity changes brought about by electric fields has been reported as far back as 1885 when Konig [12] investigated the viscosity of dielectric liquids under electrostatic stress. However, no significant change in viscosity was found. There was little further research carried out in this field until the 1930's when the Russian scientists, Sokolow and Sossinski [13], observed viscosity changes of up to $100 \%$ in polar liquids when electric current was passed through the liquid. They also discovered viscosity increases in non-polar liquids that had been contaminated with a few drops of acetone. According to Sokolow and Sossinski the effect was a hydrodynamic phenomenon due to convection of the non-homogenous liquid in the electric field.

Andrade and Dodd [14], in 1939, observed similar results to those of Solokow and 
Sossinstj; polar liquids (liquids containing atoms or molecules whose positive and negative charges are separated by a relatively large distance) responded to a transverse electric field with increased viscosity up to $115 \%$ whilst non-polar liquids showed little change. However, Andrade and Dodd refured the Russian scientists' hydrodynamic explanation on various grounds. Andrade and Dodd, whose work was published in detril in 1946 [15], concluded that there were three classes of liquid:

1. Non-polar liquids, which showed little viscosity effect under any cireumstances;

2. Polar liquids of very low conductivity and little viscosity effect; and

3. Polar liquids which do conduct and do exhibit changes in viscosity, either in the 'pure' state or upon contamination with moisture.

Viscosity changes of only $115 \%$ are of little practical value and the situation regarding electric fields in pure liquids has changed very little up to the present day. However, in 1939, an American electrical engineer, Willis Winslow [16], whilst carrying out experiments involving suspensions of semi-conducting particles in mineral oil, discovered that such mixtures formed fibrous structures when energized with an electric field. Certain particles, suspended in low viscosity oils, formed chain-like structures between the high voltage electrodes. These particle chains, in many cases, completely bridged the electrode gap and developed a shear stress when the electrodes were moved in relation to each other. A rotational (Covette) viscometer was used to measure the induced shear stress as an electric field was set up in the fluid. 
According to Winslow, the most responsive fluids were produced by suspending high dielectric constant, semi-conducting solids such as silica gel in insulating oil. Winslow attributed the increase in shear stress to the electrically induced fibration of the particles. Patents $[17,18,19,20]$ were filed on new hydraulic devices such as clutches, valves and shock absorbers which utilized the "Winslow" effect as it came to be known.

Field responsive fluids, as defined by Winslow, consisted of at least 15\% by weight oleaginous base oil of viscosity no greater than lubricating oil and a dielectric constant from 2 to 5.5, 30\% to $70 \%$ by weight fine semi-conducting particles, $0.75 \%$ to $15 \%$ by weight water and $5 \%$ to $15 \%$ by weight surface active dispersing agent. Unfortunately, due to the low yield stress and abrasive nature of the fluids, no practical applications were immediately forthcoming from Winslow's work.

Klass and Martinek began research into 'electroviscous' fluids in 1959 and began publicizing their work in $1966[21,22]$. The fluid they first formulated consisted of a napthenic carrier contaminated with silica particles. They described the effect of an electric field on specially formulated fluids as the 'electroviscous effect'. According to Klass and Martinek, 'the resulting electrostatic interaction of the distorted double layer in the medium of low dielectric constant requires the dissipation of additional energy on application of a shear stress normal to the direction of the field-induced distortion.'

In 1967 and 1968 Klass and Martinek patented $[23,24]$ several compositions of 
electroviscous fluids. The fluids mainly consisted of the following:

1. Particulate silica ( $10 \%$ by volume) ranging in size from 0.04 to 10 microns;

2. Water (0 to 4 molecules per square millimicron of surface area); and

3. A non-polar oleaginous carrier fluid with a dielectric constant of less than five which is weakly absorbed by silica.

These fluids were claimed to be superior to Winslow Fluids with respect to static stabilization and operating temperature range.

The country where progress in electrorheological fluids has probably been most rapid is the United Kingdom. Beginning around 1967, the U.K. Ministry of Defence funded research into ER fluids. One of the key researchers at the time was William Bullough who remains active in the field to this day. Bullough began publicizing his results in $1973(25,26,27]$ amongst which was a description of a variably controllable electroviscous damper. Around the same time Stangroom, at Sheffield University, was slso working on ER fluids. Stangroom's patents $[28,29,30]$ show his fluid primarily consisted of:

1. Alginic Acid Polymer in particle form comprising $30 \%$ to $35 \%$ of the total volume;

2. Adsorbed water (in concentrations of $6 \%$ to $12 \%$ by weight); and 3. A non-conducting oleaginous base oil.

In addition to the renewed activity in the U.K., reseanch into Electronheological 
(ER) fluids, as they are now called, has been either renewed or begun in countries such as the former Soviet Union, Japan, and the United States. Several American universities have some form of ER research underway at present.

\subsection{Theoretical Background}

After decades of research, there is stili an unsettled controversy regarding the fundamental mechanisms at work in ER fluids. The disparity of opinion amongst authors in the field is reflected in the variation of names by which people have referred to the effect: electroviscous, electro-rheological, electro-responsive, electro-structural and electrohydrodynamic. In this paper, the term 'electrotheological', or 'ER', shall be used to refer to any fluid, device, or effect which depends upon a mixture comprising micronsized semiconductor particles suspended in an insulating liquid or gel, and such mixture having the capability to sustain a voltage gradient in the order of 0 to $10 \mathrm{kV} / \mathrm{mm}$.

As Bullough [31] has suggested, there are possibly several mechanisms at work in ER fluids. The following sub-sections delineate some of the more plausible explanations as advanced by leading researchers in the field. Although it is beyond the scope of this thesis to prove or repudiate any one theory, it is worth examining each in some detail so as to better understand the nature of the electrorheological effect itself.

\subsubsection{Fibrillation Theory}

Willis Winslow, a name now synonymous with ER fluids, was o.se of the first 
researchers to observe the formation of fibrils, or particle chains in electrically stressed fluid mixtures. Winslow's fluids (silica dispersed in oil) produced pearl-like chain formations of particles aligned in the direction of the electric field. According to Winslow and other proponents of the fibrillation theory, ER activity, namely enhanced resistance to flow, can be attributed to the formation of skeleton structures in the ER fluid which often span the entire electrode gap. Shulman [2] ascribes the development of a yield limit, and its increase with increasing field intensity, to the development of a structure which increases in strength.

Sprecher, Chen and Conrad [32] undertook a direct investigation into the forces associated with particles in the chains formed in ER fluids. Their model fluid comprised glass spheres, 150 microns in diameter, suspended in silicone oil having an absolute viscosity of approximately $50 \mathrm{mPasec}$. A linear dependence of force with strain was observed and explained in terms of dipole-dipole torque interactions. They found that particle chains consisting of 3 spheres could withstand a maximum strain, $Y$, of 0.4 to 0.5 before breaking; the number of particles in the chain had no pronounced effect. The force, $F_{\downarrow}$ between identical dipoles was given by:

$$
F_{d}=\frac{6}{4 \pi \epsilon_{f}} \frac{p^{2}}{r^{4}}
$$

where $\varepsilon_{1}=$ permituivity of the fluid medium

$$
\begin{aligned}
& P=\text { total dipole moment of each particle } \\
& r=\text { distance between centres }
\end{aligned}
$$


Sprecher calculated the dipole moment, p, for his idealized, uniformly polarized spheres as:

$$
p=4 \pi \epsilon_{o} a^{3} k_{f}\left[\frac{k_{f}-k_{p}}{k_{f}+2 k_{p}}\right] E
$$

where $k_{1}$ = relative permittivity of the silicone huid (2.5)

$k_{p}=$ relative permittivity of the silica particle (7.2)

$\varepsilon_{0}=$ absolute permittivity of air $\left(8.854 \times 10^{-12} \mathrm{C}^{2} \mathrm{~N}^{-1} \mathrm{~m}^{-2}\right)$

$a=$ particle radius $(75 \mu \mathrm{m})$

$\mathbf{E}=$ applied electric field

As shown in equation (2) the average particle dipole moment varied linearly with E, the applied field. Sprecher and his associates believed that particle polarisation was brought about by charge migration - this was believed supported by the nonproportionality between ER strength and current. However, Sprecher and his associates did not explain how much of the ER activity was believed to occur on this macroscopic scale ie. particle to particle interaction. All ER researchers admit to the existence of particle chaining or structuring - what is in dispute is the significance of the chaining on the ER activity.

Sprecher et al., conclude their paper by noting that the ultimate strength of the particle chains was found to have a quadratic dependence on E, the applied field strength. Also, the dipole moment depends directly upon the difference in permittivity, or dielectric 
Inismatch, between the base carrier fluid and the dispersed media.

Jondan and Shaw [33] also have sought to establish a direct link between fibrillation and the rheological changes in electric fields. Jordan and Shaw performed theo-optical experiments on ER fluids in order to verify dielectrophoresis which predicts ER activity based upon the level of dielectric mismatch between the carrier fluid and the dispersed media. Whilst electrophoresis predicts particle migration to either electrode in a uniform electric field, dielectrophoresis predicts particle translation and chaining in nonuniform fields due to induced dipoles. The results from Jordan's and Shaw's theo-optical experiments suggested there was an intimate link between the ER effect and the fibrillation process. However, their experimental evidence also suggested that a high static dielectric constant was insufficient to ensure significant ER activity. They also concluded that a small finite amount of conductivity was helpful; possibly because it inhibited electrophoresis, which is considered to compete with fibrillation.

\subsubsection{Electric Double Layer Polarisation}

Klass and Martinek were among the first researchers to repudiate the fibrillation theory. Their criticism was based upon the relatively large timescale required for fibrillation to begin and complete. They proposed the theory of electric double layer interaction as an alternative mechanism to chain formation.

Electric double layers, otherwise known as space charges, are but one form of 
interfacial polarisation; and interfacial polarisation is but one form of polarisation. Electronic polarisation can occur on the atomic level as the mean position of electrons may shift towards the positive electrode and the nucleus and its constituent protons shift towards the negative electrode. The natural frequency of electronic polarisation is circa $10^{16} \mathrm{~Hz}$ [34]. Similarly, ionic polarisation results from the shifting of whole positive or negative ions due to the application of an electric field. Ionic polarisation has a natural frequency limited to circa $10^{13} \mathrm{~Hz}$. Molecular polarisation occurs in polar molecules such as methyl chloride $\left(\mathrm{CH}_{3} \mathrm{Cl}\right)$ where the centres of gravity for the positive and negative charges are not coincident. As opposed to electronic and ionic polarisation which are both induced, molecular polarisation is the result of permanent dipole. The dipole moment is defined as the product of the total charge of the molecule and the distance between charge centres. Molecular dipoles can still respond to frequencies above the Gigahertz $\left(10^{9} \mathrm{~Hz}\right)$ region.

Double layer polarisation occurs at the boundary between the carrier liquid and the particle surface. The double layer consists of a thin layer of ions closely adhering to the particle surface and a diffuse thick layer extending some distance into the liquid insulator. According to Klass and Martinek, when an riectric field is applied the double layers are distorted to an extent whereby they overlap each other. It is their mutual interaction and interference which is presumed to give rise to ER activity and resistance to shear. Specifically, Klass and Martinek suggested that the electric field induced distortions of the double layer caused repulsion forces between regions of high charge 
density. While Jordan and Shaw [35] likewise admit to the presence of double layer polarisation, they note, "it has not yet been shown that the resultant double layer interaction and overlap is sufficient to cause the drastic theological changes seen in ER fluids."

Block and Kelly [36] agree with Klass and Martinek that structure formation cannot on its own explain the excess shear stress, $\tau(E)$, in flow. In particular, whilst acknowledging that particle aggregarion in flow exists, they claim it is difficult to see how the structures could bridge the gap during flow. What is more feasible, claim the authors, are clusters of polarised particles brought together by coulombic attraction that exist as entities within the flow but not necessarily extending throughout the bulk. And whilst ascribing to the concept of polarisation being the essential mechanism in ER activity, Block and Kelly do not believe it is necessarily in the form of double layer interactions, claiming there is no evidence that ER activity involves just one form of polarisation. They suggest interfacial polarisation can involve charge migration through the bulk of the particle, or along the surface, as well as within a double layer region. They do however rule out atomic and electronic polarisation as insignificant with respect to ER activity. Ultimately, according to Block and Kelly, different fluid formulations may have different polarisacion mechanisms in operation. In their paper, the authors have compiled a list of more than forty different formulations, all of which exhibit ER activity of varying degree. The sheer variety of dispersed media within the list, from polymer semi-conductors to starches to metal oxides, lends credence to the idea that there may indeed be more than 
one mechanism at work in ER fluids. Block and Kelly apparently support the view that fibrillation alone is insufficient to account for ER activity [36].

\subsubsection{Electro-Oamosis and Capillarity}

J.E. Stangroom [1] is the originator of the "Water Glue" or "Water Bridge Theory." According to Stangroom (in 1983) the minimum requirements for a slurry to show ER activity were:

1. The base liquid must be hydrophobic;

2. The solid must be hydrophillic and porous so it can contain an appreciable amount of absorbed water without being overtly wet; and

3. The water absorbed on the solid particles is essential and its amount greatly influences the properties of the fluid.

According to Stangroom there is a strong correlation between the activity of an ER fluid and the interfacial tension between the liquid and water. Stangroom's theory postulates that mobile ions within the particle pores assemble water molecules around them, and when the electric field is applied ions move to one end of the particle carrying water with them. One end of the particle subsequently is wetted and water bridges form between particles. When the field is removed the water retreats into the particle again as the induced dipole dissipates.

As Stangroom points out, the "water-bridge" theory correctly predicts tensile and compression forces as well as shear forces. The electric double layer distortion theory 
fuils to sccount for the tensile fonces which have been measured by other reseanchers.

\subsection{Fuid Properties}

There is nearly as much controversy over fluid properties as there is reganding the exact mechanism(s) leading to ER activity. Some researchers believe water is an essential ingredient in any ER fluid while others such as Block and Kelly [37] and Inove [38] have produced what is claimed to be 'substantially dry' ER fluids. Similarly, the role of conductivity in ER activity is disputed amongst researchers. The following sections describe some of the salient properties of ER fluids.

\subsubsection{Bingham Flow Model}

The simplest model with which to explain the theological characteristics of ER fluids is the Bingham Plastic model $[39,40]$. A Bingham plastic can be represented on a shear stress $(\tau)$ versus shear rate $(\eta)$ cartesian plot as a straight line with the yield stress, $\tau_{y}$ being the value of the intercept on the ordinate shear $(\tau)$ axis and the slope being the constant plastic viscosity, $\eta_{p}$. Therefore, as a first approximation, the total shear stress of an ER fluid at a given shear rate, for a Bingham plastic, can be calculated as:

$$
\tau=\tau_{y}+\eta_{p} \dot{\gamma}
$$

The distinguishing characteristic of Bingham flow, which is a rough description of ER fluids in flow, is the presence of a static yield stress, $\tau_{\infty}$, which must be overcome before flow (shearing) begins. Very little is known about the exact properties of ER 
fluids when the applied stress, $\tau_{0}$ is less than $\tau_{0}$ other than the fluid is said to become solid. When $\tau$ is equal to $\tau_{0}$, then flow begins. It has been suggested by Jordan and Shaw that the mere occurrence of a yield stress suggests the presence of structure in ER fluids.

\subsubsection{Apparent Viscosity and Eleetroviscosity}

A Newtonian fluid is characterized by a constant viscosity whilst undergoing shear. The absolute or dynamic viscosity is defined as the ratio of the resultant shear stress to the shear rate:

$$
\eta \equiv \frac{\tau}{\dot{\gamma}}
$$

With no electric field applied most ER fluids behave more or less like Newtonian fluids; their developed shear stress increases with shear rate. On closer inspection, ER fluids tend to be slightly thixotropic and 'shear thin' rather than thickening with increasing shear rate.

At a given shear rate, $\psi$, the field induced shear stress, $\tau(E)$, will exceed the zero field shear stress, $\tau(0)$ by some margin. For an ideal ER fluid the arithmetic difference between the zero field shear stress, $\tau(0)$, and the field applied shear stress, $\tau(E)$, will be constant for any given shear rate, $\uparrow$. Figure 1 shows shear stress versus shear rate for 'ERF B', a proprietary ER fluid (in undiluted form) supplied by a commercial fluid supplier. Shear stress versus shear rate has been plotted for four different levels of electric field strength including zero electric field. The apparent viscosity, $\eta_{\mathbf{A}}$, is the term 
given to the slope of the shear stress versus shear rate curve. The electroviscosity, $\Delta \eta$. is the arithmetic difference in shear stress between the field induced shear stress, $\tau(E)$, and the zero field shear stress, $\tau(0)$ :

$$
\Delta \eta \equiv \tau(D)-\tau(0)
$$

The data, which was obtained by Chris Bortolotto with a Couette concentric cylinder theometer, represents the fundamental behaviour of an ER fluid. The electrorheometer, built at Carleton University, consists primarily of an internal rotor driven by a variable speed DC motor with digital speed readout. The stator, which is larger in diameter by a few millimetres, is restrained by a torque cell and hence subject to shear stress when the rotor is driven at speed. The ER fluid is inserted in the gap between rotor and stator and contained by fluid seals. Both the stator and rotor are aluminum and have leads attached for connection to a high voltage supply unit.

As seen in Figure 1, immediately after the onset of flow, the shear stress drops rapidly and then is re-developed as the shear rate increases. Such behaviour has been noted by other researchers [Block and Kelly, 36] and described as "complex, irreversible and irreproducible ... in regions of low $\psi . "$ It should be apparent from Figure 1 that the Bingham plastic model, while appropriate as a first approximation, has several deficiencies.

In Figure 1, the $0 \mathrm{kV} / \mathrm{mm}$ curve can be considered more or less representative of 
aingham plastic with shear stress dependent linearly on shear rate. A perfectly Newtonian fluid, would exhibit zero shear stress at zero shear rate or a complete absence of a static yield stress. The electric field induced curves $(1-3 \mathrm{kV} / \mathrm{mm})$ show an inital drop in shear stress, or deviation from the Bingham model, followed by steadily increasing shear stress with shear rate (the author is indebted to Chris Bortolotto for providing this figure as well as Figure 2 and Figure 6).

As shown in Figure 1, the maximum shear stress developed by ERF 'B' was approximately $800 \mathrm{~Pa}$. at room temperature with an induced field intensity of $3 \mathrm{kV} / \mathrm{mm}$. The electroviscosity, or difference between zero and applied field viscosity was marginal for this ER fluid and therefore considered inadequate for use in the quarter-car-model test rig.

The plastic viscosity for the four curves shown in Figure 1 are all approximately equal. Hence, the ER effect for ERF 'B' could be considered as a dynamic shear stress superimposed upon a Newtonian viscosity. The concept of static and dynamic shear stress is discussed in the next section. 


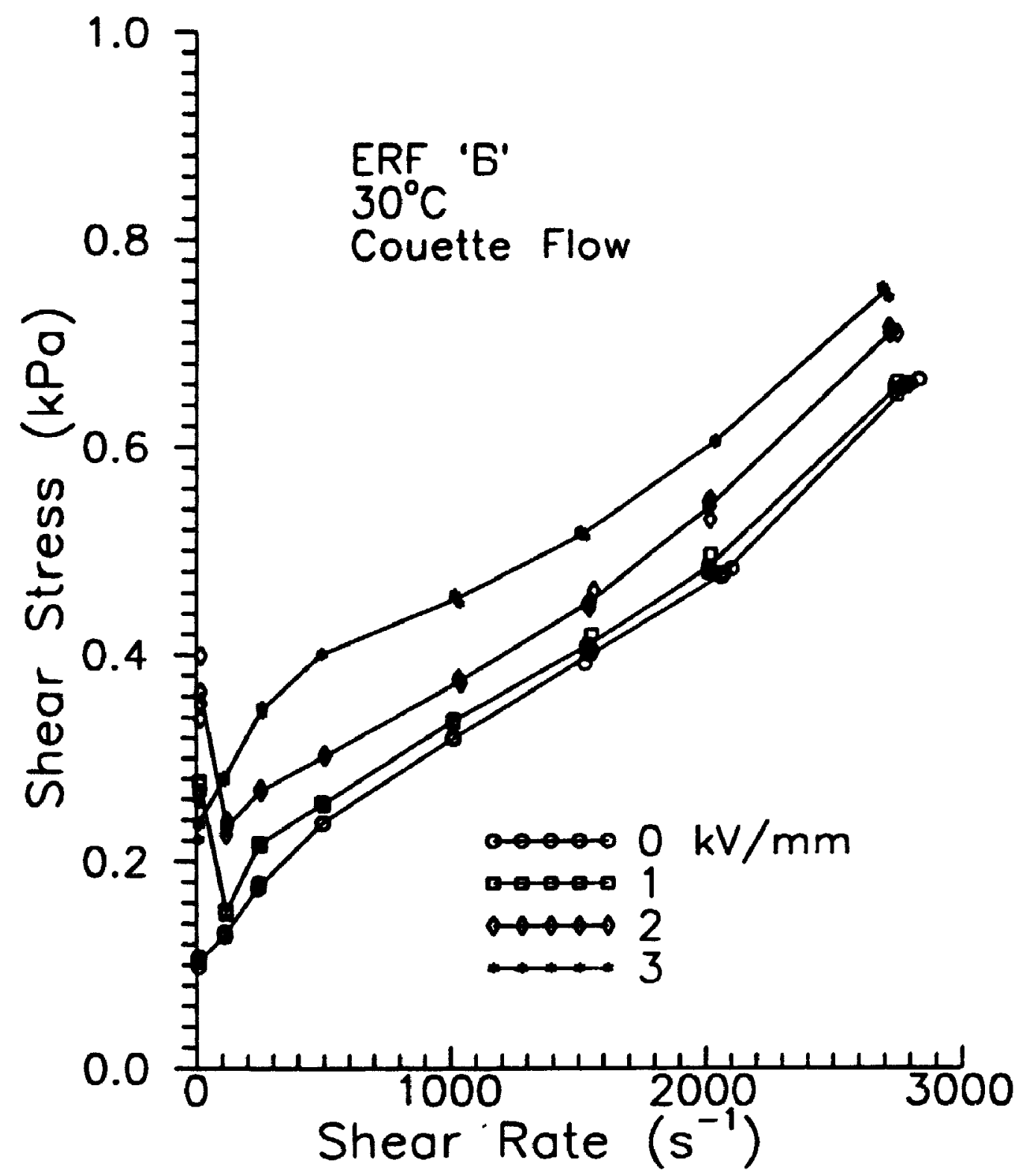

Figure 1. Rotating (Covette) Viscometer Measurements of Shear Stress versus Shear Rate For ERF 'B' (Graph Courtesy of Chris Bortolotto) 


\subsubsection{Static and Dinamic Yield Stres:}

Dynamic yield stress has been defined by Stangroom [40] as the least-equares intercept of shear stress over the range of shear rates. For example. in Figure 1 the dynamic yield stress, $\tau_{p}$ is $0.3 \mathrm{kPa}$ for an applied field strength, $E$, of $3 \mathrm{kV}(\mathrm{mm})^{-1}$. The stadic yield stress, $\tau_{0}$ may be expressed as the value of stuess which occurs at maximum surin before shesr. As mentioned previously, the maximum strain for some ER fluids has approached 0.4 .

The maximum shear stress for most ER fluids with a high intensity electric field applied appears to be under $5 \mathrm{kPa}$. Advanced Fluid Syatems Limited of London U.K. has developed a polyelectrolyte based ER fluid which can develop shear stresses up to $4 \mathrm{kPa}$. Presumably this is a water activated system although the quoted temperature range of 0 $1080^{\circ} \mathrm{C}$ is quite wide for a water based system.

\subsubsection{Shear Ratio}

Shear ratio is simply the value of the electrical shear stress, $\tau(E)$ divided by the Newtonial shear stress, $\tau(0)$, at a given shear rate. It is sometimes used to convey the amount of "control" available from a particular formulation of ER fluid. Unfortunately. the term is somewhat misleading. For example, at zero shear mite the shear matio is infinity whilst at very high shear rates $\left(\gamma>3000 \mathrm{~s}^{-1}\right)$ the shear ravio is one. This does not imply that the ER effect is decreasing at higher shear rates, but simply that "normal" viscosity effects predominate at high shear rates. 


\subsubsection{Erfect of Temperature On Shear Stress}

Not surprisingly, temperature has a pronounced effect on ER fluids, particularly on shear stress development and conductivity. The temperature effect on conductivity will be discussed in more detail in a further section; it is sufficient to say for now that increasing temperature significantly increases the conductivity of the fluid.

For most ER fluids the practical cperating temperature range is between 0 and $80^{\circ} \mathrm{C}$. In general, shear stress increases with increasing temperature up to a point, then drops off. According to Jordan and Shaw, the behaviour of a typical ER fluid with increasing temperature is steep growh of the apparent viscosity, $\eta_{\Lambda}$, followed by a sharp drop off.

Various explanations have been given for the temperature induced change in apparent viscosity for ER fluids. Klass and Martinek [22] have attributed the increase in apparent viscosity with increased temperature to increased ion mobility and hence increased poiarizability of the carrier fluid. Conversely, the steep drop in ER effect may be due to decreasing permittivity of water which is the activating agent for many ER fluids [35]. In fact it is the presence of water which is most often cited as the underlying cause of the temperature sensitivity of ER fluids. The role of water in ER fluids is discussed in the next section. Block and Kelly [36] have reported the failure of ER fluids at temperatures $>70^{\circ} \mathrm{C}$ as possibly due to the evaporation of water from the dispersed phase. 


\subsubsection{The Role Or Water In ER Fuids}

It has been suggested by Stangroom, that the only requirements for an ER fluid are a porous hydrophillic dispersed phase and an insulating hydrophobic continuous phase; the implication being that the activating agent is water which is adsorbed on the surface of the particles. There is still some element of mystery surrounding the role of water in ER fluids. Except for a few supposedly 'dry' ER fluids, the majority of present ER fluids require the presence of water to support the ER effect.

Stangroom's "Water-Glue" theory has been described earlier. Aside from Stangroom, few ER researchers have developed explanations for the role of water in ER fluid. It is well known however, that water is an excellent solvent, capable of dissolving a wide range of ionic compounds (salts), inorganic polar substances and even non-ionic organic substances. Water is a good solvent for ionic substances because its highly polar $\mathrm{H}_{2} \mathrm{O}$ molecules reduce the auraction between the anions and cations which form the ionic bonds in the lattice. Polar substances tend to align their molecules in the presence of an electric field which partially neutralizes the field. The relative permittivity of a material is the measure by which it neutralizes or dissipates the electric field. Water has a very high relative permittivity $\left(\varepsilon_{1}-80\right)$; it is capable of reducing the coulombic attraction between anions and cations by a factor of 80 . Once the ions are separated they can react with the water molecules in a number of ways. However the exact mechanism by which water activates ER fluids is still not known for certain. One theory reganding the role of water in ER fluids is that the water increases the effective permitivity of the particle 
which in turn strengthens the particle interactions [35]. As mentioned previously, Stangroom, in his eleciso-osmosis theory, introduced the idea that the surface tension of the water played an essential part in the ER effect. Or perhaps water, in its classical role as a polar solvent, is somehow responsible for initiating or enhancing ion migration and resultant polarization (ie. promotion of an electric double layer leading to enhanced flow resistance).

The fact that so many ER fluids list water as an ingredient [36] lends credence to the argument that water is essential for ER activity. Jordan and Shaw [35] note that a water-activated dispersed phase could be one of the following types of materials:

1. silica;

2. gypsum;

3. clay minerals;

4. mital oxides;

5. cellulose;

6. starch;

7. alginic acid;

8. ion exchange resins; and

9. polymers.

Jondan end Shaw have noted that there are only a few "dry" fluids in existence, most of them described only in the patent literature, and even these use the term "substantially anhydrous" to permit a very small amount of water. 
The fluids investigated at Carleton Nniversity were used "as is," with no water added or removed other than by natural evaporation. The fluid used in the experimental da nper consisted of "Analr" stanch particles from the British Drug House (BDH) company. These particles, of approximately 20 micron diameter were taken directly from the jar and stirred into silicone oil. A sample batch was dried at elevated temperatures $\left(T=165^{\circ} \mathrm{C}\right)$ for four hours whereupon there was a $5.9 \%$ loss of moisture.

\subsubsection{Particle Size}

Particle size is not generally believed to have a significant influence on the ER effect. Particle sizes quoted in the literature for various Ex. fluids have ranged from nanometres to hundreds of micrometers. Researchers tend to grind their particles as fine as possible, not to enhance the ER effect so much as to minimize the effect of particle size on the static suspension stability. From Stoke's law for freely falling spherical bodies in a gravitational field, the terminal velocity, $V_{b}$ is:

$$
V_{z}=\frac{2\left(\rho_{p}-\rho_{p}\right) r^{2} g}{9 \eta}
$$

where $P_{p}, P_{q}=$ particle and fluid densities respectively

$$
\begin{aligned}
& \mathbf{g}=\text { gravitational constant }\left(9.81 \mathrm{~ms}^{-2}\right) \\
& \eta=\text { viscosity of carrier fluid } \\
& r=\text { particle radius }
\end{aligned}
$$


It is apparent from equation 6 that minimizing the particle size and density mismatch will increase the settling time and hence tend to stabilize the suspension. It is practically impossible to completely eliminate the density mismatch between the dispersed and dispersant phase; hence there is likely to always be some amount of settling. This could be detrimental to the operation of equipment which must stand idle for long periods of time.

\subsubsection{Volume Fraction and Volume Fartor}

The fluid used in the ER fluid experimental damper consisted of starch particles suspended in 10 centistoke silicon oil. The ratio of starch particles to silicone oil was approximately $1: 5$ by mass. Increasing or decreasing the volume (or mass) fraction of the dispersed phase in ER fluids always involves a tradeoff between the zero field and applied field viscosity. Einstein [35] developed a theory to describe the viscosity enhancement of a non-charged Newtonian Fluid:

$$
\frac{\eta}{\eta_{0}}=1+2.5 \phi
$$

where $\phi=$ volume fraction

$$
\begin{aligned}
& \eta=\text { viscosity of the suspension } \\
& \eta_{0}=\text { viscosity of the medium }
\end{aligned}
$$

For most ER fluid applications it is desirable to keep the zero field viscosity as low as possible so as to maintain a sufficiently large shear ratio. However, some amount 
of dispersed phase must be added to the mixture since no known single phase or pure liquid exhibits significant ER activity.

According to Bares and Carlson [41] of the Lond Corporation, however, when the concentration of suspended particles is increased, the square of the yield suress increases faster than the viscosity of the carrier fluid. Bares and Carlson define a material parameter called the volume factor, $\eta \tau^{2}$, which is the ratio of the viscosity of the carrier fluid to the square of the shear stress. The volume of fluid required to develop a particular amount of mechanical control can then be found from the volume factor. For a shear electrode device (clutch, brake) the required volume of ER fluid is proportional to the volume factor:

$$
V_{0}=S\left(F_{E R}\right) \frac{F_{E R}}{F_{0}} \frac{\eta}{\tau^{2}}
$$

where $V_{0}=$ fluid volume between electrode plates

$S=$ relative plate speed

$F_{\mathrm{ER}}=$ force on plates with field on

$F_{0}=$ force on plates with no field

$\eta=E R$ fluid viscosity with no field

$\tau=$ ER fluid yield stress in response to electric field 
The analogous equation for a fixed electrode valve (damper) was also derived by Bares and Carlson:

$$
V_{0}=\frac{9}{C} Q \Delta P_{E R} \frac{\Delta P_{E}}{\Delta P_{0}} \frac{\eta}{\tau^{2}}
$$

where $\Delta P_{0}=$ pressure drop across the plate with no field

$$
\begin{aligned}
& \Delta P_{\mathrm{ER}}=\text { pressure drop across the plate with applied field } \\
& Q=\text { volume flow rate } \\
& C=\text { constant }
\end{aligned}
$$

In both cases, claim Bares and Carison, the volume of fluid needed is dependent upon only the volume factor previously defined. Bares and Carlson also claim that for 2 torque transmission device, it is desirable to operate at the highest concentration of particles allowable since the volume factor decreases with the loading of the ER fluid. It was found, however, that increasing the mass ratio of the starch particles and silicone oil from 1:5 to 2:5 had little effect on the shear stress. Therefore, it was decided to maintain the mixture at the 1:5 ratio. However, it is probable that every different ER mixture will have its own optimum volume fraction.

\subsubsection{Tribological Aspects of ER Fluids}

The silica based ER fluids, first formulated by Winslow, have long since been discarded for all but experimental research purposes due to their abrasive qualities. To a large extent they have been superseded by polymer based ER fluids which are far less 
aggressive to sliding parts. However, as pointed out by Lingard and Bullough [42], even pure base liquids can result in unacceptable wear problems to seals and bearings. In the case of the Carletion University viscometer it was necessary to affix a lip seal to the rotor shaft to prevent ingress of particles to the ball bearing. Before the seal was inserted. particles were agglomerating in the bearing races and preventing the balls from rolling smoothly.

According to Lingard and Bullough both the base liquid and the dispersed phase contributed significantly to the wear and friction behaviour. Their fluid ' $A$ ' used a polychlorinated biphenyl base (PCB) liquid whereas their fluid 'B' used a polymethyl/siloxane base liquid. Both liquids showed evidence of attrition far in excess of that of a good lubricant with fluid 'B' showing the most evidence of wear. However, the authors admit that non-contact applications would be relatively safe from the adverse tribological aspects of even fluid 'B'. The question remains whether elastomer seals are effective in preventing the ingress of the ER fluid into bearing races and journals.

\subsubsection{Secondary ER Efrects: Rheopexy and Electrophoresis}

Although the Bingham Flow model expressed in equation (3) is often cited as the closest approximation to ER fluids, there are significant deviations from the Bingham model observed in real ER fluids. Time dependent effects such as theopexy and electrophoresis can often skew the ER behaviour in unpredictable ways. 
Rheopexy is the tendency for the ER fluid to develop into a more definite structure as time passes with the electric field applies. It makes the determination of many ER characteristics, such as conductivity, yield stress, and ER time response very difficult to measure. Many researchers have reported "slip-stick" behaviour in ER clutches where the torque increases suddenly at low shear rates. This could be partially due to theopexy.

Another problem that afflicts ER devices is the tendency for the dispersed phase of the ER fluid to concentrate on the electrode walls (electrophoresis). In ER valves with low flow rates, the electrodes can filter out particles leading to non-uniform particle content. However, in our experiments we have not noticed electrophoresis to be a significant problem.

\subsubsection{Summary Of Mechanical Properties Of ER Fivids}

Electrorheological fluids are two phase mixtures consisting of finely divided particles of high relative permittivity dispersed in an insulating oil. When stressed with an electric field, the fluid exhibits an increase in shear stress for a given shear rate. The simplest model to describe the behaviour of an ER fluid is a Bingham Plastic Flow which is the simple summation of a yield stress plus a shear rate dependent shear stress. ER fluids have also been observed to structure under the influence of appreciable electric fields. The maximum shear stress obtainable with some ER fluids is in the kilopascal region. 
There is still an unsettled controversy regarding the exact mechanism of the ER effect. A partial list of possible contributors to the ER effect include:

1. Simple coulombic attraction;

2. Particle alignment;

3. Dipole interaction;

4. Electric Double Layer Repulsion;

5. Fibrillation;

6. Electro-osmosis;

7. Hydrodynamic Effects; and

8. Dielectrophoresis

The ER fluid used in the damper, which is the subject of this thesis, was a mixture of fine starch particles suspended in silicone oil. The ratio of starch to oil vas 1:5 by mass. The following section delineates some of the electrical properti-s of ER fluids.

\subsection{Electrical Properties}

\subsubsection{Effect of Field Strength On Shear Stress}

Although ER effects have been reported at field strengths as lcw as $200 \mathrm{Vmm}^{-1}$, most practical ER fluids respond over a range from 0 to $4 \mathrm{kVmm}^{-1}$. At field strengths higher than $4 \mathrm{kVmm}^{-1}$ the probability of electrical breakdown increases significantly. The dielectric strength of air is only $3 \mathrm{kVmm}^{-1}$ and that of silicone oil about $15 \mathrm{kVmm}^{-1}$. Even if dielectric breakdown did not place an upper limit on the electric field strength, 
there is the possibility that the shear stress, $\tau(E)$, would merely saturate at the higher field strengths.

It is extremely difficult to characterize the relationship between electric field strength, $E$, and the shear stress, $\tau$, because of the large number of variables involved. The effects of temperature, volume fraction, shear rate and settling time are at times difficult to isolate. Also, many ER fluids deviate from Bingham plastic behaviour, particularly at low shear rates. Figures 1 and 2 show $\tau$ versus $\&$ for a proprietary ER fluid and a starch based ER fluid respectively. Both fluids show a marked dip in shear stress in the low shear rate region between 10 and $500 \mathrm{~s}^{-1}$. Beyond the low shear rate region, both fluids assume approximately Bingham plastic behaviour.

Notwithstanding the difficulties in characterizing ER fluids, most researchers have found a field strength dependence of shear stress at a given shear rate, to follow some form of power law relationship with the exponent lying somewhere between one and two. 


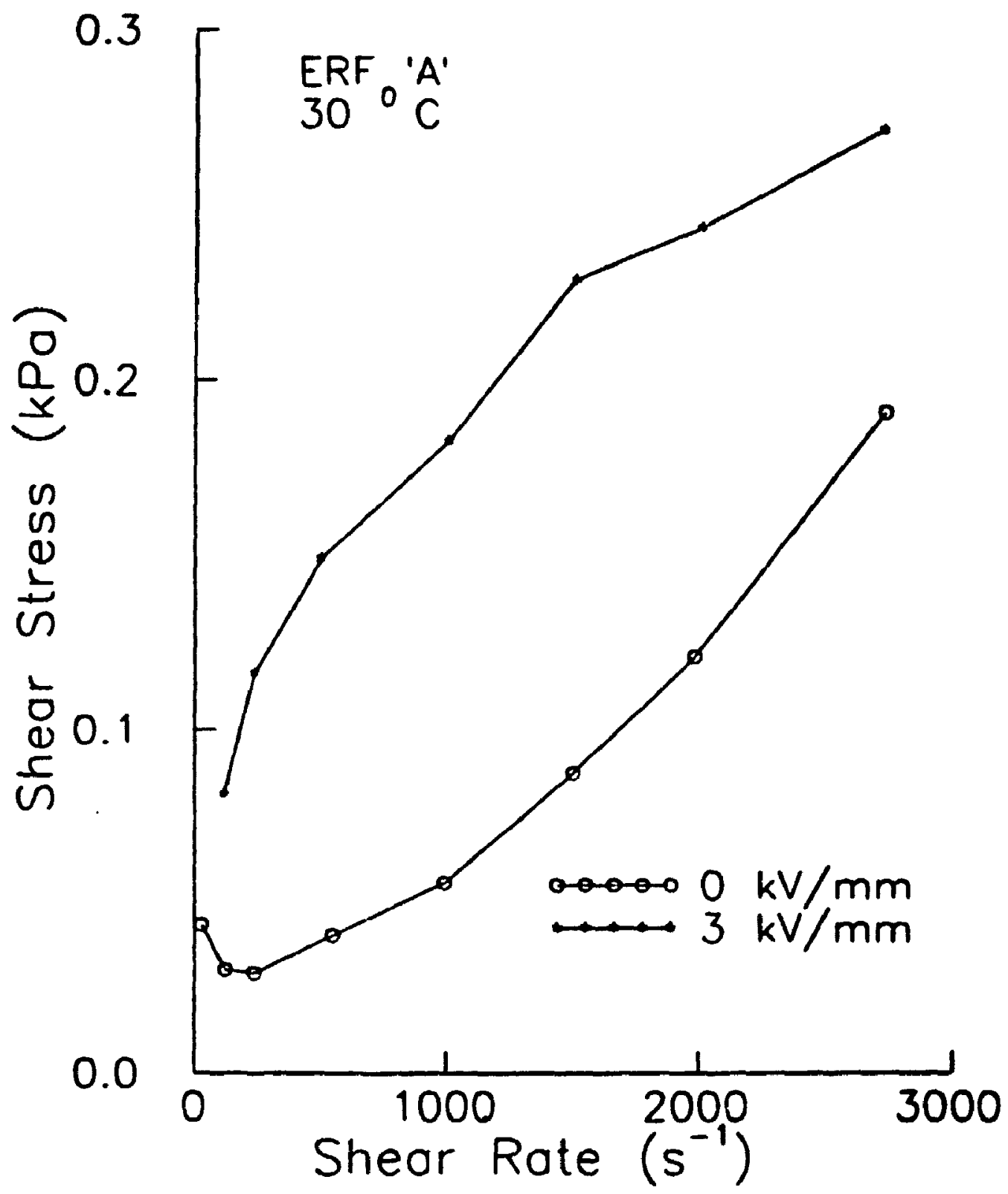

Figure 2: Rotating (Covette) Viscometer Measurements of Shear Stress versus Shear Rate For ERF 'A' (Graph Courtesy of Chris Bortolotto) 
Experiments conducted with the Covette theometer showed the proprietary fluid, 'ERF B100' exhibited a yield stress dependence on field strength to the power of 1.85 while the starch based fluid had an exponent of only 1.34. Bullough tested a valve type $E R$ device and found the pressure drop, $\Delta P_{E}$, varied exactly as the square of the field strength. This would be expected if the ER mechanism was based solely on Coulombic attraction between spherical particles. Coulomb's law of attraction between opposice charges or repulsion between like charges gives the force between the charges as:

$$
F=k \frac{Q_{1} Q_{2}}{r^{2}}
$$

where $F=$ force of one charge on the other

$$
\begin{aligned}
& Q_{1} \text { and } Q_{2}=\text { charge quantities } \\
& r=\text { distance between charges } \\
& K=\text { constant of proportionality }
\end{aligned}
$$

From Gauss's law the charge on the surface of a spherical shell is dependent upon the electric field intensity as:

$$
Q_{e}=\epsilon_{0} 54 \pi r_{s}^{2}
$$

where $\varepsilon_{0}=$ permittivity of vacuum $\left(8.85 \mathrm{pFm}^{-1}\right)$

$E=$ electric field intensity $\left(\mathrm{Vm}^{-1}\right)$

$r_{8}:=$ radius of sphere 
Other researchers have reported shear stresses varying as $\tau=a E^{b}$ with $b$ ranging as high as 2.4. Given the large number of fluids in existence, and the number of parameters involved, it is nol surprising there is no formule for equating shear stress with field strength. However, for summary purposes, the shear stress of most ER fluids varies with the equare of the eloctric field strength at any given shear rate, up to a finite limit whereupon the fluid is effectively saturated and will respond no further to increased electric field intensity.

\subsubsection{Conductivity and Current Denaity}

Conductivity in a substance implies current which in turn implies the transport of charge. In metals charge is carried by free electrons while in liquid (electrolytes) charge is carried by ions. In plasmas, charge is carried by electrons and ions while in semiconductors, charge is carried by electrons and electron vacancies (holes). An ampere is the standard unit of current and is defined by one Coulomb of charge passing a point every second. Hence for current to exist in a medium there must be an appreciable amount of charge moving with a finite velocity. The ondered movement of charge is differentiated from random electronic movement by the drift velocity. The product of the charge density, the drift velocity, and the area of the conducting medium gives the current:

$$
I=V \boldsymbol{d}
$$

where $V_{d}=$ drift velocity $\left(\mathbf{m s}^{-1}\right)$

$$
\rho=\text { charge density }\left(\mathrm{Cm}^{-3}\right)
$$


$A=$ area of conducting medium $\left(\mathrm{m}^{2}\right)$

All ER fluids exhibit some conductance and are non-linear with respect to volange and current. ER fluids also exhibit a marked sensitivity to vemperature. As noved by Stangroom [1] $\& 6^{\circ} \mathrm{C}$ rise in temperanure produces an almost doubling of the current. According to Stangrosm the rising temperature "shakes the water loose" from the hydorphyllic particles; thus enabling the current to increase.

For example, if the operating temperature range was from -40 to $120{ }^{\circ} \mathrm{C}$, which it might be for a vehicular application, then the current demand would increase by a factor of $100 \times 10^{6}$ or 8 orders of magnitude difference! In practice, it is doubtful if any existing ER fluids, could operate over such a wide temperature range. A typical vemperature range for most ER fuids is from 0 to $40^{\circ} \mathrm{C}$ with some newer fluids having $80^{\circ} \mathrm{C}$ as a usable limit.

As mentioned previously, ER fluids are non-ohmic in nature. Generally speaking. ER fluids exhibit some form of power law relationship between current and voltage of the form:

$$
J=C(B)^{\infty}
$$

where $J=$ current density $\left(\mu \mathrm{A} / \mathrm{m}^{2}\right)$

$$
\begin{aligned}
& E=\text { electric field intensity }\left(\mathrm{Vm}^{-1}\right) \\
& \mathrm{C}=\mathbf{a} \text { constant }
\end{aligned}
$$


$\mathrm{n}=$ an exponent usually between 1 and 2

As noted by D.G. Frood [43], power law current-voltage relationships are evident in vacuum diodes, solid insulators, semiconductors, and liquid dielectrics. For example the Child-Langmuir equation for a thermionic diode gives the anode current, $i$, as proportional to three-halves of the anode-cathode voltage:

$$
i=C\left(V^{1.5}\right.
$$

In the Child-Langmuir equation for a thermionic diode the constant, $C_{\text {, is dependent upon }}$ the physical form of the electrodes.

As Frood pointed out, equation 14 applies to vacuum diodes only and assumes total conservation of the emitted electrons, neglecting their thermal velocities when emitted from the cathode. The situation becomes even more complex when an insulating medium is inserted between the diode electrodes. For more discussion on the mechanism of conductivity in insulation filled diodes, the interested reader is directed to the aforementioned reference of Dr. Frood's work.

Although not clearly stated, the implicit assumption made in Frood's paper is that conduction in starch based ER fluids is electronic. Frood made current-voltage measurements for various concentrations of potato starch at various electric field intensities. He plotted the $\log$ of current density, J, versus the $\log$ of electric field intensity, E, and found that all of his data fell onto straight lines with the slope giving the 
value of the exponent, $n$, in equation 13 and 14. Frood found that for a given concentration of starch in silicone oil there were approximately three regimes of current density versus electric field intensity. For starch concentrations of $1: 5$ the exponent $\mathbf{n}$ had a value of 1.67 at field strengths between 1 to $4 \mathrm{kV}(\mathrm{mm})^{-1}$.

There were two types of fluid tested at Carleton University during the course of the research into ER fluids. The first ER fluid tested, and subsequcntly used in the experimental damper, was a simple mixture of "Anair" starch and silicone oil which was mixed in the proportion of 1:5 by mass. This fluid was labelled 'ERF A'. No surfactant or other agents were added. The sscond fluid was a proprietary ER fluid termed 'ERF B'. 'ERF B' was then subsesyut:ntly divided into two separate batches, an undiluted original strength batch, 'ERF B100', and a 50\% dilution, 'ERF B50', consisting of the original gel-like fluid and the same silicone oil used to make the starch based ERF ' $A$ '.

The current measuring apparatus consisted of two brass plate-type electrodes, each $3 \mathrm{~mm}$ thick, with a $3 \mathrm{~mm}$ air gap between them. The total area of the brass plates in contact with the ER fluid was $43.1 \mathrm{~cm}^{2}$. The brass plates were separated at the top by an acrylic sheet. Conductance through the acrylic was negligible. A digital Voltage Ohm Meter (VOM) was connected in series with the electrodes and a Voltronics DC Voltage Supply. The voltage supply unit had a range of 0 to $14^{*} /$ with the voltage measured on an analogue panel meter. Another panel meter show d current level in milliamps which was not used. The digital VOM which was used to monitor the current had a 
resolution of 0.1 microamperes. To measure the current, the electrode assembly was simply inserted into a glass beaker containing the ER fluid. Care was exercised to maintain the solid phase in a suitable condition of suspension; this proved somewhat difficult for tine starch based ER fluid as it tended to settle out quickly.

Figures 3, 4, and 5 show current density versus electric field strength for three differnt formulations of ER fluid plotted on $\log -\log$ scales. ERF ' $A$ ' was the starch/oil mixture whilst ERF 'B 100' was the proprietary ER fluid. Best fit straight lines were added to the data points; the slope corresponds to the value of the exponent in the equation (13). Table I lists the values of the exponent, $n$, and the constant, $C$, for the various temperatures at which the current measurements were made. 


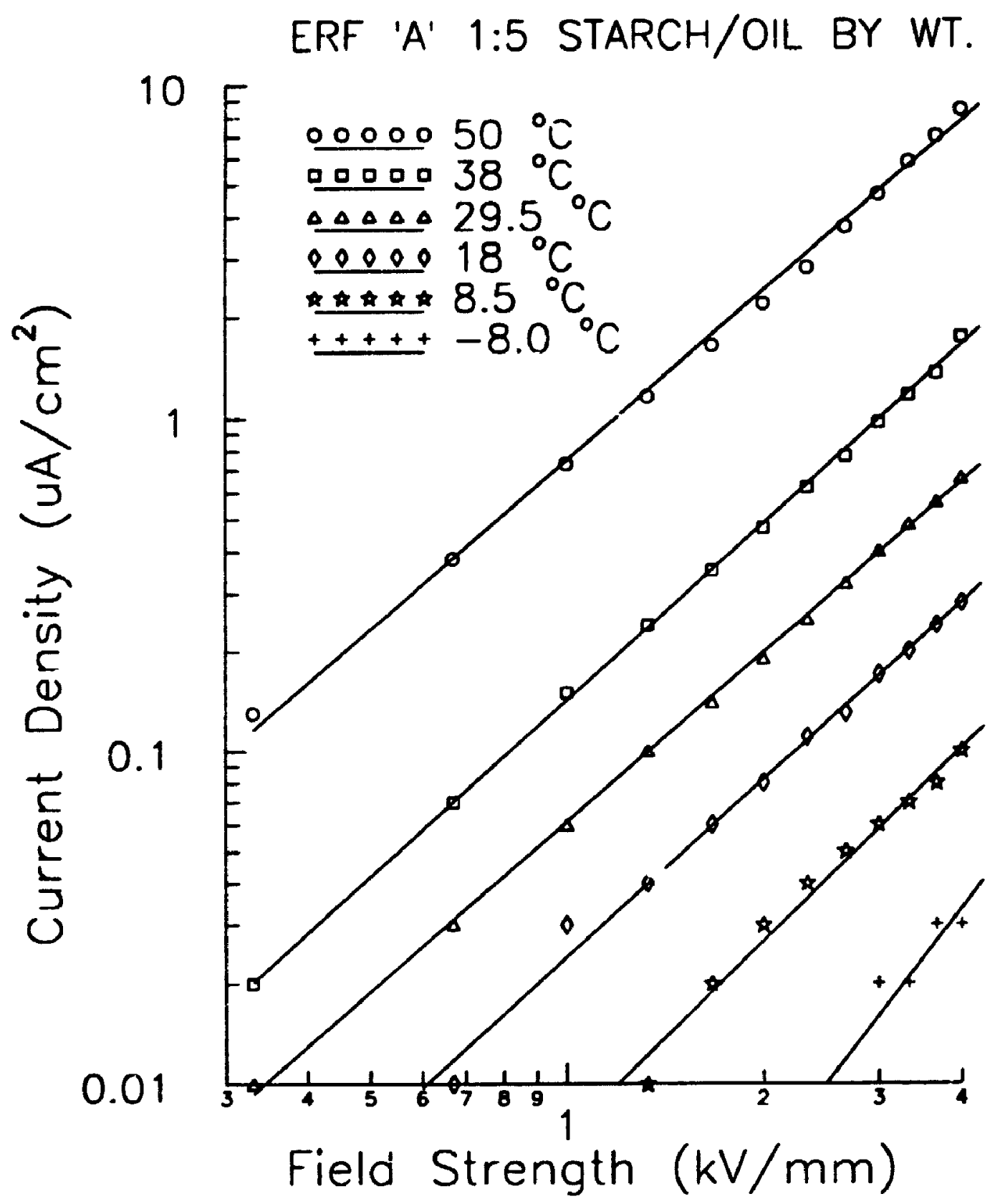

Figure 3: Parallel Plate Electrode Measurements of Current Density versus Electric Fleld Strength For ERF 'A' 


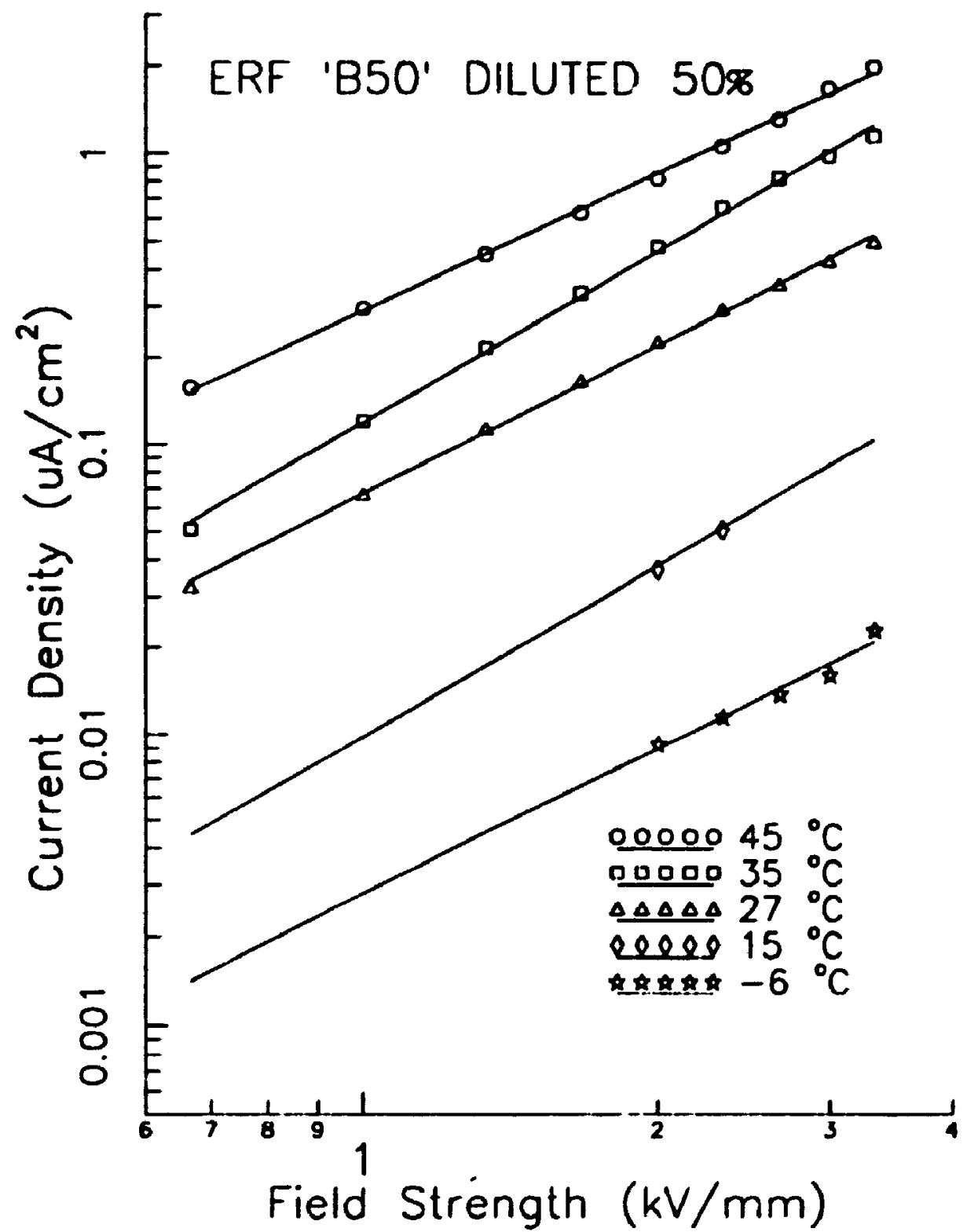

Figure 4: Parallel Plate Electrode Measurements of Current Density versus Electric Field Strength For ERF 'B50' 


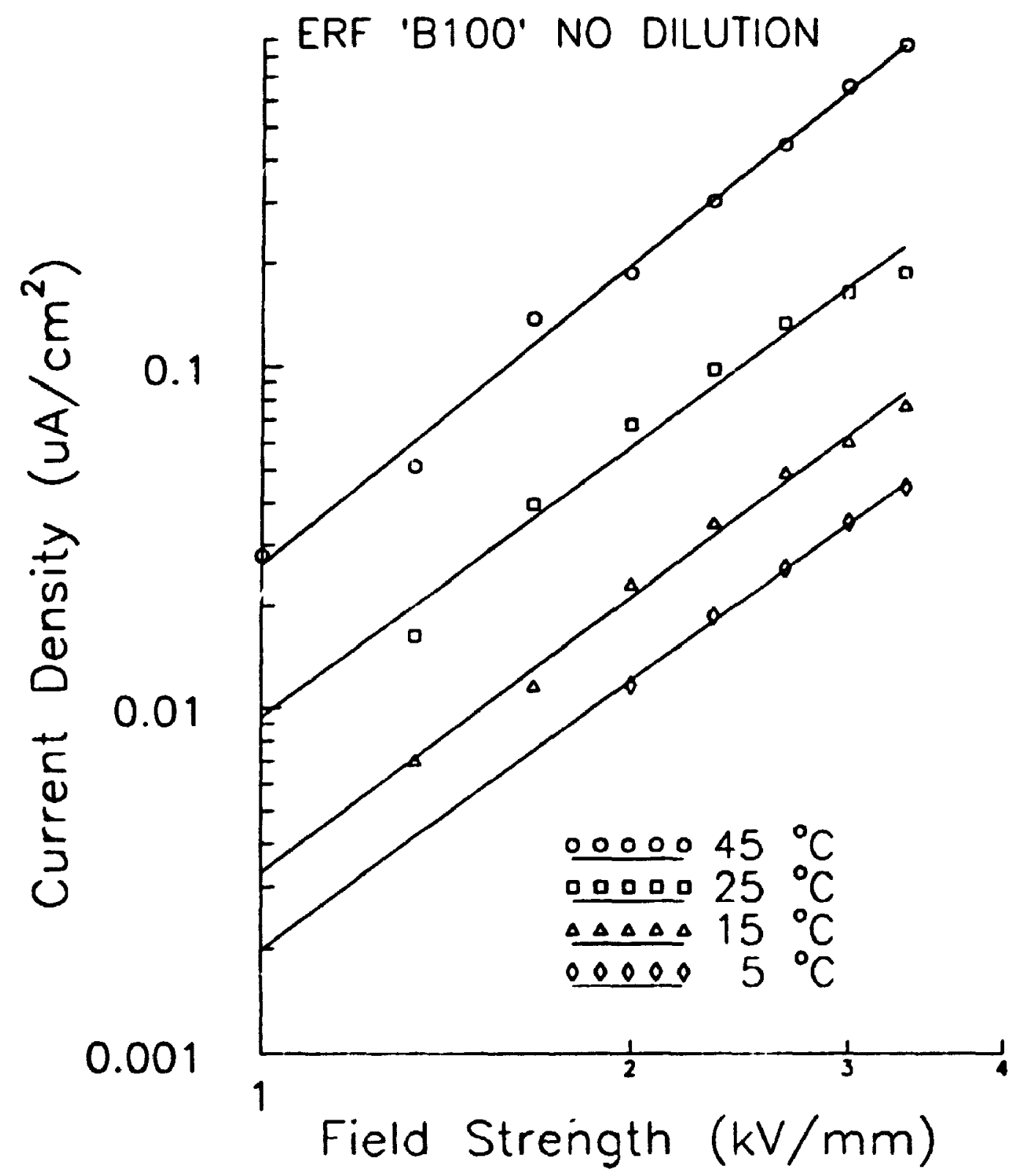

Figure 5: Parallel Plate Electrode Measurements of Current Density versus Electric Field Strength For ERF 'B100' 
Table I shows that over a fairly wide temperature range the value of the exponent for the power law equation governing current density and field strength lies between 1.68 and 1.77. For the same concentration of starch in silicone oil, Frood obained an exponent of 1.67 at room temperature so the results are strikingly similar. The constant, C, in table 2.1 varies with the temperature and it can be shown that for the above ER fluid the current density doubles for every $5.02^{\circ} \mathrm{C}$ rise in temperature.

TABLE I: ERF' 'A' Power Law Exponent and Constant (Current Density)

\begin{tabular}{|c|c|c|}
\hline Temperature $\left({ }^{\circ} \mathrm{C}\right)$ & Exponent $n$ & Constant C \\
\hline 50 & 1.68167 & 0.747136 \\
\hline 38 & 1.76514 & 0.142382 \\
\hline 29.5 & 1.69605 & 0.061267 \\
\hline 18 & 1.77303 & 0.024002 \\
\hline 3.5 & 1.92361 & 0.007051 \\
\hline-8.0 & 2.56082 & 0.000958 \\
\hline
\end{tabular}

The second ER fluid tested was the proprietary ?luid, ERF 'B50', diluted with silicone oil in the approximate ratio of 1:1. The purpose of diluting the fluid was to reduce its zero field viscosity to a level more in common with the starch based ER fluid. Without dilution the fluid had the consistency of jelly. Figure 4 shows current density versus electric field strength for the diluted fluid. When plotted on $\log -\log s c a l e s$ the data again fell onto reasonably straight lines. Table 11 lists the values for the exponents and constants used in equation (13). 
Table II: ERF 'B50' Power Law Exponent and Constant (Current Density)

\begin{tabular}{|c|c|c|}
\hline Temperature $\left({ }^{\circ} \mathrm{C}\right)$ & Exponent n & Constant C \\
\hline 45 & 1.56532 & 0.289873 \\
\hline 35 & 1.95371 & 0.119406 \\
\hline 27 & 1.70740 & 0.067592 \\
\hline 15 & 1.96443 & 0.009834 \\
\hline-6 & 1.67781 & 0.002800 \\
\hline
\end{tabular}

Averaging the values of the exponents in Table II one obtains the value of 1.77 for ' $n$ ' in equation (13) which is not different from that obtained for the starch based fluid. As also shown from the table, the constant $C$ varies with temperature; for this fluid the current density doubles for every $7.6^{\circ} \mathrm{C}$ rise in temperature.

The last batch of ER fluid tested for current density was the unaltered fluid, ERF 'B100'. Again the current density was plotted against electric field strength on log-log scales. Figure 5 shows the general trend persists with the data points falling on reasonable straight lines. The exponent values and constants are tabulated in Table III. Averaging the values in Table III produces a typical exponent value of 2.7 for the fluid. The current density doubles in this case for every $10.7^{\circ} \mathrm{C}$ rise in temperature. 
Table III: ERF 'B100' Power Law Exponent and Constant (Current Density)

\begin{tabular}{|c|c|c|}
\hline Temperature $\left({ }^{\circ} \mathrm{C}\right)$ & Exponent $n$ & Constant $\mathrm{C}$ \\
\hline 45 & 2.89285 & 0.0263512 \\
\hline 25 & 2.62715 & 0.0093867 \\
\hline 15 & 2.68437 & 0.0032834 \\
\hline 5 & 2.59973 & 0.0019772 \\
\hline
\end{tabular}

The current density measurements for the three batches of ER fluid shows discernible trends. All three fluids displayed non-ohmic behaviour. Current density w's proportional to the electric field strength raised to an exponent generally between 1.6 and 1.8 for the starch based fluid and between 2.6 and 2.9 for the proprietary fluid. The values of the constant, $\mathbf{C}$, were dependent upon temperature. The starch based fluid doubled in current demand for every $5^{\circ} \mathrm{C}$ rise in temperature. The proprietary fluid was less sensitive to temperature; current demand doubled for every $10.7^{\circ} \mathrm{C}$ rise in temperature. Both fluids displayed a power law relationship between current and voltage.

The significant drawback to most ER fluids is highlighted in these experiments; the increased conductivity with temperature. Although the quiescent current demand of all the fluids tested was fairly minimal at room temperature, never exceeding ten microamperes, the increased conductivity with temperature presents a significant and potentially hazandous problem. The question remains whether all ER fluids are inherently unstable with respect to temperature (i.e. having a negative temperature coefficient of resistance). The fact that some ER fluid research centres are now reponing openting 
ranges from 0 to $80^{\circ} \mathrm{C}$ indicates more stable fluids (possibly with significantly reduced water content) are being developed.

Another question that has yet to be resolved is the role of conductivity in the ER effect. Figure 6 shows shear ratio plotted against temperature at various shear rates for the two principal fluids, ERF ' $A$ ' and ERF 'B'. As evident from the figure there is virtually no significant ER effect below $0^{\circ} \mathrm{C}$. Above this temperature the shear ratio increases in an exponential manner similar to the conductivity. Again, the fluid, ERF 'B100', shows less temperature sensitivity than the starch based mixture. It would appear, therefore, that conductivity and ER effect may be related. It is possible that a certain mobility, either electronic or ionic, is required for both conduction and polarization, the latter being explicitly required for manifestation of the ER effect. If conduction is intrinsically linked with polarization in ER fluids then ER fluids may be doomed to severe temperature limitations. For example, liquid crystal displays (LCD) have similar temperature limitations.

At room temperature the quiescent current demand is rather minimal, within the order of microamperers. However, ER devices are rarely operated in purely static modes. As will be shown in the next section, the actual current demand consists of two parts: a conduction current and a displacement current. 


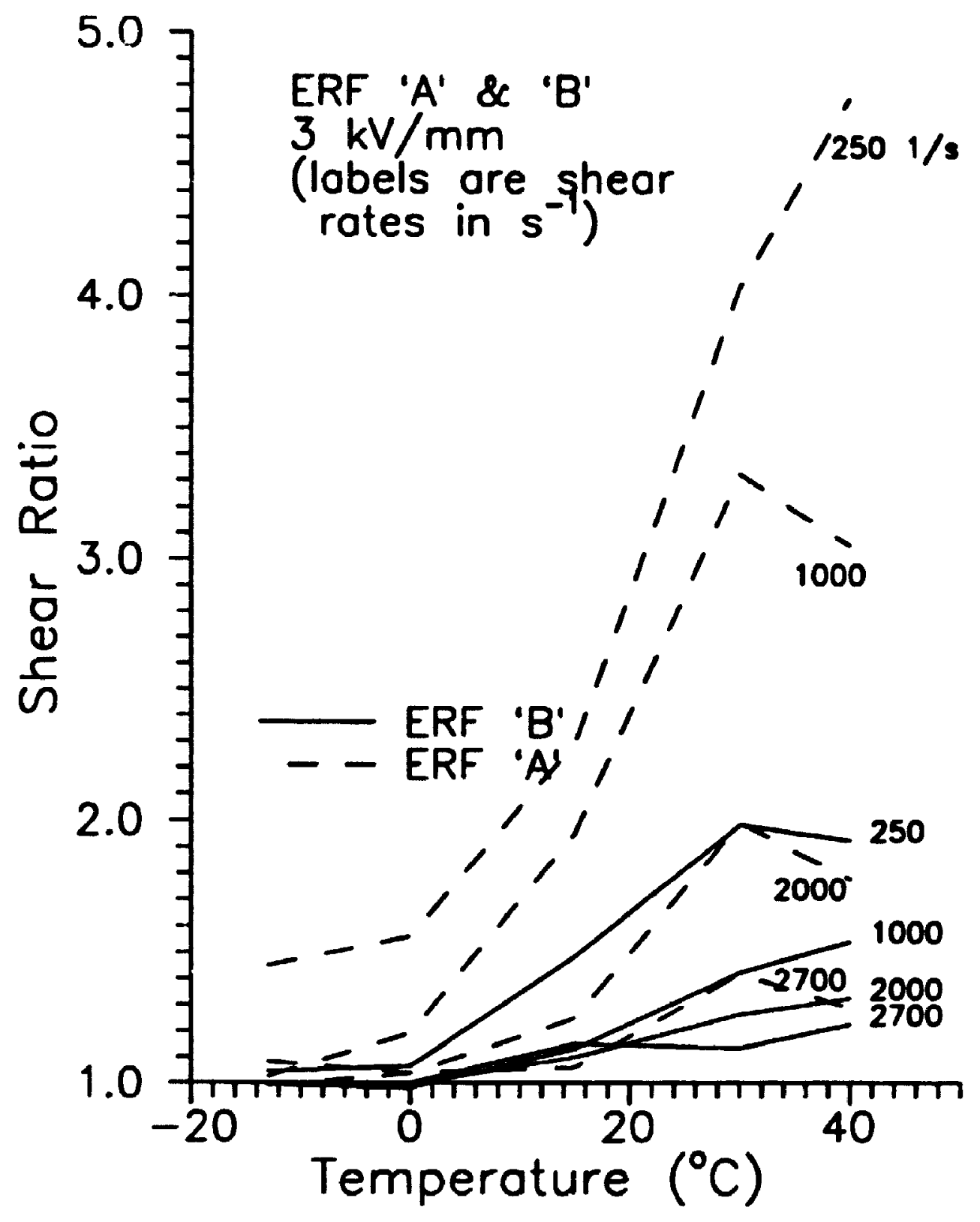

Figure 6: Rotating (Couette) Viscometer Measurements of Shear Ratio versus Temperature For ERF ' $A$ ' and ERF 'B' (Graph Courtesy of Chris Bortolonto) 


\section{4 .3 Total Current}

In section 2.4 .2 it was assumed that the current density was not changing in time. The current density was therefore easily calculated as the ratio of the direct current (DC) and the electrode area. If an ER fluid could be modeled accurately as a conductor then the current density would consist of only one term, the conduction current. However, ER fluids are conducting dielectrics, rather than conductors solely, hence the total current density, $J_{\text {mont }}$ consists of two parts:

$$
J_{\text {mand }}=J_{\text {cand }}+J_{\text {and }}
$$

where $J_{\text {onsons }} J_{a m}=$ conduction current and displacement current density, respectively

A conducting dielectric can be modeled as a resistor and capacitor in parallel [44] whereby the current density inside the "resistor" equals the product of the electric field, $E$, and the de conductivity, $\sigma$, or $J=\sigma E$. A parallel plate capacitor has a capacitance, $C$ $=\varepsilon A d^{2}$, where $\varepsilon$ is the permittivity of the dielectric medium, $A$ is the plate area and $d$ is the distance between the plates. The current measured going "through" the capacitor is the displacement current, inim:

$$
i_{d \rightarrow d}=C \frac{d V}{d t}
$$

Substituting $V=E d$ and $C=\varepsilon A d^{-1}$ into the above equation yields another form for the displacement current:

$$
i_{d x}=\epsilon A \frac{d E}{d t}
$$


Hence equation (15) can be rewritten as:

$$
J_{\operatorname{mad}}=\sigma E+\epsilon \frac{d E}{d t}
$$

For ER fluid devices that require high bandwidth control, the current demand is generally dictated by the charging requirements rather than the de conduction. Therefore, the permittivity of the ER fluid is a significant parameter in ER fluid formulation and modelling.

\subsubsection{Complex Permittivity and Dielectric Hysteresis}

Relative permittivity, $\varepsilon_{n}$ is defined as the ratio of the dielectric permittivity, $\varepsilon_{,}$to the permittivity of free space, $\varepsilon_{0}$ :

$$
\epsilon_{r}=\frac{\epsilon}{\epsilon_{0}}
$$

where $\varepsilon_{0}=8.85 \mathrm{pFm}^{-1}$

The relative permittivity of air is very close (within $0.06 \%$ ) to that of free space and therefore considered to be one. The relative permittivity of silicone oil, the carrier fluid used in the damper ER fluid, is approximately 2.5 .

Strictly speaking, permittivity is a complex quantity with real and imaginary components. The model for a polar molecule has been represented as a mechanical system comprising an electron cloud of mass, $m$, connected to an inertial reference, the nucleus, by a spring and damper [44]. The behaviour of the system can be expressed by: 


$$
m \frac{d^{2} L}{d t^{2}}+c \frac{d L}{d t}+s L=q E_{0} \cos \omega t
$$

here $L=$ dipole separation

$s=$ spring constant

$q=$ dipole charge

$c=$ damping coefficient

The polarization or dipole moment per unit volume is:

$$
F \cdot N_{\mathcal{A}} L=\frac{\left(N_{\mathcal{A}^{2}} / m\right) E_{0}}{\omega_{0}^{2}-\omega^{2}+(j \omega c / m)}
$$

where $\omega_{0}=(s / \mathrm{m})^{1 / 2}$

$\omega=$ driving radian frequency

$N_{d}=$ number of dipoles per unit volume

From Kraus [44] the complex permittivity can be expressed as:

$$
\begin{gathered}
\epsilon=\epsilon^{\prime}-j \epsilon^{\prime \prime} \\
\epsilon^{\prime}=\epsilon_{0}\left[1+\frac{\left(N_{d}{ }^{2} / \epsilon_{0} m\right)\left(\omega_{0}^{2}-\omega^{2}\right)}{\left(\omega_{0}^{2}-\omega^{2}\right)^{2}+(\omega c / m)^{2}}\right] \\
\epsilon^{\prime \prime}=\epsilon_{0}\left[\frac{\left(N_{d}{ }^{2} / \epsilon_{0} m\right)(\omega c / m)}{\left(\omega_{0}^{2}-\omega^{2}\right)^{2}+(\omega c / m)^{2}}\right]
\end{gathered}
$$

As shown from the above two equations both $\varepsilon^{\prime}$ and $\varepsilon^{\prime \prime}$ are dependent upon frequency. An expression for the equivalent conductivity, $\sigma^{\prime}$, can now be given as: 


$$
\sigma^{\prime}=\sigma+\omega \epsilon^{\prime \prime}
$$

Since power loss in a medium is proportional to conductance, the power loss in a conducting dielectric is therefore given by:

$$
P_{\text {bos }}=\sigma E^{2}+\omega \epsilon^{\prime \prime} E^{2}
$$

The second term in the above equation represents the power loss due to dielocuric hysteresis which is analogous to magnetic hysteresis. At sufficiently high frequencies there can be appreciable power loss in phase with the conduction current power loss.

The total current density in a conducting dielectric, and hence an ER fluid, can finally be expressed as:

$$
J_{\text {mand }}=\left(\sigma+\omega \epsilon^{\prime \prime}\right) E+j \omega \epsilon^{\prime} E
$$

In the above equation the lower case $j$ is an operator signifying that the displacement current density, $j \omega \mathrm{E}$, is $90^{\circ}$ out of phase with the conduction current density, $\sigma^{\prime} E=\left(\sigma+\omega \varepsilon^{\prime \prime}\right) E$. The displacement current density represents energy storage in the dielectric between the capacitor plates. The conduction current (both de and dielectric hysteresis components) represents pure power loss.

\subsubsection{Role of Permittivity In ER Fluids}

Permituivity, $\varepsilon$, is the measure of a material's ability to produce electric flux density, $D$, when excired by an electro-motive (emf) source [45], since $D=\varepsilon E$. It is also an indicator of a materials ability to become polarized in the presence of an eleitric field. 
In practical terms, the energy storing capability of a capacitor is directly proportional to the permittivity of the dielectric between its electrodes. There is stmng evidence to also suggest that the permittivity of the dispersed phase plays a significant role in the magnitude of the ER effect in ER fluids.

Bares and Carlson [41] state that the magnitude of the shear yield strength is dependent tipon a "substantial difference between the complex permitrivity of the suspended particles and the carrier fluid." According to Bares and Carlson the important term is the complex dipolar coefticient, $\beta$, which they define as:

$$
\beta=\left|\frac{\epsilon_{2}-\epsilon_{1}}{\epsilon_{2}+2 \epsilon_{1}}\right|
$$

where $\varepsilon_{1}=\varepsilon_{1}^{\prime}-j \sigma_{1} \omega^{-1}$

$\varepsilon_{2}=\varepsilon_{2}^{\prime}-j \sigma_{2} \omega^{\prime \prime}$

$\sigma_{1}, \sigma_{2}=$ conductivities of the particles and carrier fluid, respectively

According to Bares and Carlson, the permittivity difference can be achieved in two ways. The ER fluid can be designed such that the dispersed phase has a much higher dielectric constant than the carrier fluid - thus nroducing a dielectric mismatch between the two phases. Or the fluid can be designed such that the conductivity of the dispersed phase is considerably higher than the conductivity of the carrier fluid - hence a conductivity mismatch. 
Bares and Carison claim to have developed a model (the exact model is stated as being proprietary) which allows for the prediction of shear stress based upon the complex dipolar coefficient, $\beta$. Further, the authors state that the development of a yield stress is contingent in many cases upon the conductivity of the particles being substantially higher than the carrier fluid and that the particle conductivity itself is dependent upon the moisture adsorbed on the particle surface.

Block and Kelly have developed their own theories on the role of permittivity in ER fluids based upon their own technique of flow modified permittivity (FMP) [46]. According to Block and Kelly, enhanced viscosity in ER fluids could be the result of particle torques resisting the flow - the particle torques being induced by "out of phase" polarization vectors orthogonal with the electric field vectors.

\subsubsection{Permittivity (Dielectric Constant) Measurements}

Research on permittivity of ER fluids was restricted to dc field excitation of the ER fluids due to a lack of a proper high voltage amplifier. Although such equipment is available, the cost was deemed prohibitively expensive. However, permittivity measurements at zero frequency were obtained using a laboratory type high voltage de supply.

Using the same apparatus as for the conductivity measurements, permittivity values for ERF 'A' and ERF 'B100' were obtained at conditions of zero frequency, dc, 
and zero flow rate. In this regard the permittivity measurements assumed the form of a dielectric constant even though strictly speaking $p$;rmittivity values do not remain constant in conditions of changing fields and flow (FMP). Although this limited the information obtained on the full characteristics of the fluids, it gave some insight regarding the charging requirements of the high voltage power supply.

Dielectric constant is simply the relative permittivity when the latter is assumed to be constant. For many materials the dielectric constant is indeed constant cver a wide range of conditions. For example, polymer dielectrics such as polytetrafluoroethylene (Teflon), polyethylene, and polystyrene retain their relative permittivities unchai-ged over a frequency range from dc to several megahertz. At very high temperatures, beyond the glass transition temperature, polarization can break down, but such temperatures are rarely reached in practice.

The capacitance of a dielectric filled, parallel-plate capacitor of area, A, and electrode spacing, $d$, is easily determined:

$$
C=k_{d} \in_{0} \frac{A}{d}
$$

where $\mathbf{C}=$ capacitance

$k_{4}=$ dielectric constant

$\varepsilon_{0}=$ permittivity of free space

$A=$ total electrode area 
$A=$ total electrode area

$d$ = spacing between electrodes

The charge density on a plate electrode filled with a dielectric material is directly proporional to the electric field strength:

$$
P_{d}=k_{d} E_{0} E
$$

The product of the charge density and electrode area yields the total charge in Coulombs:

$$
Q_{e}=P_{d} A=k_{d} E_{0} A E
$$

Comparing equations (29) through (31) the total charge, $Q$, is also equal to:

$$
Q_{e}=C E d=C V
$$

This is the familiar expression for the charge on a capacitor. Differentiating both sides of equation (32) yields the also familiar expression for the current required to charge a capacitor:

$$
\frac{d Q_{e}}{d t}=i=C \frac{d V}{d t}
$$

where $d Q d d t=$ instantaneous rate of charge transfer $\left(\mathrm{Cs}^{-1}\right.$ or $\left.\mathrm{A}\right)$

$$
\begin{aligned}
& C=\text { capacitance (Farads) } \\
& d V / d t=\text { slew rate or rate of change } o f \text { voltage }\left(V s^{-1}\right)
\end{aligned}
$$


time rate of change of voltage across the device. For many ER device applications the slew rate is required to be in the order of tens or hundreds of volts per microsecond to meet the bandwidth requirements of the controller which is modulating the ER device.

For example, if the capacitance of our damper is equivalent to $1000 \mathrm{pF}$ and it is required to change the electric potential across the damper from zero to $10 \mathrm{kV}$ within 1 ms, which corresponds to slew rate of $10 \mathrm{~V} / \mu \mathrm{s}$, then the peak instantaneous displacement current would be 10 milliamperes. The dielectric constant has a direct influence on the capacitance of the fluid and hence the current sourcing requirements of the power supply used to excite the damper.

For a given volume of fluid required to exert some mechanical force, there will be a corresponding capacitance determined by the dielectric constant of the fluid and the geometry of the electrodes. Hence, the primary purpose of the capacitance measurements was to determine the dielectric co stants of three batches of available ER fluid.

The first batch of fluid tested was ERF 'A', which as mentioned in section 2.4.2, consisted of finely ground starch particles suspended in silicone dielectric oil. The ratio of starch to oil remained at a ratio of 1:5 by mass. The second batch of ER fluid tested for dielectric constant was ERF 'B50', the diluted proprietary composition; the final batch of ER fluid tested was the original undiluted strength concentration labelled ERF 'B100'. The apparatus used in these experiments consisted chiefly of the following: 
The apparatus used in these experiments consisted chiefly of the following:

1. Universal High Voltage DC Power Supply with manual voltage control, integral panel voltmeter (range: 16kV) and integral panel milliammeter (range: $10 \mathrm{~mA}$ );

2. Beckman Digital Multimeter model 25XI with integral capacitor tester (range: 20uF, resolution: $0.001 \mathrm{nF}$ ) and integral ammeter (range: 10A, resolution: 0.1uA);

3. Centrolab mercury thermometer (range: $150 \mathrm{C}$, accuracy: $0.5 \mathrm{C}$ );

4. American Reliance Digital Multimeter model AR-140 with integral ammeter (range: 10A, resolution: 0.1uA);

5. Glass beaker, capacity: $600 \mathrm{ml}$;

6. Brass electrodes, commercial grade alloy, thickness: $3.2 \mathrm{~mm}$;

7. Lexan Acrlic plastic sheet, thickness: $2.97 \mathrm{~mm}$;

8. Archer 3-way binding posts;

9. $500 \mathrm{ml}$ ERF 'A' ER fluid;

10. 500ml ERF 'B50' proprietary ER fluid (50\% concentration); and

11. 500ml ERF 'B100' proprietary ER fluid (100\% concentration).

The tests involved placing the parallel-plate electrode assembly in parallel with a digital capacitance meter and measuring the capacitance of the entire assembly at various temperatures ranging from approximately $-15 \mathrm{C}$ to $+55 \mathrm{C}$. In order to subtract out the effect of the plastic sheet used to separate the electrodes, recordings were also made of the electrodes "filled" with air instead of fluid. 
The results of the capacitor measurements are tabulated in Tables IV, V, and VI for ERF 'A', ERF 'BSO' and ERF 'B100' respectively. The second column in these tables represents the capacitance measured with the electrodes "filled" with air. The adjacent column represents the capacitance measurement with the electrodes immersed in the ER fluid. The fourth column in each table shows the calculated difference between the plates filled with fluid and the piates immersed in air. Finally, the last column shows the calculated dielectric constant based on the electrode geometry and the results of the fourth column. The dielectric constant for each batch of ER fluid was calculated using the formula:

$$
k_{\text {sudd }}=\frac{\left(C_{\text {sudd }}-C_{\text {dir }}\right) d}{\epsilon_{o} A}+k_{\text {atr }}
$$

where $\varepsilon_{0}=$ permittivity of free space

$$
\begin{aligned}
& A=\text { area of the plate electrode } \\
& d=\text { distance between plate electrodes } \\
& k_{\text {miso }}, k_{\text {air }}=\text { dielectric constant of the fluid and air, respectively } \\
& C_{\text {nis. }}, C_{a i r}=\text { capacitance of the fluid and air, respectively }
\end{aligned}
$$

Because equation (34) uses only the difference in capacitance to calculate the dielectric constant, the capacitive contribution from the plastic sheet is cancelled out. 
Table IV: Capacitance Measurements of ERF 'A'

\begin{tabular}{|c|c|c|c|c|}
\hline Temp. & $\begin{array}{c}\text { Capacitance } \\
\text { With Air }\end{array}$ & $\begin{array}{c}\text { Capacitance } \\
\text { With Fluid }\end{array}$ & $\begin{array}{c}\text { Capacitance } \\
\text { Of Fluid }\end{array}$ & $\begin{array}{c}\text { Dielectric } \\
\text { Constant }\end{array}$ \\
\hline (') & $(\mathrm{nF})$ & $(\mathrm{nF})$ & $(\mathrm{nF})$ & \\
\hline 55 & 0.074 & 0.112 & 0.038 & 4.0 \\
\hline 50 & 0.074 & 0.110 & 0.038 & 3.8 \\
\hline 43 & 0.073 & 0.111 & 0.038 & 4.0 \\
\hline 39 & 0.073 & 0.111 & 0.038 & 4.0 \\
\hline 34 & 0.072 & 0.110 & 0.038 & 4.0 \\
\hline 29 & 0.072 & 0.109 & 0.037 & 3.9 \\
\hline 25 & 0.071 & 0.107 & 0.036 & 3.8 \\
\hline 21 & 0.069 & 0.103 & 0.034 & 3.7 \\
\hline 10 & 0.069 & 0.103 & 0.034 & 3.7 \\
\hline-1.5 & 0.069 & 0.104 & 0.035 & 3.7 \\
\hline
\end{tabular}


Table V: Capacitance Measurements of ERF 'B50'

\begin{tabular}{|c|c|c|c|c|}
\hline Temp. & $\begin{array}{c}\text { Capacitance } \\
\text { With Air }\end{array}$ & $\begin{array}{c}\text { Capacitance } \\
\text { With Fluid }\end{array}$ & $\begin{array}{c}\text { Capacitance } \\
\text { Of Fluid }\end{array}$ & $\begin{array}{c}\text { Dielectric } \\
\text { Constant }\end{array}$ \\
\hline 50 & $(\mathrm{nF})$ & $(\mathrm{nF})$ & $(\mathrm{nF})$ & \\
\hline 45 & 0.074 & 0.110 & 0.036 & 3.8 \\
\hline 40 & 0.073 & 0.109 & 0.036 & 3.8 \\
\hline 35 & 0.073 & 0.108 & 0.035 & 3.7 \\
\hline 30 & 0.072 & 0.107 & 0.035 & 3.7 \\
\hline 25 & 0.072 & 0.105 & 0.033 & 3.6 \\
\hline 20 & 0.071 & 0.102 & 0.031 & 3.4 \\
\hline 15 & 0.070 & 0.101 & 0.031 & 3.4 \\
\hline 10 & 0.070 & 0.100 & 0.030 & 3.3 \\
\hline 5 & 0.069 & 0.099 & 0.030 & 3.3 \\
\hline 0 & 0.069 & 0.098 & 0.029 & 3.3 \\
\hline-5 & 0.068 & 0.096 & 0.028 & 3.3 \\
\hline & 0.068 & 0.096 & 0.028 & 3.2 \\
\hline
\end{tabular}


Table VI: Capacitance Measurements of ERF 'B:00'

\begin{tabular}{|c|c|c|c|c|}
\hline Temp. & $\begin{array}{c}\text { Capacitance } \\
\text { With Air }\end{array}$ & $\begin{array}{c}\text { Capacitance } \\
\text { With Fluid }\end{array}$ & $\begin{array}{c}\text { Capacitance } \\
\text { Of Fluid }\end{array}$ & $\begin{array}{c}\text { Dielectric } \\
\text { Constain }\end{array}$ \\
\hline 50 & $(\mathrm{nF})$ & $(\mathrm{nF})$ & $(\mathrm{nF})$ & \\
\hline 45 & 0.074 & 0.101 & 0.027 & 3.1 \\
\hline 40 & 0.073 & 0.106 & 0.033 & 3.6 \\
\hline 35 & 0.073 & 0.108 & 0.035 & 3.7 \\
\hline 30 & 0.072 & 0.107 & 0.035 & 3.7 \\
\hline 25 & 0.072 & 0.105 & 0.033 & 3.6 \\
\hline 20 & 0.071 & 0.104 & 0.033 & 3.6 \\
\hline 15 & 0.070 & 0.102 & 0.032 & 3.5 \\
\hline 10 & 0.070 & 0.100 & 0.030 & 3.3 \\
\hline 5 & 0.069 & 0.098 & 0.029 & 3.3 \\
\hline 0 & 0.069 & 0.097 & 0.028 & 3.2 \\
\hline-5 & 0.068 & 0.096 & 0.028 & 3.2 \\
\hline & 0.068 & 0.094 & 0.026 & 3.0 \\
\hline
\end{tabular}


Unlike the current/voltage tests the capacitance measurements did not indicate a strong temperature dependency. The capacitance changed only marginally with the vemperature and instrument error can not be ruled out entirely as the major contributor to changes in measurement.

ERF 'A', the starch based fluid with 1:5 mass ratio, had the highest reconded dielectric constant of 3.81 at room temperature. This is significantly higher than many commercial grade solid dielectrics such as polyethylene and polystyrene (2.3 and 2.5 respectively). ERF 'B 100', the $100 \%$ concentrated fluid, had the next highest dielectric constant at $25 \mathrm{C}$ of 3.57 . At the same temperature, ERF 'B50', the $50 \%$ concentrated nuid, had a dielectric constant of 3.42. The dielectric constant of the carrier fluid in all three cases was approximately 2.5. Evidently, the dielectric constant of the dispersed phase was slightly higher than the carrier fluid in all three fluid groups. Using the constants derived above, it is possible to calculate the capacitive loading for any ER device of known geometry. As mentioned earlier, the capacitive loading effect of the ER fluid represents the primary influence on such system parameters as frequency response and power requirements. The total capacitance, C, of an ER fluid damper can be estimated using the familiar expression for a cylindrical capacitor:

$$
C=\frac{4 \pi \epsilon_{r} \epsilon_{0} L}{2[\ln (b / a)]}
$$

where $a, b=$ inner and outer radii of cylinders respectively

$$
L=\text { length of cylinders }
$$


$\varepsilon_{1}=$ relative permittivity or dielectric constant

$\varepsilon_{0}=$ permittivity of free space

The ER fluid damper used in the investigation of the semi-active vibration control consisted of five concentric aluminum cylinders arranged around a hollow brass rod; the entire assembly serving as the damper piston, as shown in Figure 7. The cylinders. immersed in the ER fluid. were alternately either grounded or connected to the high voltage supply in order to create an eloctric field within the annular gaps through which the ER fluid flows. A gap size of $3 \mathrm{~mm}$ between each cylinder was chosen. The total effective electrode area of the damper was approximately $400 \mathrm{~cm}^{2}$. The height of the electrodes was $60 \mathrm{~mm}$ Calculating the capacitive values for each pair of adjacent cylinders and summing yielded an equivalent capacitance value for the test damper to be 420 picofarads which was sinilar to the measured value.

\subsubsection{Dielectric Strength}

Another important characteristic of a dielectric material is its dielectric strength or ability to withstand voltage breakdown. No direct correlation exists between dielectric constant and dielectric strength. Dielectric breakdown is more often associated with fissures or impurities in the dielectric medium rather than any intrinsic property of the medium itself. 


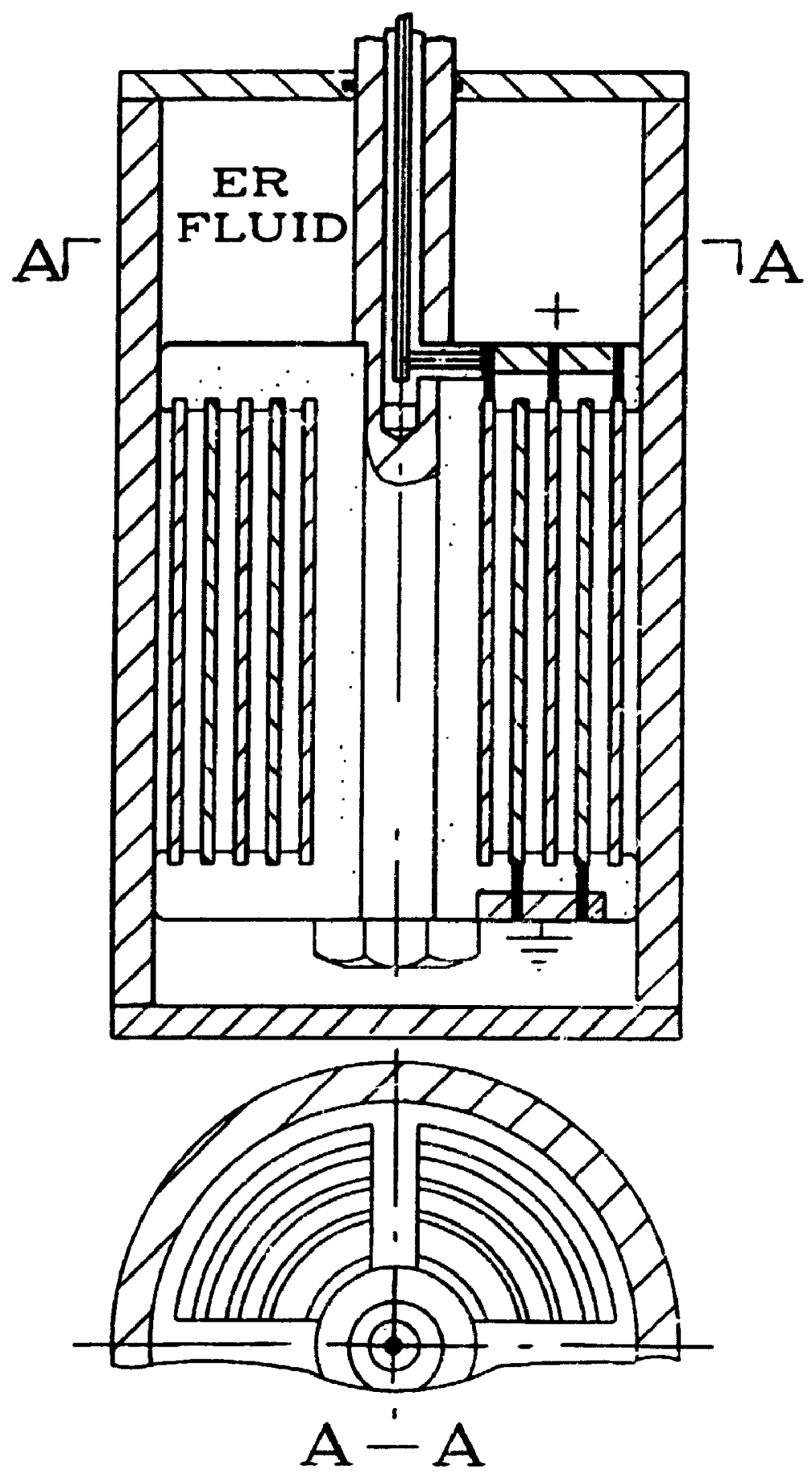

Figure 7: Cross Sectional View of Electrotheological Fluid Damper Used In Semi-Active Suspension System Testing 
Dielectric strength was not tested directly in the experiments. Rather, current density as a function of voltage and temperature was measured up to the limits imposed by the equipment available. It was quite difficult 00 determine the exact limit of the dielectric strength of the fluid since voltage breakdown often occurred suddenly and without warning. In fact it was the sudden breakdown which resulted in the destructi.n of several digital current meters. However, during many rests it was possible to apply up to $12 \mathrm{kV}$ across the $3 \mathrm{~mm}$ gap without incident. Other times the breakdown would occur at as low as $7 \mathrm{kV}$. The probable cause of the breakdown was microcracking of the plastic sheet although impurities in the fluid could not be ruled out altogether. From observations made during the test a safe minimum dielectric strength of the fluids was estimated at $4 \mathrm{kV} / \mathrm{mm}$. There was no discernible difference in the tendency to breakdown from one fluid to the next.

\subsection{Frequency Effects}

All of the electrical property measurenients were made with the ER fluids excited by a unipciar de electric field. Many researchers have reported diminishing ER activity with increasing frequency. ER activity is reponed to drop off significantly at frequencies above $10^{6} \mathrm{~Hz}$ [36]. It is possible that there exists some critical frequency of polarization above which the dipoles cannot respond fast enough to the alternating field. Table VII lists " the relative dielectric constants for polyvinyl chloride (PVC) and polytetrafluoroethylene (PTFE) at various frequencies. 
Table VII: Relative Dielectric Constants Of Two Polymers

\begin{tabular}{|c|c|c|}
\hline Frequency & Dielectric & Dielectric \\
$(\mathrm{Hz})$ & Constant & Constant \\
& PVC & PTFE \\
\hline $10^{2}$ & 6.5 & 2.1 \\
\hline $10^{3}$ & 5.6 & 2.1 \\
\hline $10^{4}$ & 4.7 & 2.1 \\
\hline $10^{5}$ & 3.9 & 2.1 \\
\hline $10^{6}$ & 3.3 & 2.1 \\
\hline $10^{7}$ & 2.9 & 2.1 \\
\hline $10^{2}$ & 2.8 & 2.1 \\
\hline $10^{9}$ & 2.6 & 2.1 \\
\hline $10^{10}$ & 2.6 & 2.1 \\
\hline
\end{tabular}

According to Van Vlack [47], the reason PTFE has a constant permittivity is due to the symmetrical nature of its polymer structure. Polyvinyl chloride has an unsymmetrical mer with a large dipole moment. At high frequencies the dipoles cannot respond fast enough to the alternating field to maintain alignmerit. If these two polymer examples can be taken as a guide then it would be apparent that ER fluids comprising dispersed particles with large dipole moments may have difficulty responding to high frequency fields.

Stevens, Sproston, and Stanway [48] have shown that ER fluids are controllable using pulsed dc signals. As the authors note, the adventage of using unipolar signals is 
that the dispersed particles do not have to completely reverse rotation. The authors claim that power consumption for an ER clutch was reduced to one-thind of that required for a constant voltage supply by using pulsed signals. Furthermore, the viscosity enhancement can be controlled directly using either variable frequency or variable pulse duration techniques.

\subsubsection{Summary Of Electrical Properties}

ER fluids are generally non-ohmic in nature with current density dependent upon some power, usually between 1 and 2 , of the electric field strength. The current density is also extremely sensitive to temperature, for some fluids doubling every $5^{\circ} \mathrm{C}$ rise in temperature. The exact role of conductivity in the $\mathrm{T} R$ effect is not exactly known but some researchers believe the ER effect to be contingent upon some finite amount of conductivity.

Permittivity plays an important but ill-defined role in ER fluids as well. According to some researchers the static yield strength of ER fluids is directly dependent upon the dielectric mismatch between the carrizr fluid and dispersed particles. Permittivity in some materials decreases with increasing frequency. Many researchers have reported diminished ER effect with frequencies above $1 \mathrm{kHz}$. ER fluids have been shown to be effective when excited with de pulsed signals. 
The experimental findings on electrical properties for the three types of ER fluids tested at Carleton are summarized in Table VIII.

Table VIII: Summary Of Electrical Properties

\begin{tabular}{|c|c|c|c|}
\hline Fluid & $\begin{array}{c}\text { Resistivity } \\
(\Omega \mathrm{m}) \\
T=25^{\circ} \mathrm{C} \\
\mathrm{E}=3 \mathrm{kV} / \mathrm{mm}\end{array}$ & $\begin{array}{l}\text { Dielectric } \\
\text { Constant } \\
T=25^{\circ} \mathrm{C}\end{array}$ & $\begin{array}{l}\text { Dielectric } \\
\text { Strength } \\
\left(\mathrm{kVmm}^{-1}\right)\end{array}$ \\
\hline ERF ' $A$ ' & $6.9 \times 10^{8}$ & 3.81 & $=4$ \\
\hline ERF 'B50' & $6.7 \times 10^{8}$ & 3.42 & $\approx 4$ \\
\hline ERF 'B 100 ' & $1.8 \times 10^{9}$ & 3.57 & $\approx 4$ \\
\hline
\end{tabular}




\section{CHAPTER III}

\section{HIGH VOLTAGE SUPPLY UNIT}

This chapter describes the development of the high voltage supply unit. The high voltage supply unit was designed and developed by the author in order to meet the requirement of a mobile power supply which might be carried in a vehicle for the purpose of energizing a vehicle shock absorber. The development and testing of the experimental power supply for an ERF damper is the central topic of this thesis.

\subsection{Requirements of The High Voltage Power Supply}

ER fluid valves have been cited as the comerstone of electrorheological technology [49] with high expectations placed upon the development of an ER fluid damper for vehicular applications; either for wheel to body damping, body to seat vibration isolation, or engine to body damping. The potential benefits of an ER daniper are plentiful:

1. Rapid change of state (milliseconds);

2. Low power consumption;

3. Mechanical simplicity; and

4. Large control ratio (Max. damping/ Min. damping).

As discussed in the next chapter, there are significant benefits that can be accrued from a controllable damper in terms of vehicle performance. The limitations of conventional dampers are well known. The damper design must compromise between the 
conflicting requirements of ride comfort and ride handling. ER fluid dampers, when controlled by closed-loop feedback techniques, can react to body and wheel movements and provide appropriate damping levels rather than constant damping coefficients.

For an ER damper to become commercially successful, it must demonstrate a significani performance increase over conventional hydraulic units without incurring a significant increase in price. ER dampers have been cited as unfeasible, among other reasons, due to the complex hardware required to energize the ER fluid [50]. It was the purpose of the research described herein, to demonstrate the opposite: that a simple, lowcost, high voltage power supply could be designed to energize an ER damper.

Electrorheological fluids generally respond in) electric fields in the range of 1 $\mathrm{kV} / \mathrm{mm}$ to $4 \mathrm{kV} / \mathrm{mm}$. At the lower limit there is little change in fluid property, whilst at the higher limit, either saturation of the ER effect occurs or the electrical breakdown strength of the fluid is soon reached. As mentioned previously, ER fluids respond favourably to both direct currer DC) and altemating fields. However, there is probably a critical frequency, $f_{e}$, above which the ER effect diminishes substantially. The critical frequency is probably related to the magnitude of the dipole moment of the dispersed phase and therefore could be expected to vary from fluid to fluid depending upon the composition of the fluid and structural form of the dispersed phase. These is evidence in the published literature that low frequency unipolar pulses can also stimulate the ER effect [51]. 
Although ER fluids will generate the greatest amount of shear stress when energized by low frequency or dc signals, the application of such signals is unsatisfactory for modulating the force of an ER damper which may require a change in response within milliseconds. A high voltage amplifier with an extremely high slew rate in the order of $10 \mathrm{~V}(\mu \mathrm{s})^{-1}$ is required to provide satisfactory response of the ERF damper to typical rad inputs. Such high voltage amplifiers do exist but are extremely expensive and bulky as well as requiring mains input (ac) supply power, making them generally unsuitable for vehicular applications.

The prime requirement for a high voltage power supply for ER devices is the ability to establish an electric field of high intensity, in the order of several $\mathrm{kV} / \mathrm{mm}$, transverse to the motion of the fluid. For a static application where the ER device is maintaining a constant force, such as a brake or a clutch, then tie power consumption, if it is a de field with no fluctuations, will be proporional only to the conduction current density:

$$
P=J V_{0} E
$$

where $\mathrm{J}=$ current density $\left(\mu \mathrm{A} / \mathrm{cm}^{2}\right)$

$V_{0}=$ volume of the fluid between the electrodes $\left(\mathrm{cm}^{3}\right)$

$E=$ electric field intensity $(\mathrm{V} / \mathrm{mm})$

If the ER device is required to vary its force, and hence the electric field intensity applied across the electrodes, then the total current will consist of both the conduction 
current and the displacement current. Although only the conduction current passes "through" the fluid the net effect on the extemal circuit is as if both the displacement and the conduction current were passing through. In actuality, the displacement current is accumulating charge on the fluid electrodes. Work must be done by the external circuit in order to charge up the capacitance represented by the ER fluid between the electrodes. Since by definition, potential, V, is work per charge, then the work done, W, in charging up the ER fluid can be expressed as:

$$
d W=V d q=\frac{q}{C} d q
$$

If the charging process stans from zero charge on the electrodes and proceeds until a final charge, $Q_{e}$ is accumulated on the electrodes, then integrating the above equation will yield the total work and also the total energy stored within the electric field:

$$
W=\frac{1}{C} \int_{0}^{Q_{0}} q d q=\frac{1}{2} \frac{Q_{e}^{2}}{C}
$$

In consequence, the high voltage power supply must supply work in order to deliver the charge to the electrodes separated by the ER fluid in order to establish the electric field. Moreover, due to conduction current effects within the fluid, the electric field will eventually be dissipated as charge moves through the fluid from one electrode to the other. Hence, work must be done in order to regenerate the field as the original charge decays over time. 
The situation is analogous to the input capacitance of field-effect transistor. A FET is a three terminal device consisting of a drain, source, and gate terminals. A slab of semiconducting material is sandwiched between the source and drain terminals. When an emf source is placed across the source and drain terminals no current immediately flows; there are no carriers present to constitute a charge transfer. However, if polarization is induced within the body of the semiconducting material, then charge transfer and hence current will flow out of the source and into the drain terminals. In a FET the polarization is induced by the gate terminal which is connected to a slab of dielectric at right angles to the drain and source terminals. Charge is transferred to the dielectric slab which induces the creation of minority (electron) charge carriers in the main body of the semiconducting material. In consequence, for the FET to conduct, charge must be first transferred by the gate terminal to the channel of the FET formed between the source and drain terminals.

For the FET to turn on and off, charge must be transferred into and out of the capacitance formed at the gate terminal. FETs are often erroneously referred to as voltage controlled devices. But charge transfer must occur at the gate terminal for modulation of the FET to occur. It is true, that unlike a bipolar transistor no "standby" or "maintenance" current is required. However, at high switching frequencies the current requirements of FETs can become significant. The input capacitance of some FETs can exceed $1500 \mathrm{pF}$. 
Similarly, to vary the intensity of the electric field within the ER fluid, charge must be transferred either into or out of the electrodes surrounding the fluid. For applications involving high bandwidth controllers, such as an active damper on an automobile, the slew rate, or rate of change of potential can be tens or hundreds of volts per microsecond. The charging current will be proportional to the capacitance represented by the fluid between the electrodes:

$$
i=C \frac{d V}{d t}
$$

If the ER device consists of concentric cylindrical electrodes, then neglecting fringe effects, the charging current can be calculated as:

$$
i=\frac{4 \pi \epsilon_{r} \epsilon_{0} L}{2 \ln (b / a)} \frac{d V}{d t}
$$

where $b, a=$ outer and inner radii of cylinders respectively

$\varepsilon_{1}=$ relative permittivity

$\varepsilon_{0}=$ permittivity of free space

$L=$ length of cylinder

After the ER device is charged, in order to eliminate or reduce the ER effect, charge must be drained off the electrodes. Hence, for complete variability of the ER device, the high voltage power supply must be capable of both sinking and sourcing current. 
The total measured capacitance of the experimental ER damper, when filled with ERF 'A' was $420 \mathrm{pF}$. With $10 \mathrm{kV}$ applied across the $3 \mathrm{~mm}$ gap to produce and electric field intensity of $3.33 \mathrm{kVmm}^{-1}$, the total charge accumulated on the electrode surfaces was 4.2 $\mu \mathrm{C}$. In order to deliver this rather small amount of charge to the electrodes at a nominal slew rate of say, $10 \mathrm{~V} / \mu \mathrm{s}$, would require a charging current of $4.2 \mathrm{~mA}$, a considerable amount of current considering the charging potentials involved.

The conduction current can be calculated from the current density and the total electrode area:

$$
i=J A=C E^{N} A
$$

where $\mathrm{J}=$ current density $\left(\mu \mathrm{A} / \mathrm{cm}^{2}\right)$

$$
\begin{aligned}
& C=a \text { constant }\left(0.061267 \text { for } E R F ' A^{\prime} \text { at } 30^{\circ} \mathrm{C} \text { at } E=3.33 \mathrm{kV} / \mathrm{mm}\right) \\
& n=\text { an exponent }(1.69605 \text { for } E R ، \text { ' } A \text { ' at above conditions }) \\
& A=\text { total electrode area }\left(400 \mathrm{~cm}^{2} \text { for the ER damper }\right) \\
& E=\text { electric field intensity }(3.33 \mathrm{kV} / \mathrm{mm})
\end{aligned}
$$

For the above conditions the conduction current would be equal to $188.5 \mu \mathrm{A}$ or approximately $4.5 \%$ of the displacement current. Hence, depending upon the slew rate required by the application, the displacement current can exceed the conduction current by one or several orders of magnitude. 
An interesting design problem is determining the optimum number of annular gaps within an ER damper. To achieve the highest damping lorce for a given fluid volume (length and outside diameter specified) the gaps should be as narrow as possible. However, for a Bingham-flow type of ER fluid, decreasing the gap will severely increase the zero-field shear stress as well, as evident from the equation for pressure drop, $\Delta P$. across an ER channel [52]:

$$
\Delta P=\Delta P_{0}+\Delta P_{E R}=\frac{12 \mu Q L}{b h^{3}}+3 \frac{L}{h} \tau
$$

where $\mu=$ viscosity of carrier fluid

$$
Q=\text { volume flow rate }
$$

b.L,h = width, length and gap size respectively

$\tau_{y}=$ shear yield stress

$\Delta \mathrm{P}_{0}=$ pressure drop with no applied electric field

$\Delta P_{E R}=$ pressure drop with applied electric field

The effect of gap size on the electrical parameters of the damper are also interesting. Increasing the gap will decrease the capacitance but the electric potential must be increased in order to maintain a given field strength since $E=V / d$. The electrostatic energy stored in the damper is $\mathrm{J}=1 / 2 \mathrm{CV}^{2}$. In order to store energy in the damper, work must be performed by the high voltage power supply. The magnitude of the charging current will be determined by the product of the capacitance and the voltage slew rate. 
For a damper comprising multiple cylinders, alternately connected in parallel, and if the thickness of the cylinder walls is assumed infinitely thin, then the total capacitance of the damper can be estimated by:

$$
C=2 \pi \epsilon_{0} \in L \sum_{i=1}^{n} 1 / \ln \left[1+\frac{k-1}{n+(i-1)(k-1)}\right]
$$

where $\mathbf{C}=$ capacitance

$$
\begin{aligned}
& L=\text { lengaturi cylinders } \\
& \varepsilon_{00} \varepsilon_{i}=\text { permittivity of free space and relative permittivity } \\
& k=R_{0} / R_{i} \\
& R_{0}, R_{i}=\text { outermost and innermost radii of damper } \\
& n=\text { number of cylinders }
\end{aligned}
$$

Figure 8 shows the effect of number of cylinders on a damper of $10 \mathrm{~cm}$ in length and various diameters. A dielectric constant of 4.0 was chosen for the ER lluid. As the number of cylinders increases (and hence the gap size decreases) the capacitance rises sharpiy, which is not unexpected.

Figure 9 shows the total maximum electrostatic energy for the same damper having a maximum field strength of $4 \mathrm{kVmm}^{-1}$. Surprisingly, the total energy storage remains fairly constant regardless of the number of cylinders. This is because the toral electric potential and the capacitance are increasing/decreasing in opposite directions as the number of cylinders varies. 


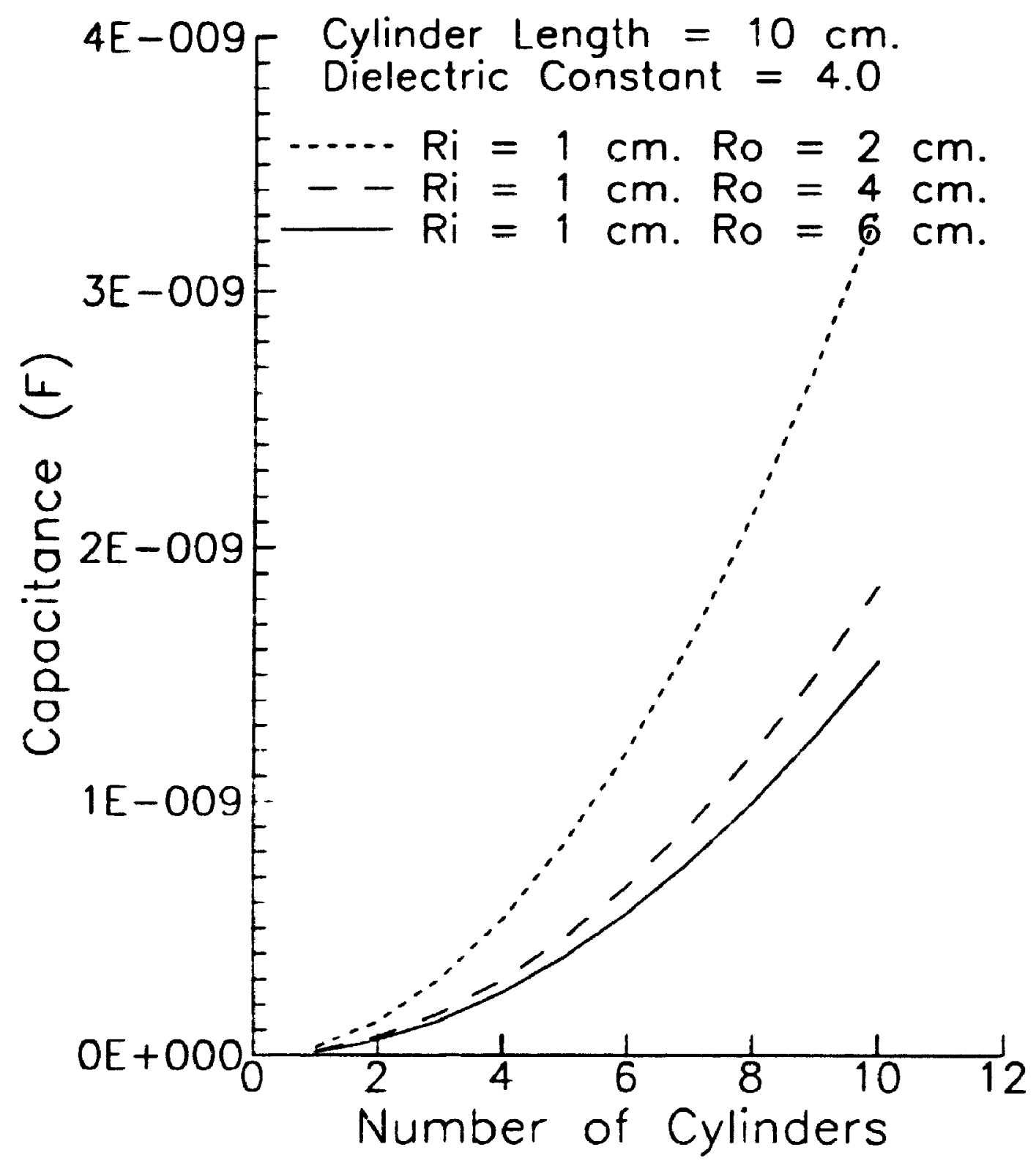

Figure 8: Estimated Capacitance of An Electrotheological Fluid Damper With a Fixed Length and Diameter Bur Varying Number of Cylinders 


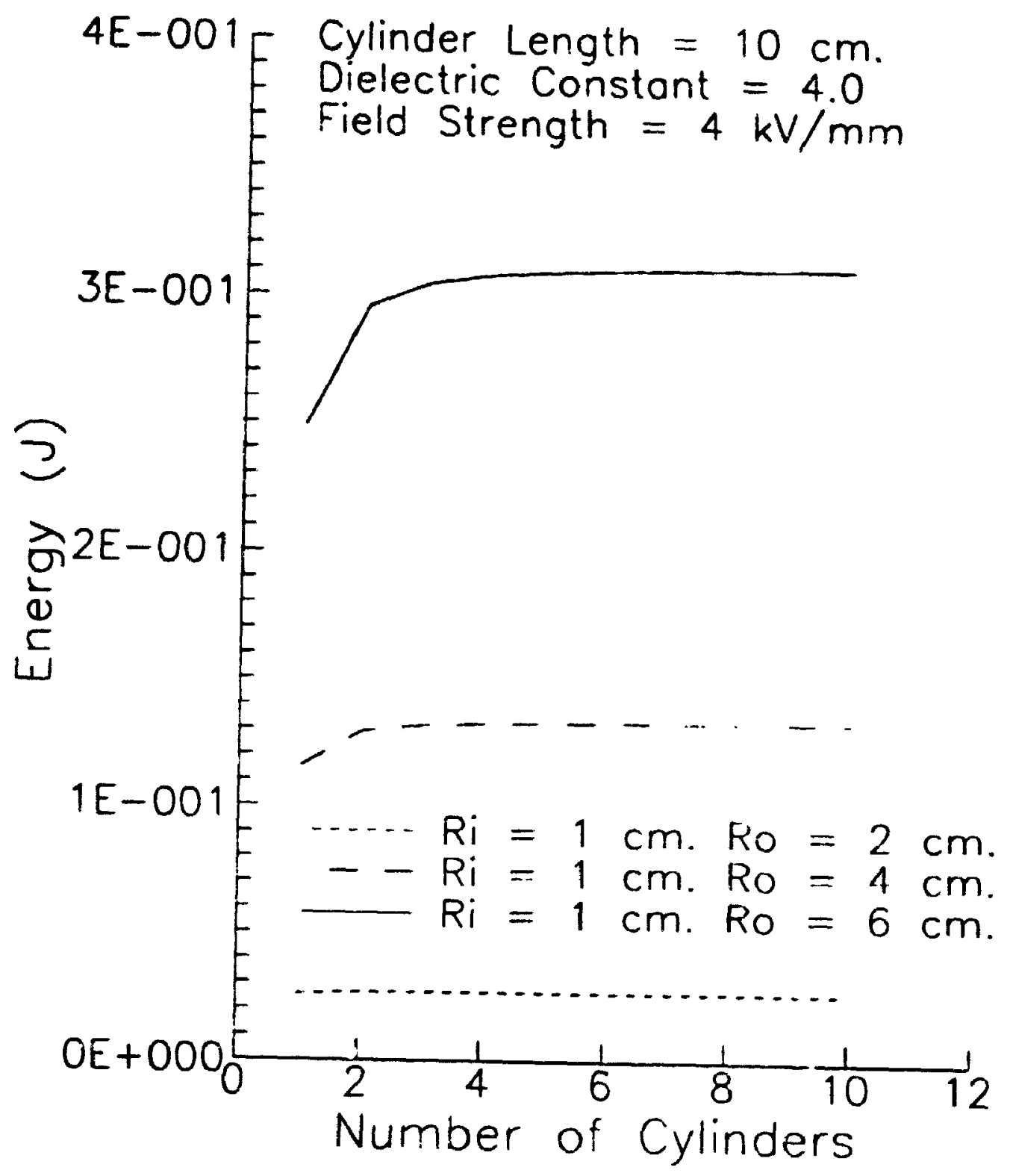

Figure 9: Estimated Electrostatic Energy Storage of An Electrorheological Fluid Damper With a Fixed Length. Diameter and Eleciric Field Strength But Varying Number of Cylinders 


$$
2
$$


The energy storage capability of the damper is a direct indication of how much charge must be delivered to the damper for a given slew rate or bandwidth requirement as dictated by the system. For the experimental damper which had a measured capacitance of $\mathbf{4 2 0}$ picofarads, and was energized up to a maximum of 9 kilovolts, the maximum electrostatic energy stored was $17 \mathrm{~mJ}$.

Utilization of an ER damper in an automotive application places additiona! requirements on the high voltage power supply. There is generally no available space for bulky equipment on light duty automobiles and weight is usually reduced to the practical limit. Therefore, the successful application of ER dampers in light duty vehicles is contingent upon designing compact and lightweight power supplies. As a rough estimate of what might be acceptable in terms of volume, the power supply at each wheel (assuming each ER damper is afforded its own power supply) should probably not be in excess of $1000 \mathrm{~cm}^{3}$ and the weight should not be in excess of $1 \mathrm{~kg}$. As a comparison, the TREK ${ }^{\mathrm{TM}}$ high voltage amplifier (model 10/10), which is probably state-of-the-art in current electrorheological power supplies, has a weight of $16 \mathrm{~kg}$. and a total volume of $33,219 \mathrm{~cm}^{3}$. This comparison is not meant to disparage this particular piece of equipment but rather, demonstrate that a laboratory-grade, high voltage amplifier is not practical for automotive applications. Also, the cost would be prohibitively expensive.

In addition to the size, weight, and cost factors, a car-borne power supply would probably be required to operate from a 12 -volt de operating system. The vast majority of 
automobiles and small trucks operate on 12 volt de systems. Therefore either an inverter (dc/ac) or converter (dc/ac) transformer is required. As previously mentioned, a $3 \mathrm{~mm}$ gap was chosen for the damper. Consequently, the applied voltage must vary up to $12 \mathrm{kV}$ in order to provide an adequate range of damping force. Therefore, a high voltage supply unit for an ER fluid damper should be capable of transforming low voltage to high voltage in one or more steps, with continuously variable output between 0 and $12 \mathrm{kV}$. For high voltage devices, there are additional requirements pertaining to protection against corona discharge, dielectric brcakdown, arcing etc. In general, the ' $x$, yrotection against corona discharge is a hermetically sealed, liquid filled case, since air is a relatively poor insulator. For automotive applications the case should also be fairly insensitive to shock and vibration. The primary requirements for a high voltage supply unit for charging ER fluids could therefore be summarized as follows:

1. Operate from a $12 \mathrm{DC}$ volt power source;

2. Provide a continuously variable output from 0 to $12 \mathrm{kV}$;

3. Charge a relatively small capacitive load $(<0.001$ microfarad $)$ to the specified voltage in the minimum time possible;

4. Encipsulate high voltage transformer windings in a hermetically sealed, liquid filled cs se for maximum protection against arcing and maximum efficiency of heat transfer;

5. Minimize radio frequency interference (RFI);

6. Protect against shock and vitration; and

7. Use minimal space and inexpensive components. 


\subsection{Flyback Converter}

\subsubsection{Theory of Operation}

One type of power supply which is quite effective for charging small capacitive loads to high voltage levels is the flyback converter. The flyback converter has been described by Hnatek [53] as operating on the principle of inductive energy storage whereby energy is cyclically stored in the magnetizing or shunt inductance of a transformer then "dumped" into the load upon opening of the primary circuit. During the interval $t_{\text {oa }}$, when the primary circuit is closed, magnetic energy builds up in the magnetizing inductance of the transformer; during the interval tor, when the switch in the primary circuit is opened, the stored energy is released through tine vlocking diode into the load. The output voltage level is varied by controlling the build-up of current in the magnetizing inductance. A simplified schematic of a flyback converter circuit is shown in Figure 10a, where $Q_{1}$ is the switch, $T_{1}$ is the transformer, $D_{1}$ the blocking diode and $C_{8}$ and $R_{1}$ the output impedance elements. The pulse-width-modulator (PWM) circuit controls the transistor duty cycle and hence the time duration of $t_{b}$ and $t_{o r f}$. The reactive load, $C_{k}$, is connected to the output of the transformer secondary. In the present application the reactive load represents the capacitance of the ER fluid damper. The design and function of each component shown in Figure 10a is described, briefly, in the in the following paragraphs. 


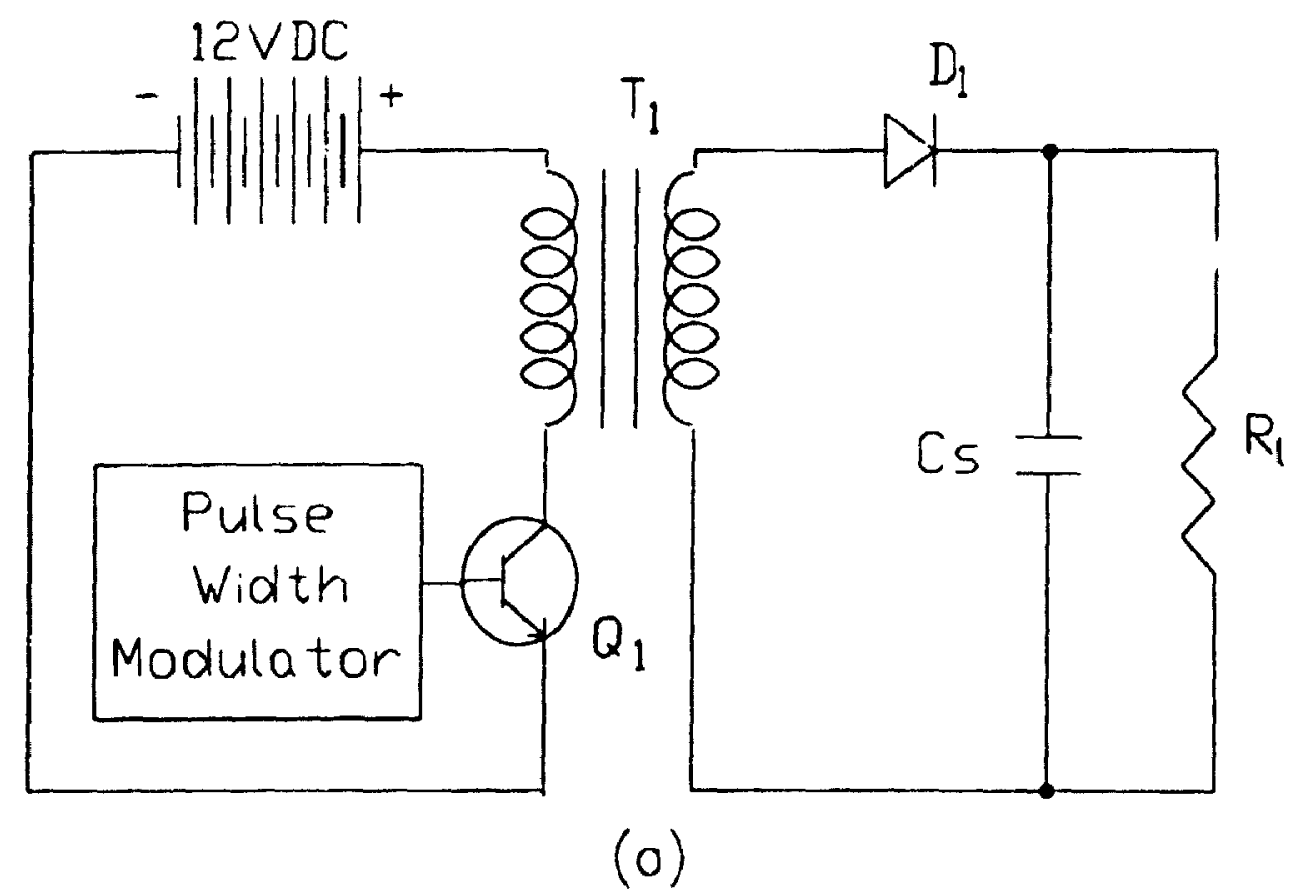

82

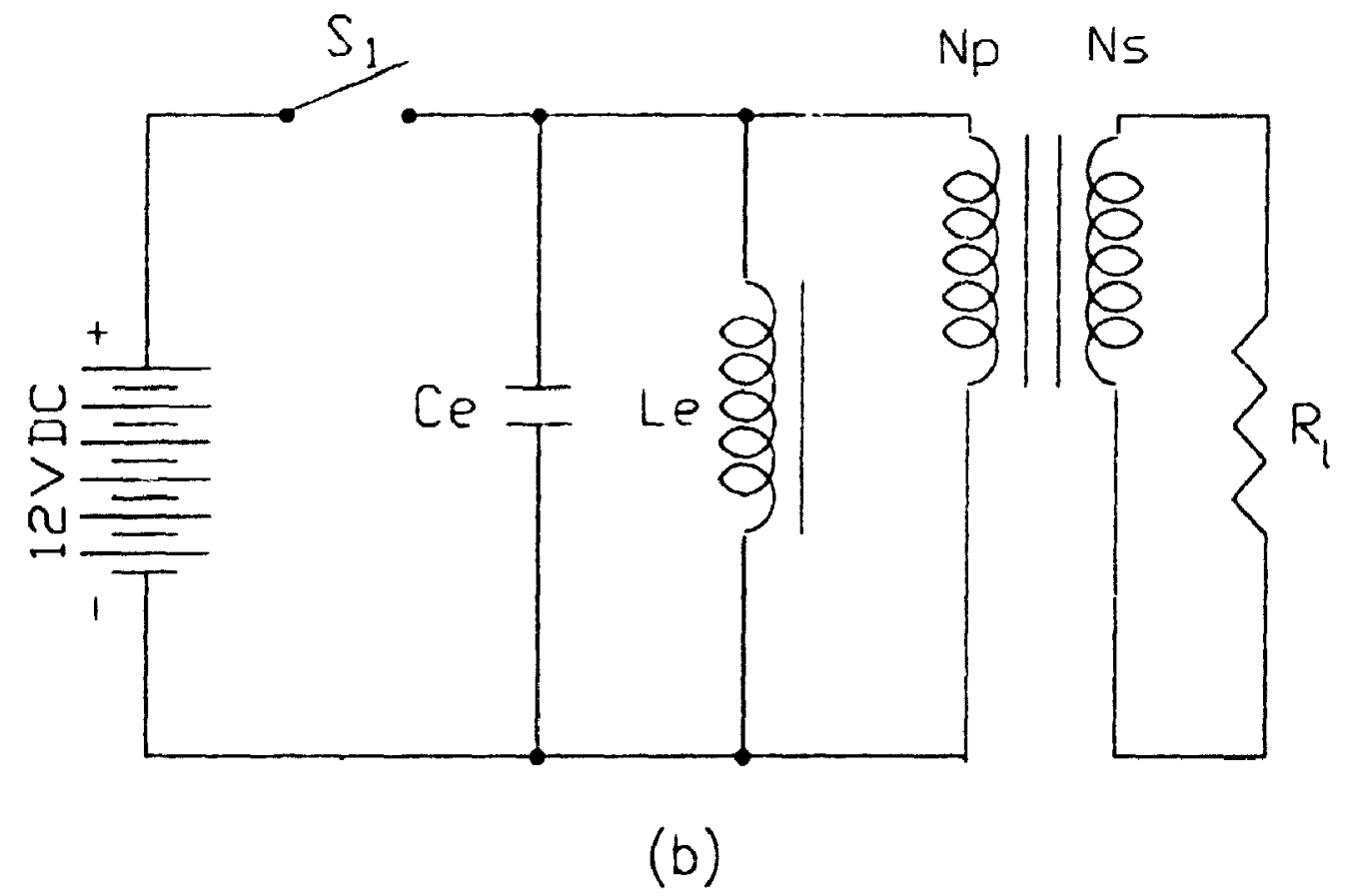

Figure 10(a): Fyback Convener Electrical Schematic

(b): Simplified Equivalent Model 
The transformer, $T_{1}$, consists of two coils wound on a core (either air or ferromagnetic), each coil having a predetermined number of windings. The transformer serves two functions in the flyback converter circuit of Figure 10a. The magnetizing inductance of the transformer stores magnetic energy in the flux surrounding the primary and secondary coils. As noted above, this energy is subsequently released into the load. Also, the transformer also acts as a voltage multiplier by virtue of the turns ratio, $\mathbf{N}$, between the primary and secondary windings. An ideal transformer can be modeled simply as a voltage multiplier where the output voltage is simply equal to the input voltage times the turns ratio, $N, N_{p}$. In an ideal transformer, the only current that flows is that in response to the load applied to the secondary. As noted by Smith [54], the action of an ideal transformer is to maintain equal ampere-turns in both the secondary and primary windings. In the flyback converter, the action of the transformer is to store magnetic energy during the on interval of the switching period, then transfer that energy to the load during the off interval, whereupon the cycle repeats itself.

In Figure 10a, the transistor, $Q_{1}$, serves as the switching element, either opening or closing the primary circuit. The transistor must have an adequately large Safe Operating Area (SOA) to handle the simultaneous peak voltage and current at turn-off. At turn-on, the current increases linearly in proportion to the primary inductance; as noted by Hnatek, one of the advantages of the flyback converter is the transistor always has some series impedance to limit the amount of current passing through the transistor. 
The blocking diode, $D_{1}$, is \& key component in the flyback operation in that it not only provides de isolation between the source and the load but is also responsible for the unique operating mode of the flyback converter. The blocking diode isolates the load from the source during the transistor on-time interval; energy is released to the secondary only during the off-time interval. Furthermore, in the case of a reactive load (which is the case for the damper) the load cannot discharge back into the source. A peak-to-peak doubling circuit is sometimes used between the blocking diode and load to double the output voltage. The doubling circuit enables the turns ratio to be reduced by half while increasing the output ripple and circuit complexity. No doubling circuit was used for the ERF damper power supply.

In a conventional flyback converter power supply, a filter capacitor, $C_{z}$, is placed across the secondary to smooth the voltage across the load. In the case of the ERF damper, the place of the filter capacitor was taken by the effective capacitance of the damper itself. In Figure $10 \mathrm{a}$, the load resistance, $R_{1}$, and the shunt capacitance, $C_{8}$, represent the impedance presented by the ERF damper. The capacitance of the ERF damper was $420 \mathrm{pF}$ while the shunt resistance, while varying with voltage, could be assumed to be in the tens or possibly hundreds of megohms. Hence, the ERF damper, in practical terms, presented a purely capacitive reactance to the flyback converter. 


\subsubsection{Transfer Function And Voltage Gain}

The flyback converter is derived from the buck-boost converter (so named due to its ability to either step-up or step-down the input voltage). The transfer function, or relation between input and output voltage for the flyback convener is given by Kit Sum [55] and Hnatek as:

$$
V_{\text {out }}=V_{d x}\left(\frac{D}{1-D}\right)\left(\frac{N_{s}}{N_{p}}\right)
$$

where Vdc $=$ input voltage

$\mathrm{D}=$ duty cycle

$N_{\varepsilon}, N_{p}=$ number of secondary and primary turns, respectively

The duty cycle is simply defined as the ratio of transistor on-time, $b_{\text {ba, }}$ to the total switching period, $T$, as expressed by:

$$
D=\frac{t_{\text {on }}}{t_{\text {on }}+t_{\text {of }}}=\frac{t_{\text {on }}}{T}
$$

The transfer function for the flyback converter can be derived from a model of a modified ideal transformer. In an ideal transfer the action of the transformer is to maintain equal ampere turns in the primary and secondary windings. This statement is often expressed as Ohm's Law For Magnetic Circuits:

$$
I_{p} N_{p}-I_{p} N_{z}=\phi \mathrm{R}
$$

where $\mathbf{l}_{\mathbf{p}}, \mathbf{I}_{\mathbf{s}}=$ current in the primary and secondary, respectively

$N_{p}, N_{s}=$ number of windings in the primary and secondary, respectively 
$\Phi=$ magnetic flux of circuit (Webers or Maxwells)

$R=$ reluctance

For an ideal transformer, secondary current, $i_{k}$, will flow in response to a load. The magnetomotive force (mmf) will thereupon change by an amount equal to $i_{2} N_{r}$. According to ohm's law for magnetic circuits, primary current, $i_{p}$, must then flow in magnitude necessary to restore the mmf balance in the core. Which is equivalent to saying that the transformer acts to maintain equal ampere-turns in both primary and secondary. For an ideal transformer the total reluctance of the magnetic circuit is zero; hence $\mathbf{L}_{p} N_{p}=L_{8} N_{8}$.

One of the first modifications to the ideal transformer model is the removal of the assumption of zero reluctance or infinite permeability. In a flyback converter, and every other transformer application, magnetizing current will flow even if the load is removed from the secondary. To account for this load independent current, a shunt inductance is placed in parallel with the primary transistor winding. In Figure 10b, this shunt inductance, or primary inductance, is labelled $L_{e}$. If a rectangular voltage pulse, $V_{\alpha e}$ is applied across the primary transformer winding of the flyback converter, the peak current, 1.t. that flows in the shunt inductance can be determined by integrating the defining relationship for inductance [56]:

$$
I_{p t}=\int_{0}^{t_{m}} \frac{V_{d c}}{L_{e}} d t=\frac{V_{d t_{o n}}}{L_{e}}
$$


Alternatively, the magnetizing current, $I_{m}$, can be derived directly from ohm's law for magnetic circuits with $\mathbf{L}_{\mathbf{z}} \mathbf{N}_{\mathbf{s}}=\mathbf{0 . 0}$ :

$$
I_{m}=\frac{\mathrm{D \phi}}{N_{p}}=\frac{\mathrm{R}\left(V t_{o n} / N A\right) A}{N_{p}}=\frac{V t_{o n}}{L_{e}}
$$

If the transistor on time is significantly shorter than the $L / R$ time constant of the primary circuit, then the current through the primary, or shunt inductance, will increase linearly with time, reaching a peak level just before the transistor switch opens. The energy, $J_{e}$ stored in the shunt inductance at the end of the transistor on-time is given by:

$$
J_{*}=\frac{1}{2} I^{2} L_{e}=\frac{V_{d}^{2} I_{c o n}^{2}}{2 L_{c}}
$$

When the transistor switch opens the energy stored in the magnetic field of the shunt inductance is transferred to the load by the secondary winding. As nnted by Hnatek, all of this energy is theoretically available to the load. Assuming 100\% transfomer efficiency then:

$$
\frac{1}{2} I_{s}^{2} L_{s}=\frac{1}{2} I_{p}^{2} L_{p}
$$

For the flyback converter, secondary current, $I_{\text {, }}$, only flows during the transistor off-time interval, ramping down linearly from its peak value of:

$$
I_{s}=\frac{V_{s}}{L_{s}} t_{c j}
$$

However, due to the transformer action of the turns ratio, the peak secondary 
current is also related to the peak primary current:

$$
I_{s}=\frac{N_{P}}{N_{s}}
$$

It is fairly straightforward to show (see Hnatek) that the output voltage, $V_{s}$, is governed by:

$$
V_{s}=V_{d x} \frac{N_{s}}{N_{p}}\left(\frac{t_{\text {on }}}{!_{\text {ofj }}}\right)=V_{d x} \frac{N_{s}}{N_{p}}\left(\frac{D}{1-D}\right)
$$

As shown by the above equation the output voltage of the flyback converter is directly proportional to the product of the input voltage, $E_{\alpha e}$, the turns ratio, $N / N_{p}$, and the ratio of the on-time to off-time, $6 / 6$ or. The flyback converter is capable of very large voltage transformations which makes it very suitable for charEing up an ERF damper. The flyback converer also provides de isolation between the load and the source. In fact, the power delivered to the load is almost completely independent of the magnitude and power factor of the load itself.

By varying the duty cycle the flyback converter is able to modulate its output voltage over a very wide range. By utilizing switchmode rather than linear (dissipative) regulation, efficiency can be (theoretically at least) very high. When a high turns ratio tranisformer is used, the output voltage can be made several orders of magnitude larger than the input voltage. The switching function can be performed in various modes:

1. varying the frequency only; 
2. varying the pulse width (PWM) while maintaining constant frequency: and

3. varying both the pulse width and the frequency.

Since the switching transistor is only driven either full-on or full-off, the switching circuit can be interfaced directly with digital logic or a pulse generator/regulator can be used between the analog comrnand input and the switching circuit.

In summary, the flyback converter operates by cyclically storing energy in the transformer windings during one part of the cycle, then releasing this energy to the load during the latter part of the cycle. A more detailed description of the major components used and their effect on the overall response of the high voltage generator is given in the following sections.

\subsubsection{Power Supply Components}

The flyback converter has probably the fewest number of parts and the simplest topology of any power supply. In its simplest configuration it consists primarily of a switching element in series (pass) formation with the primary winding of a tras.sivermer. The switching transistor can be either self-oscillating or driven. Since the primary winding passes only de current however, some form of oscillating signal must be applied to the base or gate of the switching transistor. 
The flyback convener only passes power to the load during the off time interval. A blocking diode prevents secondary current from flowing during the on-time interval. A filter capacitor is generally placed in shunt with the secondary winding to filter the output signal; however in the case of the ERF damper no filter capacitor is needed or desired.

Therefore, the flyback converer consists primarily of these compronents:

1. The transformer,

2. The switching transistor,

3. A driving circuit for the transistor which generally includes an ancillary feedback circuit for regulation; and

4. A blocking diode in series with the load to rectify the output signal.

These components are described in more detail in the following sections.

\subsubsection{Transformer}

The transformer used for the ERF damper was an off-the-shelf autumotive ignition coil. An automotive ignition coil was selected due its high turns ratio design, ready availability, extremely competitive price, and because it met most of the requirements iterated in section 3.1. Actually three ignition coils in all were investigated which shall henceforth be termed coil*1, coilk2 and coil\#3. 
The ignition coil transforms a rectangular voltage pulse of relativeiy long duration (supplied by the battery via the distributor) to a high energy pulse of short duration which is delivered to a load comprising a very high resistance (an air gap) and a small amount of shunt capacitance.

A representative secondary load for an automotive ignition circuit might be a 500 $k \Omega$ resistance shunted with a $50 \mathrm{pF}$ distributed capacitance [57]. A table in reference [57] shows that an ignition coil with a primary inductance of $8 \mathrm{mH}$, regulated with a duty cycle of $80 \%$ ( 5 ampere current limit) can deliver a $100 \mathrm{~mJ}$ pulse at a rate of approximately 240 cycles per second, which corresponds to a power output of 24 watts. The ERF danuper with a capacity of $4.20 \mathrm{pF}$ and a nominal voltage of $8 \mathrm{kV}$ represents an energy storage of only $13.44 \mathrm{~mJ}$. In order to deliver this amount of energy at a pulse repetition rate of 1000 cycles per second would require an output power of 13.4 watts from the power supply. It would therefore appear the power output of a standard ignition coil is closely matched to the power requirements of the ERF damper.

In addition to the approximate power requirements, an ignition coil is capable of producing output voltages in the tens of kilovolts. The maximum voltage requirement of the ERF damper was 8 to $9 \mathrm{kV}$ with $8 \mathrm{kV}$ being the more commonly used upper limit to prevent dielectric breakdown within the damper and to prevent corona from occurring around the high tension cables. 
The standard automotive ignition coil is usually encased in a hermetical sealed vacuum, filled with transformer oil. As noted by Flanagan in reference [56] this packaging method is the optimum method of encasing a high voltage transformer. By vacuum filling with oil, air which would normally cause voids and subsequent arcing is expelled. The transformer is also self-healing in respect to the fact if arcing should occur oil will immedir ily flow in to quench the spark. Heat is also convected efficiently from the windings to the outside casing.

Coil"ll was the first coil used for generating the high energy pulses delivered to the ERF damper. Its normal application was to fire the sparking plugs of a four cylinder light duty engine (Honda Civic). In retrospect it was slightly inferior to coil\#2 but was retained throughout the entire session of damper testing for purposes of maintaining experimental consistency.

Coil\#2 was a "high performance coil" similar in external appearance to coil"l but slightly more expensive ( $\$ 30 \mathrm{Cdn}$ vs $\$ 15 \mathrm{Cdn}$ ) and of reported higher energy output. Coilk2 was not used directly in the testing of the ERF damper but its suitability as a magnetic component for an ERF damper power supply was examined.

Coil\#3 was also similar in external appearance to coil\#1 and coilk2. Coilk3 was purchased with the intent of a further comparison of the three coils. Eventually it was carefully dismantled (the outside cover was removed) in order to eramine its structure. 
A brief description of the mechanical construction of coil" 3 is given below as it is probably representative of the majority of automotive ignition coils including the one used in the Alyback converter for the ERF damper.

Coil\#3 consisted of a multi-layer primary winding. a multi-layer secondary winding and a laminated rod-type core. The secondary winding was formed from $12 \mathrm{mil}$ (0.012 inch diameter) stainless steel wire, coated with a vamish-type insulation, wound onto a bobbin form. There were an estimated 60-100 layers of windings with up to 100 turns per layer. The nominal outside diameter of the secondary winding was 0.95 inches and the inside diameter 0.50 inches. The total length of the secondary winding was 1.47 inchci. Assuming a maximum number of turns of 100 and a maximum number of layers of 100 then the total length of the secondary winding was estimated at 578 meters! The nominal resistivity, Q. of stainiess stee, wire is $10^{-6} \Omega \mathrm{m}^{-1}$ [10]; the resistance of the secondary winding, $R_{\mathbf{r}}$, was estimated from:

$$
R_{z}=\frac{\rho L}{A}
$$

The resistivity for the secondary winding was thus estimated as $7.9 \mathrm{k} \Omega$. The actual measured resistance of the secondary winding was $8.4 \mathrm{k} \Omega$ which is surprisingly close considering the exact length of the wire was not known. The inductance, $\mathrm{L}_{\mathbf{b}}$, for a solenoid-type winding of this geometry can be calculated from:

$$
L_{s}=\frac{\mu N^{2} \pi r^{2}}{l}
$$


where $\mu=$ permittivity of the core

$$
\begin{aligned}
& A=\text { cross sectional area of core } \\
& I=\text { length of core } \\
& I=\text { mean radius of winding }
\end{aligned}
$$

For an air core solenoid the estimated inductance of the secondary winding would be $4.0 \mathrm{H}$. According to Frungel [58], the inductance of a solenoid-type winding is approximately 10 times higher for an iron core solenoid than an air type solenoid. Hence the effective inductance for the secondary should be $\mathbf{4 0}$ henrys! Although the secondary inductance for coil\$3 was never recorded the secondary inductance for coil\#1 was measured at $52.6 \mathrm{H}$ so the value of $\mathbf{4 0}$ henrys may be reasonably accurate.

The primary winding of coil\#3 consisted of 28 tums of 25 mil magnet wire coiled into 6 layers with Kraft paper interleaved between layers. The winding was wound onto a bobbin form; the entire assembly had an outside diameter of 1.45 inches and an inside diameter of 1.07 inches. The primary winding assembly fitted loosely over the secondary winding assembly such that a slight gap of one or two millimetres (excluding the thickness of the primary bobbin form) existed between the primary and secondary windings. The primary winding of coil\$3 was estimated to be $6.33 \mathrm{mH}$ based upon the formula for an air-core solenoid. The actual measured inductance was $6.1 \mathrm{mH}$ which is surprisingly close to the estimated value. There are several possible reasons why a coil tmanufacturer might design a high voltage coil with an air gap between the primary and secondary windings. One use of an air gap would be to provide isolation between the 
low voltage primary and high voltage secondary. Also, the inclusion of an air gap helps to linearize the effective permeabiinty and prevent the flux density coupling the primary and secondary from saturating. Saturation in a transformer is generally undesirable nor only becaust it distorts the output waveform but also can lead to sudden high inrush current. The air gap in coil\$3 was deliberately introduced for possibly all of these reasons.

The core in coil $\$ 3$ consisted of 29 laminations of silicon steel each lamination being 14 mils thick, 3.75 inches long and .41 inches wide. The entire assembled core had 2 resultant square cross-sectional area of $.41 \times .41=.168 \mathrm{in}^{2}$. Silicon steel is a "soft" magnetic material generally used in low frequency power transformers. The laminations are generally insulated to reduce eddy current losses and come in various thicknesses from 2 to 14 mils with the thinner laninations used for higher frequencies. The maximum operating frequency of silicon surel (Si-Fe) is generally in the low audio range. The maximum flux density is $10-20$ kiloGauss (kG).

It is very difficult to determine the actual flux density in a core due to the inherent non-linearity of most ferromagnetic materials. Only air can be assigned a true constant of proportionality between flux density, B, and magnetic field intensity, $\mathrm{H}$ :

$$
B=\mu_{0} \mu, H=\mu_{0} \mu_{r} \frac{N \cdot I}{l}
$$

$\mu_{0}=$ permeability of vacuum $\left(4 \pi \times 10^{-7} \mathrm{Hm}^{-1}\right)$ 
$\mu_{t}=$ relative permeability $\left(\mu_{\mathrm{at}}=1.0\right)$

$H=$ magnetic field intensity $\left(A+m^{-1}\right)$

The action of the flyback converter is to apply a rectangular voltage pulse across the primary inductance. The flux density increases linearly with the magnetizing current. A coil wound across a core can be considered as a volt second integrator [54]. The resulting flux in the primary inductance at the end of the on-time interval will be:

$$
B_{\max }=\frac{V_{\text {peak }} t_{\text {on }}}{N \cdot A}=\frac{L \cdot I_{\max }}{N \cdot A}
$$

The flux density is proportional to the magnetizing current. For coil\$3 an estimation can be made as to the peak flux density in the coil when used in an automotive ignition circuit. In this application the on-time corresponds to the dwell time; the interval when either the contact breaker points are closed or the transistor is conducting. For a four cylinder engine at $1000 \mathrm{rpm}$, with an $70 \%$ dwell limit the on-time would be approximately 20 milliseconds; hence for coil\#3 the maximum flux density would be 1.8 Tesla (T) or 18 kilogauss (kG). However, for the ERF damper application, the on-time would be considerably shorter, therefore the flux density would be proportionately smaller. Therefore, there it was expected the coil would not saturate.

Coil\#1 was used to energize the ERF damper for all the subsequent control strategy evaluations. Intended for automotive ignition application, it was not modified internally in any way; in fact the cover seal was never tampered with. A base drive circuit for the extemal switching transistor was designed and built to provide pulse-width- 
modulation of the magnetizing current and hence voltage output. Details of the drive circuit and ancillary components are given in the following sections. The coil was switched upon command from the central computer which analyzed real-time motion signals coming from the quarter-car-model and sent appropriate command signals to the high voltage supply which comprised coil\#l and ancillary components.

Some of the salient characteristics of coil\#1 and coil\#2 are listed in Table IX. The primary inductance and secondary inductances were measured on a Universal Bridge (model TF1313A) inductance meter using a $1 \mathrm{kHz}$ excitation frequency. The leakage inductance was measured by shorting out the secondary and measuring the primary inductance, also at $1 \mathrm{kHz}$ frequency. The effective shunt capacitance values were estimated from the known primary inductance values and measuring the resonant frequency, $f_{\mathrm{res}}$. The resonant frequency is determined by the shunt inductance, $L_{e}$, and shunt capacitance, $\mathrm{C}_{e}$ :

$$
f_{n=0}=\frac{1}{2 \pi \sqrt{L_{c} C_{c}}}
$$

Coil\#2 was similar to coil\#1 but exhibited a higher resonant frequency and consequently afforded the high voltage unit a higher bandwidth. Although coilझ2 performed slightly better than coill1 in energizing the ERF damper, it was not used for the quarter-car-testing since the testing had already been started at that time with coil"\#1. A comparison between coill1 and coil\#2 is given below in Table IX. 
Table DX: Coil Comparison

\begin{tabular}{|c|c|c|}
\hline Characteristic & coil\#1 & coil\#2 \\
\hline Primary Inductance & $7.76 \mathrm{mH}$ & $5.86 \mathrm{mH}$ \\
\hline Leakage Inductance & $1.11 \mathrm{mH}$ & $1.11 \mathrm{mH}$ \\
\hline Shunt Capacitance & $0.388 \mu \mathrm{F}$ & $0.190 \mu \mathrm{F}$ \\
\hline Resonant Frequency & $2.90 \mathrm{kHz}$ & $4.76 \mathrm{kHz}$ \\
\hline Apprx. Tums Ratio & 95 & 100 \\
\hline
\end{tabular}

\subsubsection{Switching Transistor}

Nearly all modem power supplies designed today are switching (switchmode) rather than linear (dissipative). The advantages of switching power supplies are increased efficiency and low weight. The disadvantages are high output ripple and high noise (EMI) generation. Switching power supplies utilize active switching elements to regulate the output power. Active devices for switching include thyristors (eg. Triac, SCR) and transistors.

The flyback converter employs either a field-effect, FET, or bipolar (BJT) transistor which alternately operates in either the fully on or fully off condition. The advantages of operating in the cutoff and saturated modes is that dissipation in the form of ohmic losses is kept to a minimum. The on resistance of bipolar transistors is often less than $0.1 \Omega$ while that of MOSFET transistors is usually around $1 \Omega$. 
Both power MOSFET and power bipolar transistors are suitable switching elements for flyback converters, each having advantages and disadvantages. A brief summary of the tradeoffs involved are listed in Table $X$.

Table X: Transistor Comparison

\begin{tabular}{|c|c|c|}
\hline Characteristic & MOSFET & BIPOLAR \\
\hline On Resistance & $=1 \Omega$ & $=0.1 \Omega$ \\
\hline Blocking Voltage & $50-500 \mathrm{~V}$ & $50-500 \mathrm{~V}$ \\
\hline Max. Frequency & $20 \mathrm{MHz}$ & $50 \mathrm{kHz}$ \\
\hline Drive Circuitry & simple & complex \\
\hline
\end{tabular}

The choice between using a power MOSFET or power bipolar transistor is usually based upon switching speed with the MOSFET enjoying clear advantage at higher switching speeds. According to Hnatek the MOSFET has lower switching losses at all frequencies when both input drive requirements and saturation (on) losses are considered. However, the bipolar transistor is (at the time of this writing) still relatively less expensive than the MOSFET.

The transistor chosen for the experimental power supply was a power bipolar transistor made by Motorola (MJ11032). This transistor has a maximum collector-emitter voltage $\left(V_{C z o}\right)$ of 120 volts and a maximum peak collector current of 100 amperes. This transistor was specifically chosen for its high current, high current gain, and large $\mathbf{V}_{\mathbf{c s o}}$ 
rating. The large $V_{C B o}$ rating was chosen to ensure protection against secondary breakdown. The peak voluage across the primary inductance can be several times higher than the applied voltage; hence a large $V_{C B O}$ was desirable. The large current rating was also deemed prudent to protect against current overloads which might result if the transformer temporarily saturated. The high current gain $\left(h_{r E}=2000 @ I_{c}=1 A\right)$ kept base current requirements to a minimum. Since the switching frequency was always less than $5 \mathrm{kHz}$ the advantages of using a MOSFET transistor would have been relatively slight.

One advantage of the MOSFET transistor is the simplified gate drive circuitry. It is possible to have a MOSFET output stage driven directly from a CMOS integrated circuit (IC). The power bipolar transistor generally requires a fairly complex driving circuit which may incorporate one or several other transistors. For the experimental ERF damper power supply, the power bipolar transistor was driven by a general purpose PNP transistor which in turn was driven by the output stage of the CMOS pulse generator/regulator. It is probable that a less complicated switching arrangement could be designed around a power MOSFET transistor. In fact, it is expected that the economic situation will someday swing in favour of the MOSFET completely, delegating bipolar transistors to only those circuits where it is not cost-effective to redesign the existing circuit. 


\subsubsection{Integrated Circuit Regulator}

The transfer function for the flyback convener is repeated below for reference:

$$
V_{a x}=V_{d c}\left(\frac{N_{s}}{N_{p}}\right) \frac{D}{1-D}=V_{d}\left(\frac{N_{s}}{N_{p}}\right) \frac{t_{d d} / T}{t_{d d} d T}
$$

As shown by the above equation, one way to vary the output voltage is to vary the on-time or width of the input voltage pulse. This is commonly referred as pulsewidth-modulation (PWM). Alternatively, the frequency could be varied with the pulse width kept constant. However, one advantage of using PWM is that the switching frequency can be cptimized for a particular set of magnetic components; simplifying the design of the magnetic components substantially.

It is very difficult to design a control circuit using discrete components that will provide all the features necessary (eg. soft-starting, overload protection, pulse-widthmodulation, variable dead time etc.) to properly drive the switching transistor.

There are a number of integrated circuits (IC) on the market that will perform the function of regulating the width of a small voltage pulse (generally $12 \mathrm{Vdc}$ ) which in tum is capable of driving a small transistor. Both the Signetics SG2524 (and SG3524) and Motorola MC3420 are specifically intended for pulse-width modulation of two external power uransistors. These IC's provide control circuitry features that include:

1. Output frequency variable by adjustment of extemal RC components;

2. Variable output frequency from $500 \mathrm{~Hz}$ to $200 \mathrm{kHz}$ (typical); 
3. Soft starting and variable dead-time compensation;

4. Ability to sink and source current up to $75 \mathrm{~mA}$ (SG3524);

5. Shut down facility: and

6. Pulse-width-modulation of output signal by low-level $(0-5 \mathrm{~V})$ analogue input signal.

As noted by Gottlieb [59] these features are nearly impossible to achieve using purely discrete components. The SG3524 for example, comprises a sawtooth generator, comparator, darlington power output stage, and even regulates its own internal 5V supply voltage. This 16 pin DIP (dual inline package) has provision for programmable shutdown, a scope trigger output, and external timing control; the retail price is approximately $\$ 2.25 \mathrm{Cdn}$.

The Pulse Width Modulator IC provides a convenient interface between the Electronic Control Unit (ECU) and the switching element. In the experimental set-up the ECU was a personal computer with both $A / D$ and D/A converter boands located in expansion slots and connecting to the PC bus. In theory, it would be possible to dispense with the switchmode IC regulator and D/A converter altogether by sending a train of ECU controlled digital signals to the switching power transistor. However, for experimental purposes, the switchmode regulator is very convenient as it allows for manual operation via an external $5 \mathrm{k} \Omega$ potentiometer for controlling the duty cycle (pulse width) and also the switching frequency is also easily varied for timing control. 


\subsubsection{Diode}

The rectifying diode, $D_{1}$, as shown in Figure 10, effectively isolates the load from the source voltage. In the flyback converter, energy is stored in the primary inductance during the on-time and no secondary current flows during this interval except from $C_{r}$ to $R_{\mathbf{r}}$ In other words, unlike a conventional forward converver, no load current flows during the conduction period Instead, the magnetizing current induces a magnetic flux which increases linearly with the magnetizing current. Any forward current is blocked by the rectifying diode. When the transistor abruptly ceases conducting, the collapsing magnetic field in the primary inductance induces a voltage pulse in the secondary which causes current to flow in the secondary as now the diode is forward-biased.

The diode used in the power supply for the ERF damper was a high voltage (television) rectifying diode with a peak reverse voltage rating of $45 \mathrm{kV}$ and a forward voltage drop of 75 volts (at $50 \mathrm{~mA}$ ). No information was obtained on the recovery characteristics (eg. peak inverse current, recovery time etc.) Since the secondary circuit is at a high voltage and low current it is expected that $I^{2} R$ losses should be relatively low. The forwand voltage drop of 75 volts represents a fairly insignificant power (I-V) loss.

\subsubsection{Parasitic Components}

An ideal transformer acts to maintain equal ampere-turns in both the primary and secondary circuits in response to changes in the load applied across the secondary. Modifications to the ideal transformer model must be made in order to account for the 
influence of parasitic components. The major parasitic components that effect the flyback converter are shown in the equivalent circuit of Figure $10 \mathrm{~b}$. The shunt inductance, $L_{m}$ eccounts for the magnetizing current which must flow regardless of the load current. In fect, for the flyback converner the total primary current is comprised of the magnetizing current since the load is effectively isolated from the voltage source. The shunt capecitance, $C_{9}$ sccounts for the distributed capacitance scross the shunt inductance including the seconciry capacitance multiplied by the square of the turns ratio and the loed capacitance, $C_{r}$ if present, also multiplied by the turns ratio. The load resistance, $R_{p}$ eccounts for core loss due to eddy current and load resistance if connected. The transistor, shown in Figure 10a, can be approximated by a switch in series with the primary circuit. These are the major parasitic components which affecting the wideband performance of the circuit. Not shown in Figure $10 \mathrm{~b}$ is the leakage inductance, $L_{2}$, which appears in series with the switch and accounts for failure of the transformer to achieve the actual voliage transformation which should occur based upon the actual ratio of tums. Leakage flux energy is stored in the leakage inductance which is formed by the space between the primary and secondary coils. Hence, leakage inductance is a function of geometry. Toroidal cores concentrate nearly all the produced flux in the core, hence there is little associated leakage inductance. Rod-type cores inserted into solenoid-type windings cannot concentrate all the flux, hence there will be a finite amount of leakage inductance associated with rod-type cores inserted into bobbin-wound windings.

Also not shown in the squivalent circuit of Figure $10 \mathrm{~b}$ is the primary winding 
resistance, $R_{p}$, and the secondary winding resistance divided by the tums ratio, $R / N^{2}$. For coil \#1 the primary winding resistance was $1.4 \Omega$ and secondary winding resistance was $9.1 \mathrm{k} \Omega$. The peak primary current, $L_{\text {met, }}$ can be found from:

$$
I_{\text {puat }}=\frac{V_{d}}{R_{p}}\left[1-e^{-\frac{R_{2}}{h} c_{m}}\right]
$$

However, if the primary resistance, $R_{p}$ is relatively small in value, then the maximum current in the shunt inductance at the end of the conduction interval can be still estimated from:

$$
I_{\text {mat }}=\frac{V_{d t_{0 n}}}{L_{c}}
$$

For coil"1 the primary inductance was $7.76 \mathrm{mH}$ and the maximum on-time was approximately $0.3 \mathrm{~ms}$. Therefore the peak current calculated from equation (60) is 0.467 A while the peak current calculated from equation (61) is $0.480 \mathrm{~A}$; not a significant amount of difference. For a primary resistance of $10 \Omega$, the peak primary current would still be $0.40 \mathrm{~A}$.

According to Flanagan [56], the flyback circuit can be analyzed as the trailing edge response of a pulse transformer. The equivalent circuit for the trailing edge response of a pulse transformer is similar to the primary side of the circuit shown in Figure $10 \mathrm{~b}$ with the following modifications:

1. A shunt resistance, $R_{4}$, representing core loss appears in parallel with the shunt 
inductance, $L_{e}$ and the shunt capacitance, $C_{e}$. The core loss results from eddy current induced in the ferromagnetic core and represents real power loss. The source resistance (negligible anyways in the case of a lead-acid battery) is disconnected and does not appear. The load resistance is extremely large in the case of the ERF damper, due to the very small conductivity of the ER fluid. Hence, when the ERF damper is connected to the secondary output, the output appears to the transformer as a virtual open-cincuit; and

2. The source electromotive force (emf) is removed since at this instant the voltage pulse has reached the end of its cycle.

During the transistor on-time, an approximately rectangular voltage pulse is applied to the shunt inductance. The integration of this voltage pulse with respect to time is what determines the current in the shunt inductance. When the transistor switch opens the magnetizing current is at its prak value. As noted by Flanagan, a singularity would then oceur if not for the shunt resistance and shunt capacitance. However, due to the shunt components a transient responsc occurs and can be evaluated.

At the instant the voltage pulse has just passed, the current equation will be:

$$
C_{e} \frac{d V}{d t}+\frac{1}{L_{e}} \int_{\tau}^{t} V d t+\frac{V}{R_{l}}=0
$$

where $\mathrm{t}=\mathrm{a}$ point in time afier the voltage pulse has passed

$\tau=$ the time interval of the voltage pulse 
The magnitude of the magnetizing current, $L$, will be determined by:

$$
I_{m}=\frac{1}{L_{e}} \int_{0}^{T} V \text { dit }
$$

The Laplace transform of the current equation will be:

$$
C_{e} s V(s)-C_{e} V_{i}+\frac{V(s)}{S L_{e}}+\frac{1}{S L_{e}} \int_{0}^{\tau} V d t+\frac{V(s)}{R_{l}}=0
$$

Substituting the initial value for the current in the inductor, $I_{m}$, into the above equation yields:

$$
C_{e} S V(s)-C_{e} V_{l}+\frac{V(s)}{S L_{l}}+\frac{I_{m}}{s}+\frac{V(s)}{R_{l}}=0
$$

The above equation can be put into the more familiar form for a transfer function:

$$
\frac{V(s)}{V_{l}}=\frac{\left(S-\frac{\tau}{L_{e} C_{e}}\right)}{\left(S^{2}+\frac{s}{R_{t} C_{e}}+\frac{1}{L_{e} C_{e}}\right)}
$$

The system represented by the above equation is second-order. The system has left-plane stability with poles at the following locations:

$$
P_{1,2}=-\frac{1}{2 R_{e} C_{e}} \pm \sqrt{\left(\frac{1}{2 R_{e} C_{e}}\right)^{2}-\frac{1}{L_{e} C_{e}}}
$$


The system will become oscillatory for the following condition:

$$
\text { if } \frac{\sqrt{L / C_{e}}}{2 R_{l}}<1
$$

Since the ERF damper appears virtually as an open-circuit to the flyback converter, the result is an oscillatory response with the flyback voltage often exceeding the input voltage by several times. The flyback converter is sometimes referred as a "ringing choke" converter, presumably for this reason. For the oscillatory response the inverse Laplace transform can be reduced to:

$$
\frac{V(t)}{V_{i}}=e^{\left(-2 \pi T^{\prime}\right.}\left[\cos \left(2 \pi \sqrt{1-D_{f}^{2}}\right) T-\frac{D_{f}+F}{\sqrt{1-D_{f}^{2}}} \sin \left(2 \pi \sqrt{1-D_{f}^{2}} T\right)\right]
$$

where $D_{f}=\sqrt{ }\left(L_{d} / C_{e}\right) / 2 R_{1}$

$$
\begin{aligned}
& F=\tau N\left(L_{e} C_{e}\right) \\
& T=\pi / 2 \pi\left(L_{e} C_{e}\right)
\end{aligned}
$$

Flanagan defines $D_{r}$ as the damping factor, $F$ as the initial current factor and $T$ as normalized time. Altematively, from the Laplace transformation, the damping factor is simply the damping coefficient and the initial current factor is the on-time interval, $\tau$, multiplied by the undamped natural frequency formed by 1 over the square root of the $L_{e} C_{e}$ product. The independent variable, $T$, is the time normalized to the undamped natural frequency in cycles per second. 
The transient response governed by equation (69) shows the higher the effective shunt resistance, the higher the peak flyback voltage, which can exceed by several times the input voltage. It is in fact this characteristic which allows the flyback voluge to produce an output voltage which is higher than would ordinarily be produced with a sinewave transformer having the same turns ratio. By the same respect, the flyback voltages create very high voltage stresses on the switching elements and magnetic components. Secondary breakdown from transient voltages has to guarded against. Snubber circuits can be added to attenuate the worst transient voltage spikes; but decreased output voluage and increased power dissipation will also result.

A snubber circuit for a flyback converter generally comprises a flyback diode in series with a linear dissipator (resistor) across the switching transistor. The flyback diode is reverse biased for normal operation but is forward biased during the flyback interval.

\subsubsection{Flyback Converter Operation and Performance}

\subsubsection{Power Supply System Overview}

The high voltage power supply system used to control the ERF damper comprised an Electronic Control Unit (ECU) with installed data acquisition system, the flyback converter powered from a 12 Vde power source, sensers attached to the quarter-carmodel, a reactive load (the ERF damper), and a discharge circuit (discussed in section 3.3) to drive down the damper voltage when less or zero damping was required. 
During the vibration tests, vibration signals (acceleration, relative velocity, relative displacement, representative tire dynamic deflection etc.) were input to the AND data system for real-time analysis. Depending upon the relative magnitude of these feedback signals (a complete description of the control strategies is discussed in chapter 4) decisions were made by the ECU which commanded the D/A system boand to send a 0-5 volt continuously variable signal to the pulse generator/regulator IC. The PWM regulator IC output a 12 volt pulse whose duty cycle was in direct proportion to the magnitude of the input signal, (ie. a 5 volt input signal would trigger a pulse with $100 \%$ period duration, a 2.5 volt input signal would trigger a pulse with $50 \%$ period duration). The 12 voit pulses from the PWM regulator drove a power transistor into saturation which would in tum cause the magnetizing current to increase in an approximately linear fashion. By pulse-width-modulating the coil, high voltage pulses of variable intensity were transmitted to the ERF damper which varied its damping rate in response to the applied voltage.

A $400 \mathrm{M} \Omega$ resistor was placed in parallel across the ERF damper electrodes. A $100 \mathrm{k} \Omega$ sampling resistor in series with the $400 \mathrm{M} \Omega$ resistor was used to sense the voltage across the damper and feed a signal back to the ECU. A look up table (LUT) was coded in the control software that correlated the output voltage from the flyback converter with the commanded 0-5 volt input signal to the PWM regulator. When the vibration apparatus required a certain level of damping (as determined by the control strategy) then the voltage across the damper was sensed, a decision was made to either 
drive the damper excitation voltage up or down, and the appropriate signals were sent to the high voltage generator and discharge circuit. The high voltage generator and discharge circuit always operated consecutively, never concurrently.

\subsubsection{Duty Cycle (PWM) Control}

As already discussed, the PWM regulator IC varied the duty cycle of a 12 volt pulse going to the base of a power bipolar transistor. The theoretical transfer function for the flyback converter is repeated below for reference:

$$
\frac{V_{\text {out }}}{V_{d x}}=\left(\frac{N_{s}}{N_{p}}\right) \frac{D}{1-D}
$$

Figure 11 shows the actual output voltage of coil"1 as well as the primary current and the theoretical voltage gain as a function of duty cycle. The primary current was measured with an digital multimeter in series with the switching transistor. As evident from the figure both the theoretical gain and the actual output voltage increase approximately exponentially with the increase in duty cycle. Although the voltage appears to be leading the voltage gain (D/1-D), the voltage gain also approaches a vertical asymptote. The initial jump in the output voltage is due to the voltage drop across the base-emitter junction of the switching transistor, the transistor requires a finite amount of on-time in order to exceed the cut-off voltage. This results in the output voltage curve deviating from the shape of the transfer function curve. Core non-linearity will also distort the output voltage curve from its ideal path. 


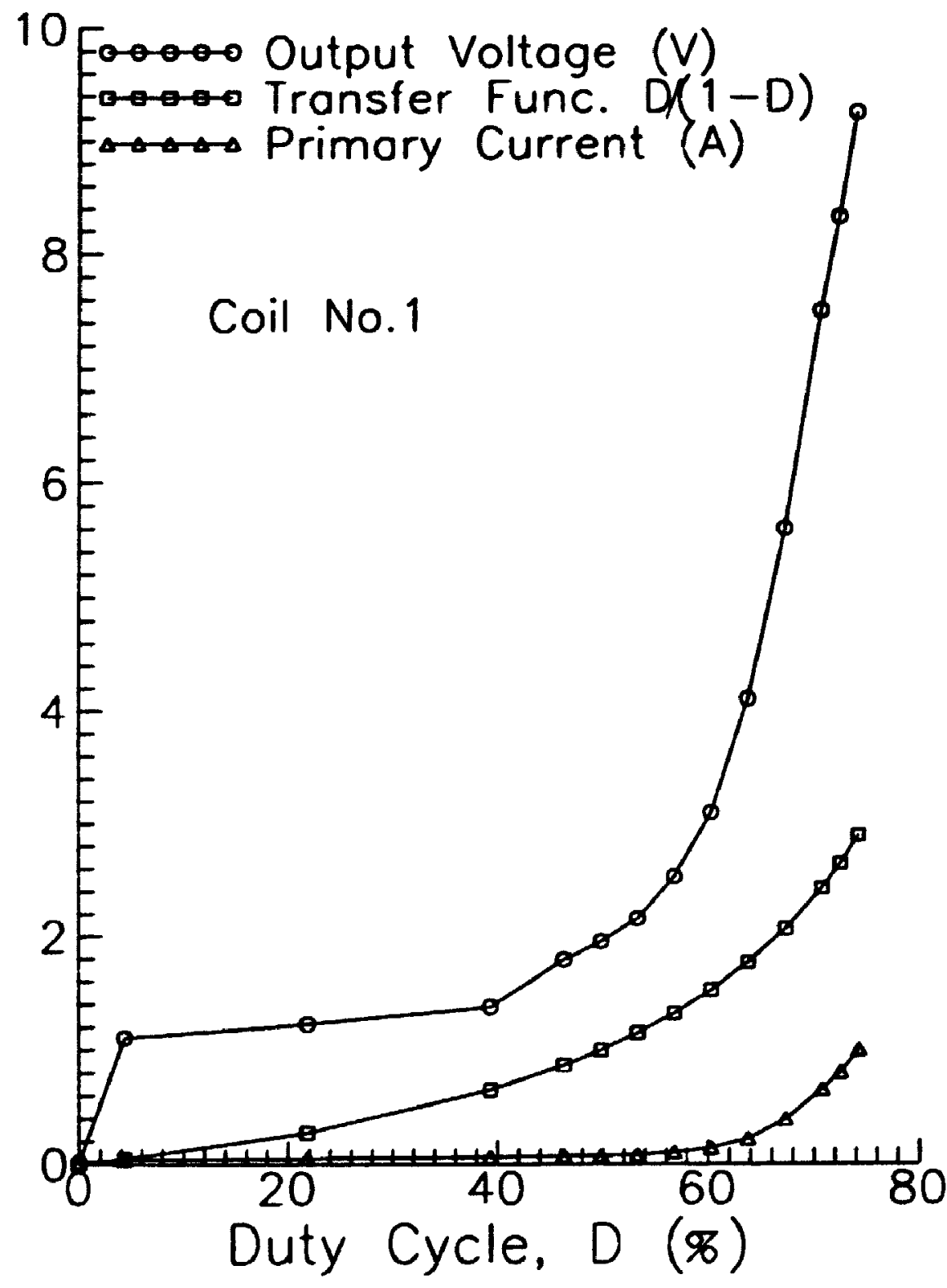

Figure 11: Output Voltage, Primary Current and Voltage Gain versus Duty Cycle For Coil No.1 
The transfer function of the flyback converter is very non-linear. This complicated the problem of developing a simple algorithm for controlling the high voluge across the damper. The simplest solution (from a software perspective) was to create a look-up table (LUT) to correlate the required PWM input voltage for the corresponding output voluage. For the quarter-car-model vibration analysis an LUT consisting of ten quantization levels was used. This represented a compromise between achieving a continuous variety of output and reducing the number of instructions and machine cycles in the ECU. The clock speed of the CPU was $33 \mathrm{Mhz}$; the sampling interval of the data acquisition system was approximately $0.1 \mathrm{~ms}$. Once a decision was made by the ECU reganding the desired level of output voltage, a small (0-5 volt) analogue signal was sent to the PWM IC regulator which varied the duty cycle of the switching transistor in proportion to the analogue signal.

\subsubsection{Switching Frequency}

As previously noted, either frequency modulation or pulse-width-modulation or both can be used to regulate/modulate the output voltage of a flyback converter. However, the advantage of using PWM is that the circuit can be tuned to an optimum switching frequency (or band of frequencies). Figure 12 shows the output voltage for coil"1 versus duty cycle for three different frequencies. The optimum switching frequency for coil" 1 was approximately $2.5 \mathrm{kHz}$ with diminished output occurring above $4 \mathrm{kHz}$. 


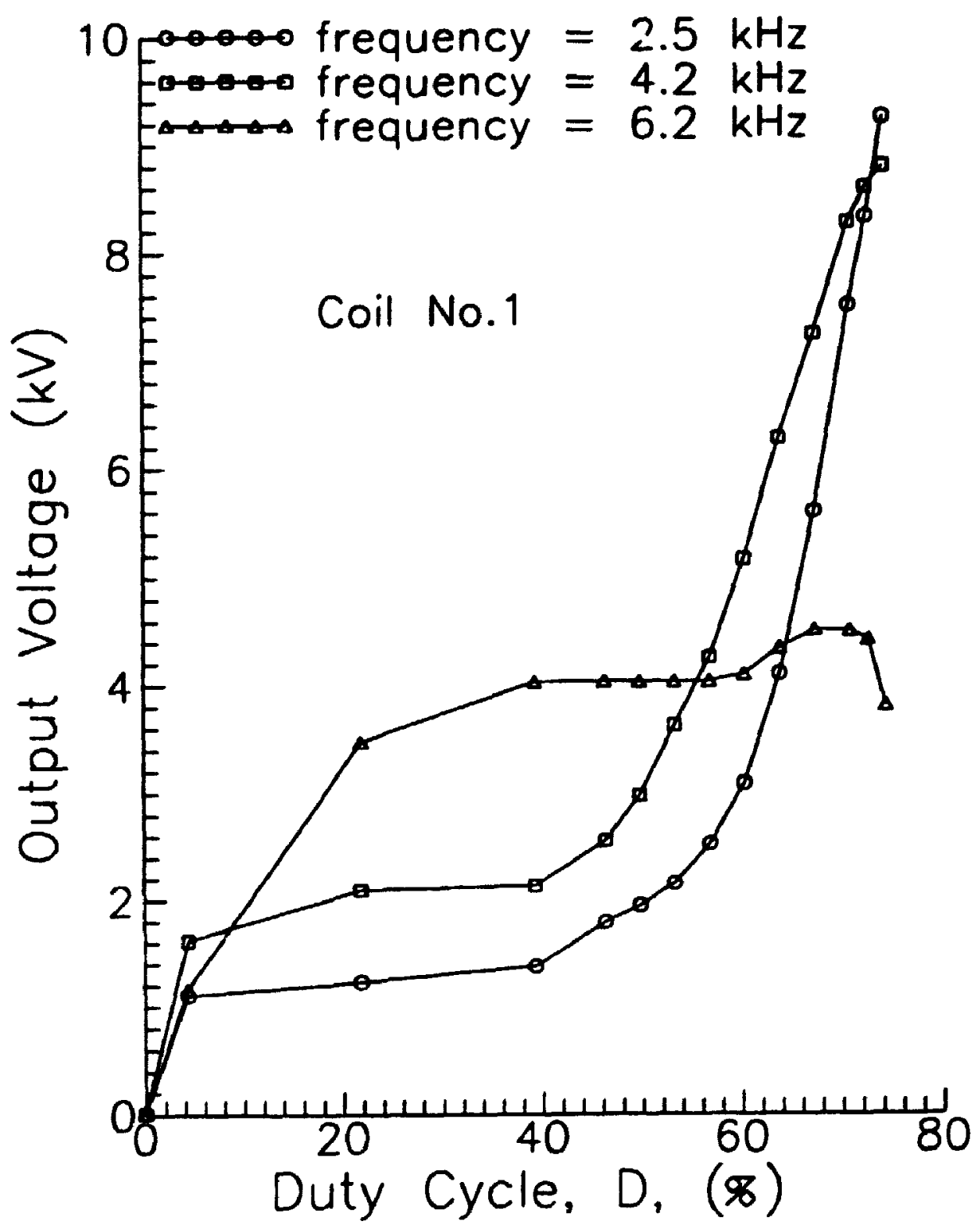

Figure 12: Output Voltage versus Duty Cycle

For Coil No.1 At Various Switching Frequencies 
The upper cut-off frequency, $\mathrm{f}_{\mathrm{e}}$ (in $\mathrm{Hz}$ ) for the flyback converter was determined by the product of the leakage inductance, $h_{1}$, and the distributed capacitance, $C_{0}$ :

$$
f_{c}=\frac{1}{2 \pi \sqrt{L C_{c}}}
$$

The distributed capacitance included the load capacitance multiplied by the effective turns ratio. The leakage inductance for coilll was $1.11 \mathrm{mH}$. Since the cut-off frequency for coilll, with the ERF damper capacitance of $420 \mathrm{pF}$ connected to the secondary, was estimated at $4.0 \mathrm{kHz}$ then the totai effective shunt capacitance was approximately $1.4 \mu \mathrm{F}$ including the load capacitance multiplied by the turns ratio plus the distributed capacitance formed by the coil windings.

Figure 13 shows the effect of duty cycle on output voltage for three different switching frequencies for coil:2. The optimum switching frequency for coilk2 was approximately $4.2 \mathrm{kHz}$ with the high frequency cut-off around $5 \mathrm{kHz}$. Coil $\$ 2$ also had an estimated leakage inductance of $1.11 \mathrm{mH}$. Therefore, the total effective shunt capacitance was $0.92 \mu \mathrm{F}$. Coilk 2 was much quieter in operation than coil*1, perhaps due to the higher switching froquency.

The total shunt capacitance-leakage inductance product places an upper limit on the operating frequency of flyback converters. Reducing the leakage inductance increases the operating frequency, however, some physical spacing is always required between the low-voltage primary and high-voltage secondary for isolation purposes. 


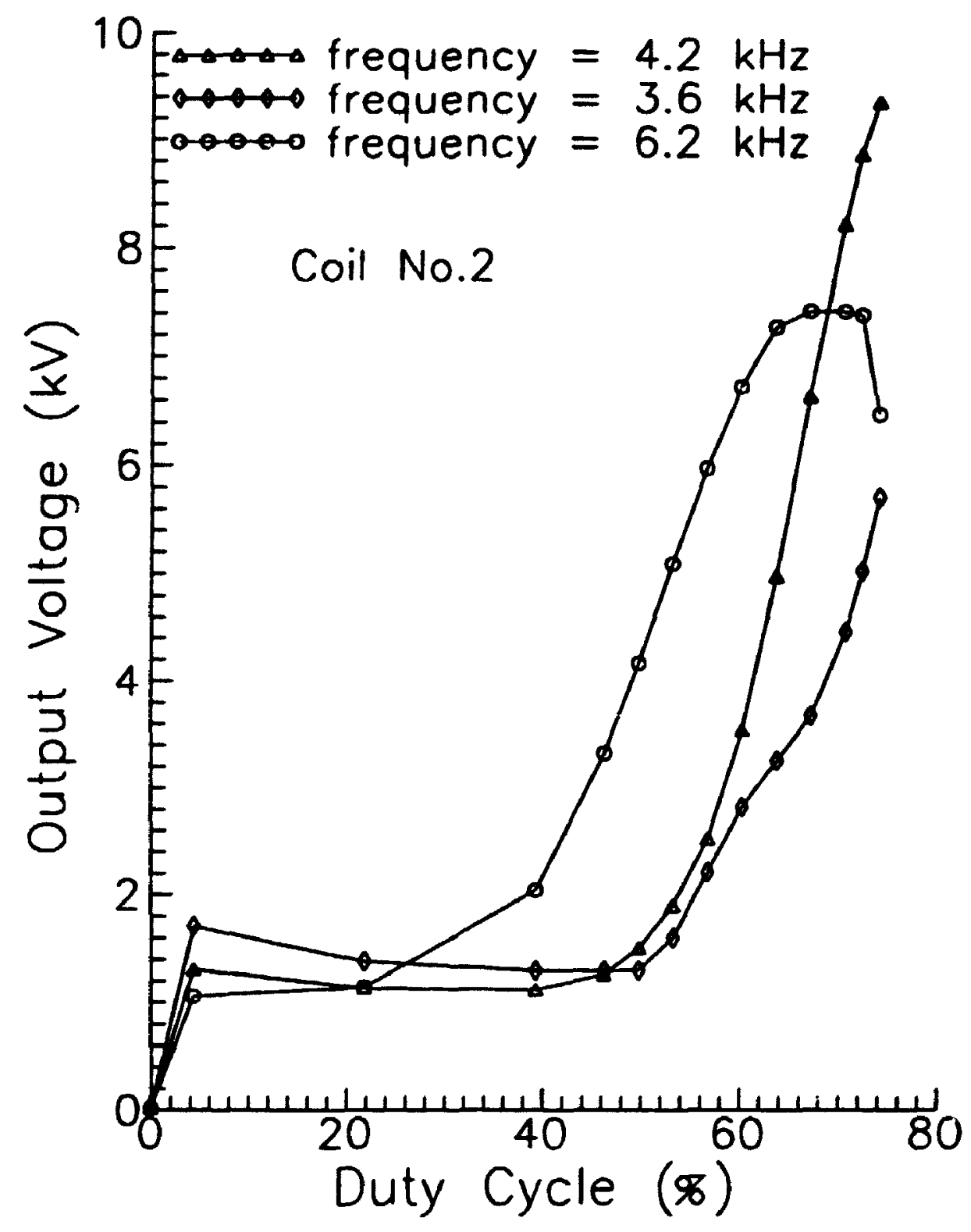

Figure 13: Output Voltage versus Duty Cycle

For Coil No.2 at Various Switching Frequencies 
The main problem of switching in the audio frequency range is unwanted acoustic noise. Coil construction may play an important role in reducing acoustic noise since coil" 2 was much quieter in operation than coilw1. Core material may also place an upper limit on operating frequency. The frequency range for silicon-steel is usually quoted in the literature as between 0-1000 $\mathrm{Hz}$. Since the power delivered by the flyback conventer is inversely proportional to the frequency, there will be consequently limits on the amount of power that the flyback conventer can actually deliver to the load. The flyback converer is not suitable for high-power requirements. Fortunately, the ERF damper requires only a few watts of power for most applications. For example, to switch the experimental damper from f:ll-off to a fully energized state in one millisecond would require, assuming no losses, only 13.4 Watts.

\subsubsection{Response Time}

The ERF damper effectively prescints a very high impedance to the nyback converter. The leakage current is of very small magnitude; less than the current flowing through the voltage divider used to sense the voltage across the damper. At $8 \mathrm{kV}$ the dc current flowing through the voltage divider $(400 \mathrm{M} \Omega)$ is only $20 \mu \mathrm{A}$. The capacitance of the ERF damper was measured at $420 \mathrm{pF}$ at zero flow conditions. The impedance of the ERF damper is so high, that to the flyback converier it appears almost as an open circuit. The flyback converter delivers a constant energy pulse that is almost completely unaffected by the load. However, the high impedance, almost open-circuit condition, of the ERF damper will affect the transient response, especially the peak flyback voltage and 
duration of oscillation, as discussed in section 3.2.4.

With regard to response time, it is instructive to consider the ERF damper as an energy storage device and the flybsck converter a pulse transmitter of energy packets. The energy storage capacity of the ERF damper is fixed by the voltage and capacitance, $J=C V^{2} / 2$. With a peak voltage across the damper of $8 \mathrm{kV}$ the total energy stored on the damper electrodes will be $13.4 \mathrm{~mJ}$. If the maximum duty cycle of the flyback converter is $80 \%$ at a switching frequency of $2.5 \mathrm{kHz}$, and the primary inductance is $7.76 \mathrm{mH}$ then the energy stored in the primary inductance, and subsequently transferted to the damper during the flybaci io:terval, will be approximately equal to $0.95 \mathrm{~mJ}$.

Figure 14 shows the voltage waveform across the same pair of plate electrodes used to measure the capacitance of ERF 'A'. The measured capacitance was 100 pF. The steady state voltage across the electrodes was $10 \mathrm{kV}$. At $8 \mathrm{kV}$ the electrostatic energy stored in the damper was approximately equal to $3.2 \mathrm{~mJ}$. For a duty cycle of $80 \%$ the pulse duration was $0.32 \mathrm{~ms}$. and the energy of the pulse was $0.95 \mathrm{~mJ}$. Hence, the time required to transfer the total charge (or energy) to the electrodes should theoretically be $1.35 \mathrm{~ms}$. From the graph, the rise time was closer to $3.6 \mathrm{~ms}$. The jagged nature of the waveform was due to the transistor switching on and off abruptly. the discrepancy between the theoretical charging time and the experimental charging time was probably due to the stray capaciance in the circuit. 


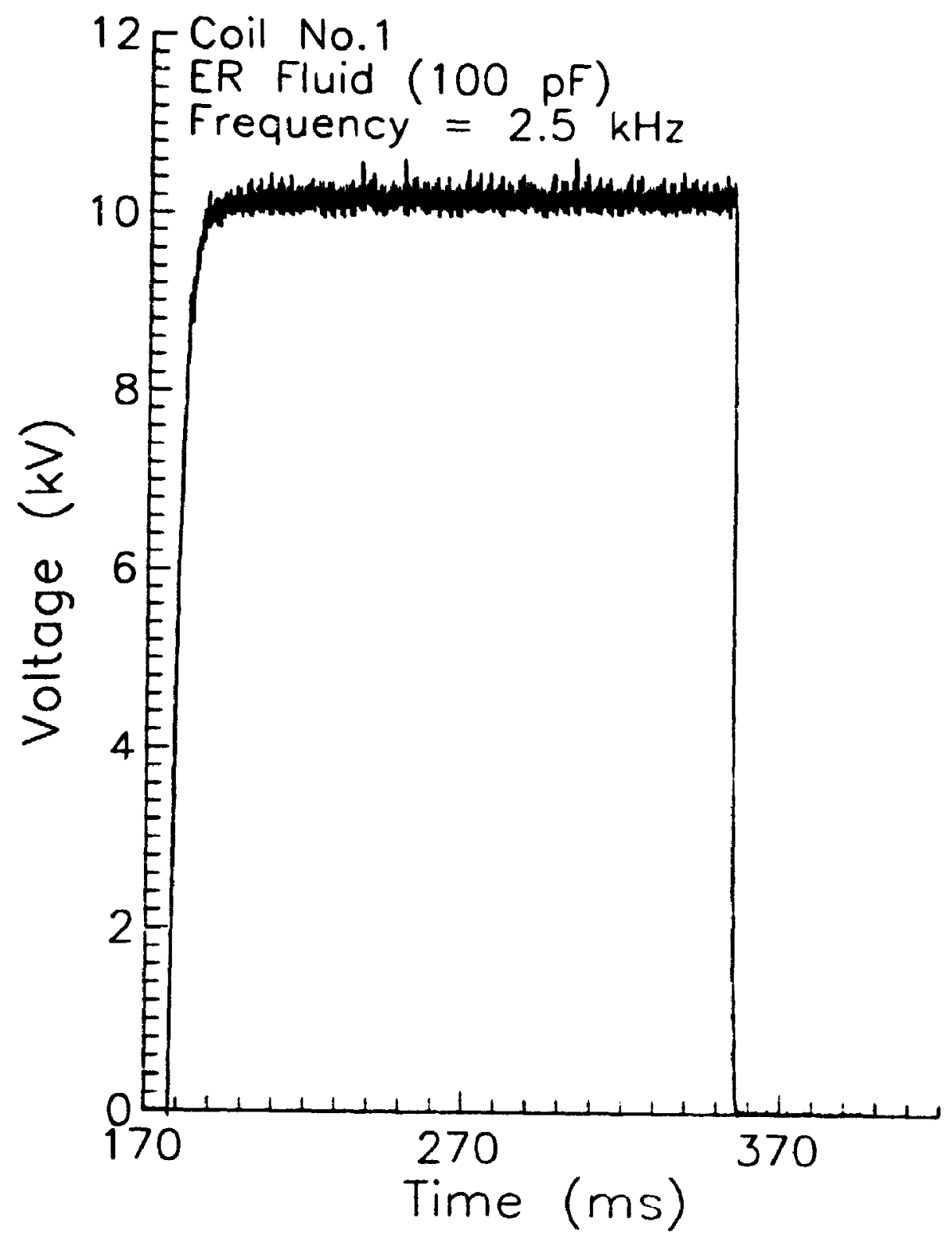

Figure 14: Outpul Voltage Across 100 pF ER Fluid Using Coil No.1 Showing Effective Rise Time and Discharge Time Of the High Voltage Supply Unit and Discharge Circuit 
Figure 15 shows a representative voltage waveform across the ERF damper. The steady state voltage was again $10 \mathrm{kV}$ and the measured capacitance of the drumper was $420 \mathrm{pF}$. At $8 \mathrm{kV}$ the electrostatic energy stored between the electrodes was $13.4 \mathrm{~mJ}$. For a pulse duration of $.32 \mathrm{~ms}$. each pulse would have a fixed energy of $0.95 \mathrm{~mJ}$. If each pulse had a period of $0.4 \mathrm{~ms}$. and it required 14 discrete pulses of energy to charge up the damper, then the rise time to reach a level of $8 \mathrm{kV}$ should have been approximately $5.6 \mathrm{~ms}$. The actual charging time was approximately $5 \mathrm{~ms}$.

Figure 16 shows the output voltage across a discrete high-voltage capacitor (dielectric material unknown) with a measured capacitance of $450 \mathrm{pF}$. The waveform of Figure 16 was very similar to the that of the ERF damper, illustrating a similar loading effoct on the input of both the discrete and ERF capacitance.

Figure 17 shows the output voltage across a discrete high-voltage capacitor (dielectric material unknown) with a measured capacitance of $770 \mathrm{pF}$. The theoretical charging time to reach a voltage level of $8 \mathrm{kV}$ is $10.4 \mathrm{~ms}$. The actual charging time as measured off the graph was approximately $12 \mathrm{~ms}$.

Finally. Figure 18 shows the output voltage measured across the ERF damper using coilw2 and a higher switching frequency. The benefits of operating a coil at a higher switching frequency are less audible noisi and a finer degree of control. Although coil"2 exhibited slightly superior performance, coil"1 was used for the semi-active tests 
since it was purchased first.

Viewing the aiorementioned graphs, it is quite evident the effect that the capacitance has on the time required to charge up the damper. Since the electrostatic energy is directly proportional to the capacitance, and the flyback converter transfers pulses of energy, it is apparent that the charging time will be in almost direct proportion to the effective capacitance of the damper. For the experimental ERF damper the time required to charge up the damper from full-off to $8 \mathrm{kV}$ (the nominal upper voltage limit used in the quarter-car-model tests) is about $5 \mathrm{~ms}$. This was considered adequate, albeit not exemplary, for the purpose of semi-active (real-time) damping control. 


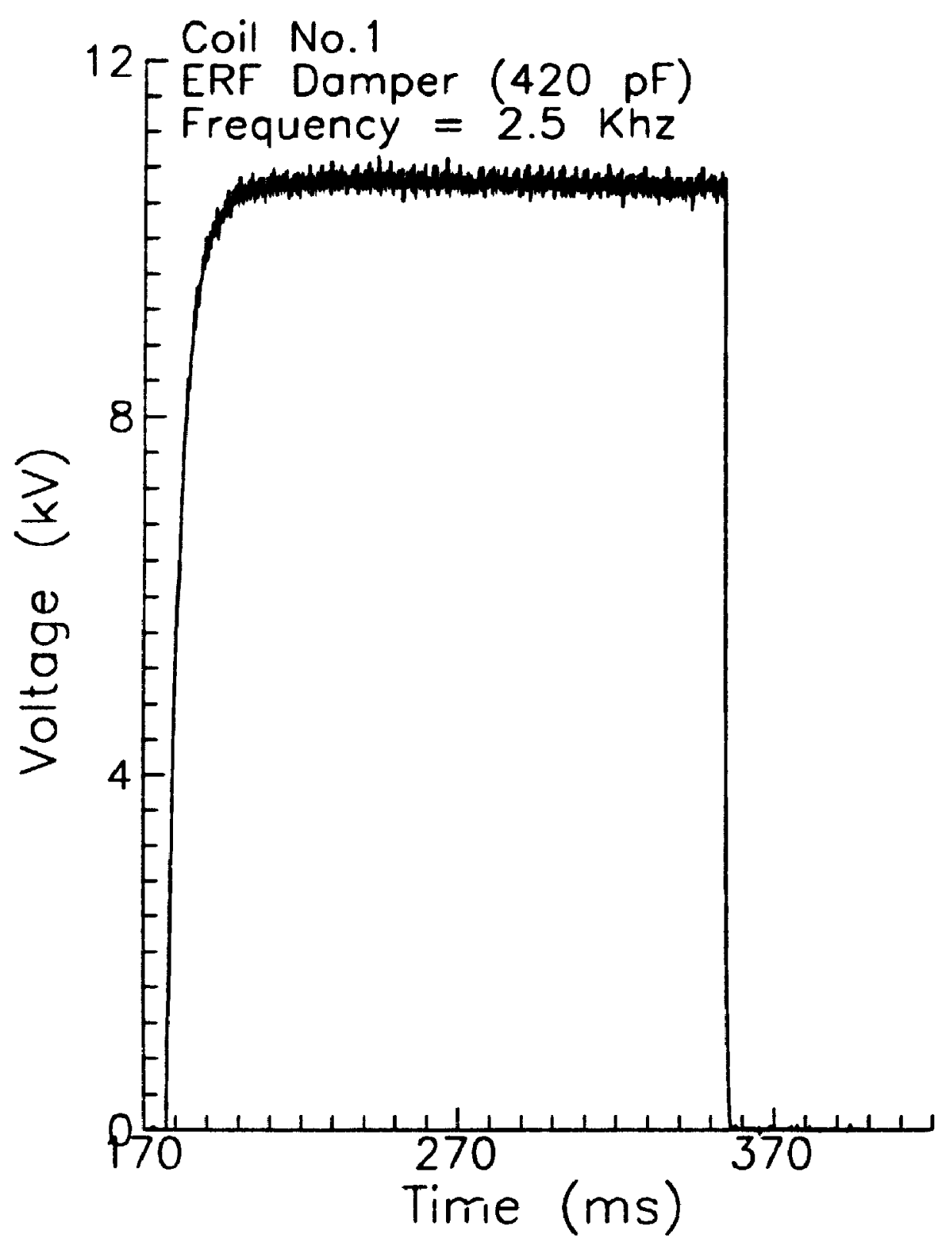

Figure 15: Output Voltage Across ERF Damper Using Coil No.1

Showing the Effective Rise Time and Discharge Time

Of the High Voltage Supply Unit and Discharge Circuit 


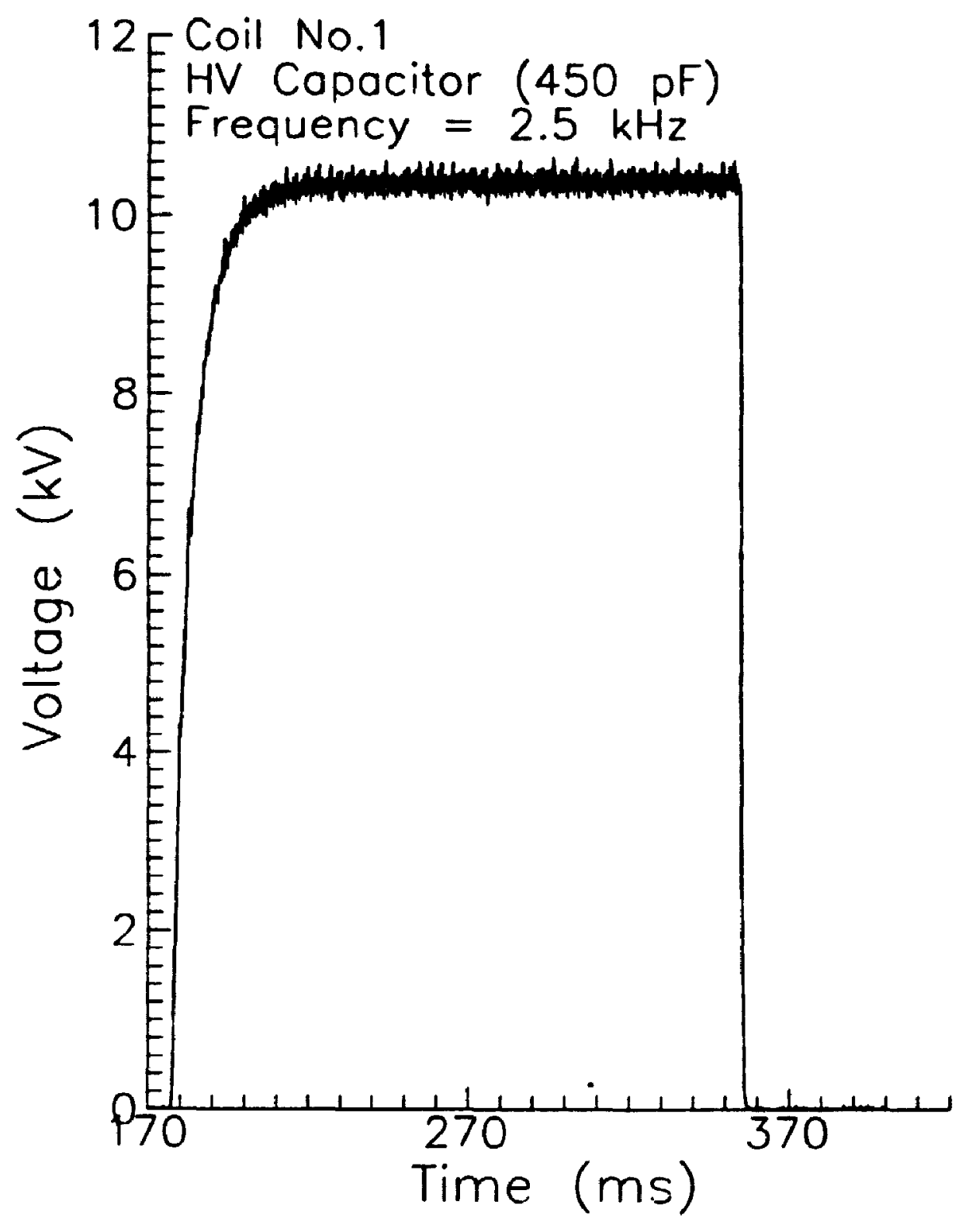

Figure 16: Output Voltage Across 450 pF Capacitor Using Coil No.1

Showing the Effective Rise Time and Discharge Time

Of the High Voltage Supply Unit and Discharge Circuit 


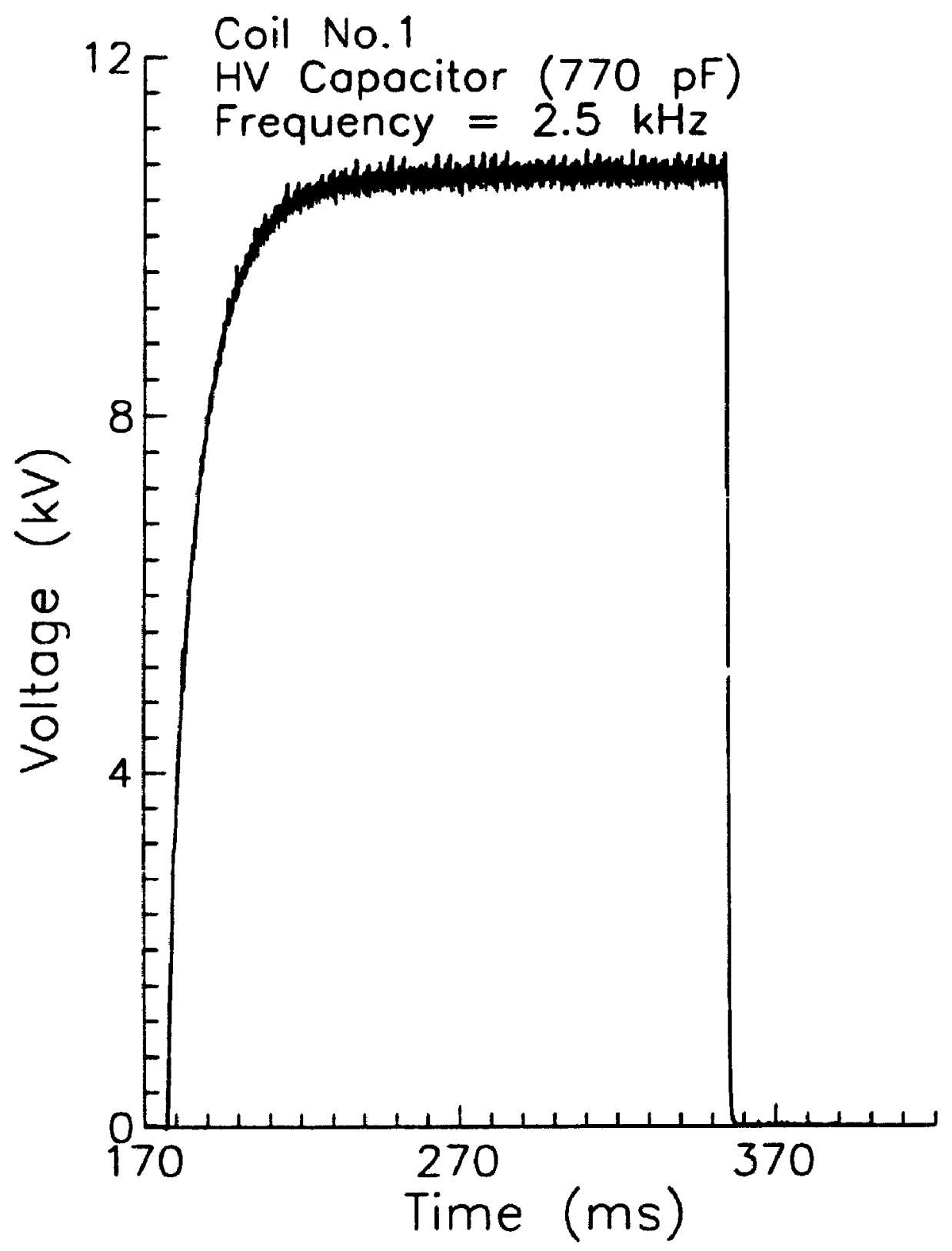

Figure 17: Output Voltage Across 770 pF Capacitor Using Coil No.1 Showing Effective Rise Time and Discharge Time Of The High Voltage Supply Unit and Discharge Circuit 


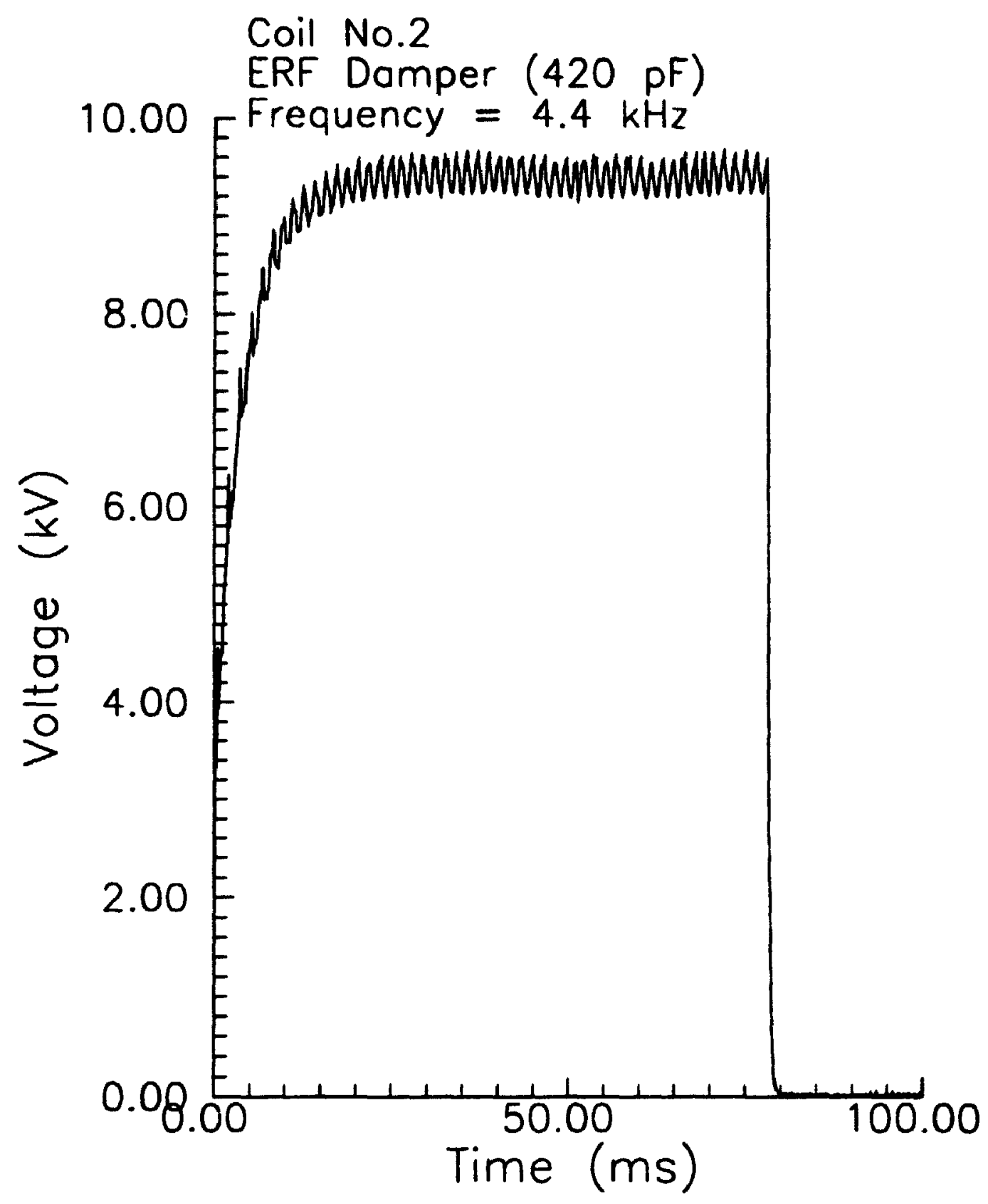

Figure 18: Output Voltage Across ERF Damper Using Coil No.2 Showing Effective Rise i ime and Discharge Time Of High Voltage Supply Unit and Discharge Circuit 


\subsection{Diacharge Cireuit}

In order to mgulate the electric field across the damper electrodes, a discharge circuit was incorporated into the high voltage supply unit. The damper, by itself, required several seconds to discharge due to the long time constant formed by the capacitance and resistance of the ER fluid. Therefore, it was necessary to construct an auxiliary circuit capable of removing the electric charge stored in the damper in a rapid, efficient and controllable manner.The major considerations in designing the discharge circuit were the maximum voltage level across the electrodes in the damper and the maximum charge stored by the fluid. Although the absolute maximum voltage level was expected to be 12 $k V$ the total charge was estimated at only $4.2 \mu C$. If the maximum discharge interval was targeted at $1 \mathrm{~ms}$ then the avernge current should be only $4.2 \mathrm{~mA}$. Therefore the major requirement was to find a semiconductor device with the highest voltage breakdown rating available capable of switching a fairly small amount of current. The final configuration involved several high voltage opto-couplers connected in series and driven by a common base-drive circuit. The driver circuit was pulse-width-modulated in a manner similar to the switching transistor for the charging circuit. Hence, the amount of current passed by the discharge circuit, and corresponding drop in output voltage, could be controlled to a reasonably fine degree. The maximum voltage drop across each output transistor was kept well below the rated breakdown voltage in order to ensure component reliability. The entire circuit was potted in silicone sealant to prevent corona and arcing. As shown in Figures 14 through 18, the time to completely discharge the damper from a maximum voltage level of $10 \mathrm{kV}$ was less than $1.5 \mathrm{~ms}$. 


\subsection{System Performance}

Figure 19 shows the real-time acceleration signal from an accelerometer mounted on the sprung mass of the quarter-car-model as the high voltage is suddenly switched on. The solid line shows the effect of the flyback converter output voltage on the ERF damper. After approximately 3000 L.s. the voltage was tumed on and the ER fluid "solidified" causing a resultant attenuation in absolute acceleration of the sprung mass. The non-sinusoidal acceleration response is primarily due to non-linear effects in the damper and could possibly be due to "stiction". The dashed line shows a second set of accumulated data; for this trial the output voltage originated from a Universal Voltronics High Voltage Power Supply. The Voltronics power supply basically consisted of a 60 $\mathrm{Hz}$ autotransformer input transformer connected to a high voltage output transformer with the autotransformer providing the means of modulating the output voltage level. The 60 Hz sine-wave output voltage is rectified inside the power supply with external taininals providing access to low-ripple de voltage continuously variable between $0-14 \mathrm{kV}$.

As evident from the figure, there is virtually no difference in the results between the Voltronics de power supply and the flyback converter in terms of final attenuation of the acceleration signal. The flyback converter can produce nearly the same level of output voltage (maximum $10 \mathrm{kV}$ ) using considerably smaller magnetic components and operating from a dc source as opposed to the $60 \mathrm{~Hz}$ mains which the Voltronics power supply must operate from. 


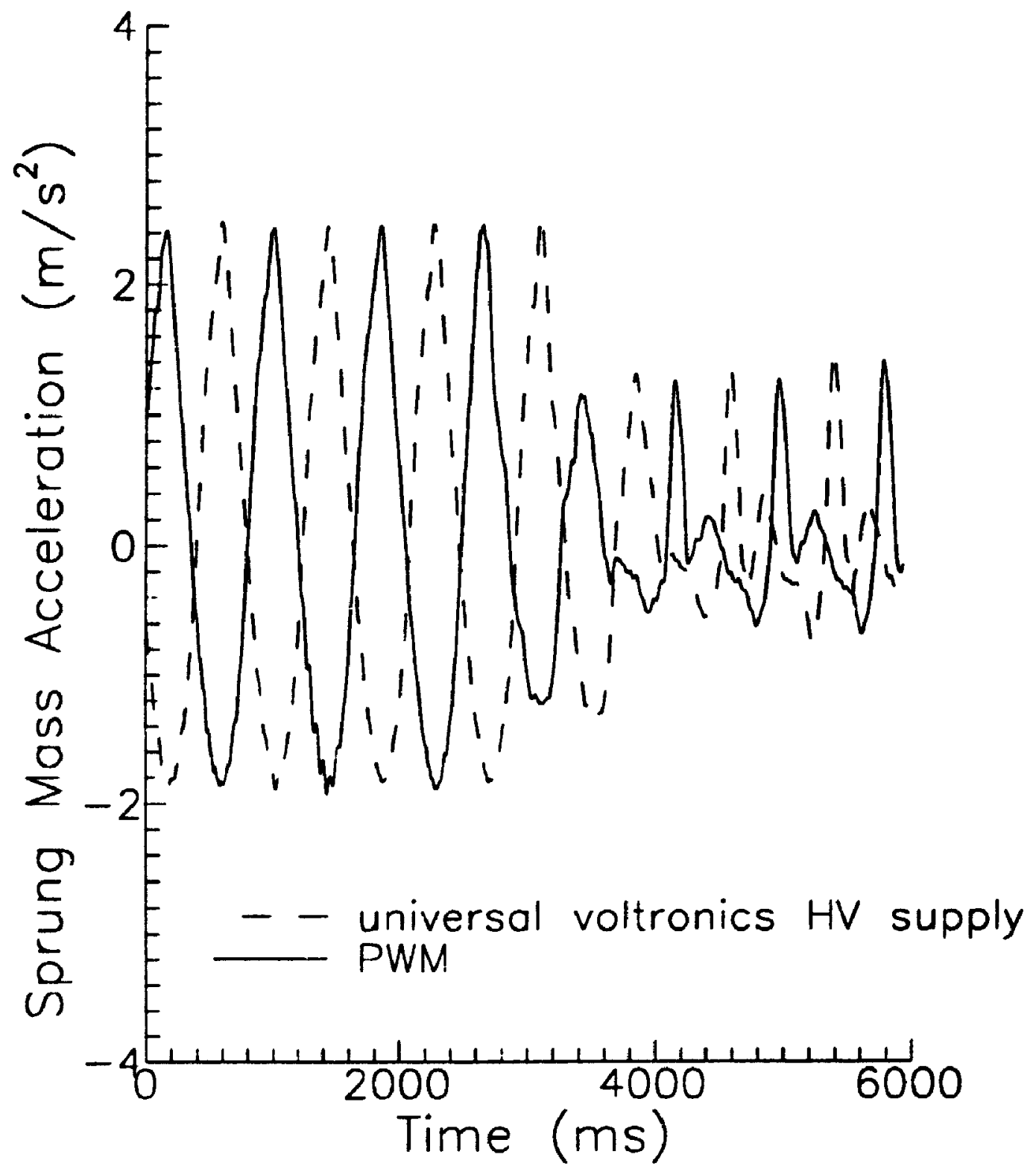

Figure 19: Measured Sprung Mass Acceleration Of The Semi-Active Suspension System Before and After Application of High Voltage 
As shown in Figure 19, the sprung mass acceleration becomes non-sinusoidal after the application of the high voltage. Because of the non-linear behaviour of the ER fluid, the irregular shape of the acceleration response results.

Figure 20 shows the actual output voltage of the damper for two cycles of vibration of the quarter-car-model. The dashed line represents the desired or commanded voltage as determined by the ECU. The solid line represents actual measured voltage across the damper. The jaggedness of the damper voltage is due to many factors. The ECU software employed a look-up-table (LUT) routine that effectively chopped the voltage into a stair-step pattern. More steps in the LUT would have smoothed the output voltage but probably would not have significantly improved the performance of the damper (as will be discussed further in the next section).

The next chapter provides a brief discussion of Electronic Controlled Suspensions (ECS) including active and semi-active suspensions. Both historical and current control strategies are discussed in the context of their relative merits. 


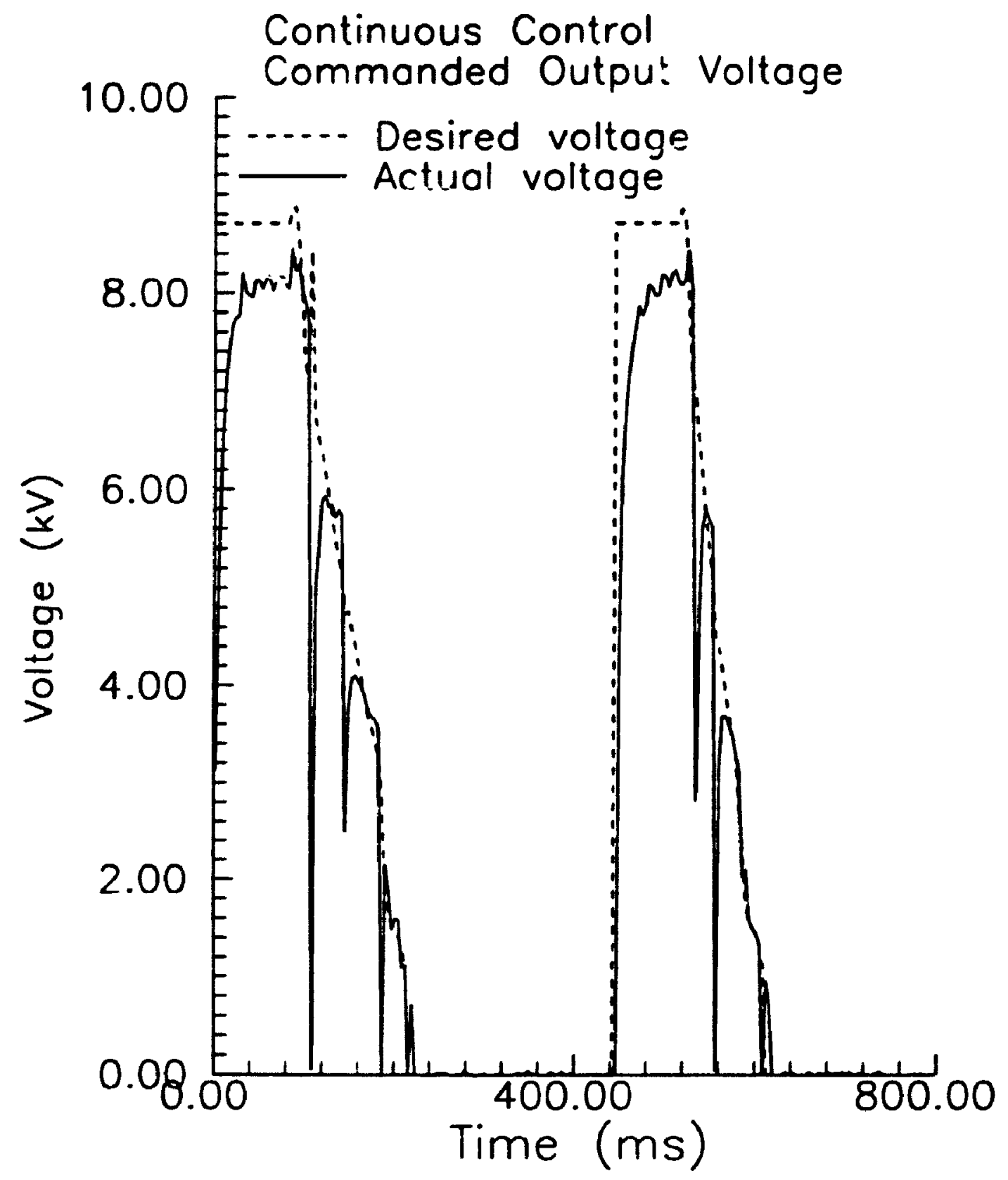

Figure 20: Representative Output Voltage and Commanded or Desired Voltage For the Semi-Active Suspension System 


\section{CHAPTER IV}

\section{ELECTRONIC CONTROLLED SUSPENSIONS}

\subsection{Introduction}

Electronic Controlled Suspensions (ECS) have developed into a multiplicity of designs ranging from adaptive to fully active suspension systems. Decker et.al.[60] have come up with a classification scheme which consists of the following four basic types of ECS:

1. Passive;

2. Adaptive or Slow Semi-Active;

3. Semi-Active (SA); and

4. Active.

Passive systems are characterized by passive elements such as springs and dampers which can only dissipate energy; hence the term passive. External power requirements are zero. They are generally well understood and will not be discussed further in this thesis except by way of direct comparison with SA systems.

Adaptive systems can automatically respond to varying environmental inputs, albeit at a rather slow rate. They are characterized by having a conventional spring element in parallel with a damper of variable damping coefficient. The response time of the damper is in the onder of ens of milliseconds or greater. Power requirements are in the order of 100 watts or less for a light duty vehicle damper. 
Semi-active (SA) systems are similar to Adaptive systems but their response time is much faster, in the order of 10 milliseconds or less. They are theoretically capable of changing states (damping coefficient) within a single cycle of vibration. Their power requirements are anticipated to be within 100 watts for a light duty vehicle.

Semi-active systemi are often further classified as being ON-OFF or continuous depending upon their switching strategy and hardware implementation. Their simulated and experimental performance is discussed in greater detail in the sections dealing with performance of SA systems.

Active systems employ acurators that can generate force in all four quadrants of an absolute/relative velocity diagram. Active systems are often considered the benchmark against which SA systems are compared. They are theoretically capable of providing good vibration isolation without sacrificing road handling performance. Their chief disadvantages are system complexity and cost.

\subsection{Active Suspensions}

Active suspensions, such as the one available on the Nissan Infiniti Q45, generally comprise a high pressure oil pump, several hydraulic oil-pressure accumulators, a multivalve manifold, pressure-control units and (for four wheel vehicles) four hydraulic actuators. The variable output hydraulic pump circulates hydraulic oil at a high pressure (1,420 psi on the Nissan Infiniti) through a regulator and then directs the oil to pressure 
control units and actuators at each wheel. The power penalty imposed by this system is significant (six horsepower on the " $"$ issan Infiniti).

The price/performance ratio is very high at the present time for active suspensions. Although Nissan claims a 70\% reduction in vibration levels for the Inifiniti [61], this only holds for ride frequencies between two and three $\mathrm{Hz}$, and at a reduction in fuel economy of 1.5 mpg. Lotus has built active suspensions capable of responding to inputs in the 0 $1020 \mathrm{~Hz}$ frequency range but with a weight penalty of $300 \mathrm{lbs}$. To avoid the complexity of hardware associated with active suspensions, engineers have looked to altermative methods of suspension control such as semi-active suspensions.

\subsection{Semi-Active Suspensions}

The concept of the semi-active vibration isolator using the active damper was developed by M. Crosby of the Lord Corporation and D. Kamopp of the University of California in the early 1970's. The actual concept was patented (U.S. patent no.3,807,678) on April 30, 1974. In their paper [62], the authors describe a device which, "produces a controllable force which is derived from the relative velocity of its attachment points."

The goal of the researchers at Lord Corporation and University of California was to develop a suspension system that would provide significant performa. $x$ improvements over conventional passive systems without incurring the cost, weight and complexity 
problems associated with active suspensions. Their solution was to use $=$ conventional damper and spring arrangement, but with the damper having a controllable damping coefficient. For the conventional parallel spring/damper assembly, increasing the damping ratio serves to control the resonant peak amplitude but increases the transmissibility at higher frequencies. This is the basic compromise that all passive systems must endure. A suspension tuned for good high frequency isolation, ie. a low damping coefficient, will result in large amplitudes near the resonant peak. Conversely, a high damping coefficient will control the conditions at resonance but suffer degradad performance (harsh ride) at higher frequencies. A passive single degree-of-freedom (DOF) system comprising a parallel spring/damper assembly may be considered as a closed-loop feedback system generating the following control force:

$$
F_{c}=c(\dot{y}-\dot{x})+k(y-x)
$$

where $F_{c}=$ control force $(N)$

$$
\begin{aligned}
& y, x=\text { absolute displacement of body, wineel respectively }\left(\mathrm{m}_{\mathrm{i}}\right) \\
& \dot{\mathrm{y}}, \dot{\mathrm{x}}=\text { absolute velocity of body, wheel respectively }\left(\mathrm{ms}^{-1}\right) \\
& \mathrm{c}=\text { damping coefficient }\left(\mathrm{Nsm}^{-1}\right) \\
& k=\text { spring rate }\left(\mathrm{Nm}^{-1}\right)
\end{aligned}
$$

In the above equation the forces generated are pronortional to the relative displacement and the relative velocity of the suspension attachment points. However, as Kamopp stated, an active force generator is not restricted to equations of the form (74). Kamopp proposed that an ideal feedback law for an active force generator would be of 
the form:

$$
F_{e}=c \dot{y}+k(y-x)
$$

It can be shown by linear optimal control theory that equation (75) gives superior vibration isolation [63]. Equation (75) can be implemented only where the sprung mass is isolated from the base input by a compliant element (spring) and a dissipative element (damper) is connected from the mass to an inertial reference. The key distinguishing feature between equation (74) and (75) is that in the first instance the damping forces are generated by the relative velocity, whilst in the second case the damping forces are generated by the absolute velocity. Hence, for high frequency inputs the conventional system tends to stiffen the suspension whereas no such stiffening occurs for the second system. The system represented by equation (75) is extremely difficult to implement directly for a moving ground vehicle; it is commonly referred as a "skyhook" system.

As Karnopp suggested, however, an active system programmed to simulate a skyhook damper is theoretically capable of achieving both resonance control and high frequency isolation. Furthermore, if an active force generator responding to the absolute velocity input can achieve satisfactory vibration isolation, then it was intuitively reasonable that a passive element could also give good performance if it was made to simulate the active force generator as closely as possible. This established a new ret of control laws: 


$$
\begin{aligned}
& F_{c}=c \dot{y} \text {, if } \dot{y}(\dot{y}-\dot{x})>0 \\
& F_{c}=0, \text { if } \dot{y}(\dot{y}-\dot{x})<0
\end{aligned}
$$

As noted by Krasnicki [64] the strategy of skyhook control is to modulate the passive damper force to equal the force that would be generated by a skyhook damper if one were present. This can only be done when the desired damping force (force that would be generated by a skyhook damper) and the actual damping force are of the same sign. For all other times the actual damping force is set to zero. The skyhook damper achieves two results which improves the vibration isolation over a conventional passive system; firstly, it produces (theoretically) a damping force in exact proportion to the force necessary to limit the absolute velocity of the mass, and secondly it produces no force (ideally) during a portion of the vibration cycle when a conventional damper would actually be serving to accelerate the mass.

Although semi-active suspension systems can only react against forces imposed by the relative motions of the suspension atachment points (they cannot generate forces independently), active suspensions also have limitations. Active suspensions can only produce a force reaction pair between the spring/damper attachment points. In linear system terms, the limitations manifest themselves as non-adjustability of certain terms in the numerator of the transfer function [65]. Crolla and Aboul Nour [66], and Sharp and Hasska [57] have also reported performance improvements by semi-active suspensions that are very close to active systems. The next section reviews some practical aspects of 
semi-active suspensions.

\subsection{Practical Applications of Semi-Active Suspensions}

\subsubsection{Historical Background}

A hardware prototype of a single DOF system using skyhook control was successfully constructed and tested in 1979 at the Lord Corporation research facilities in Erie, $\mathrm{Pa}$. Despite the success of the first known active damper it was readily apparent that the price/performance ratio of a fully adjustable active damper was still 100 high for commercial use. It was envisioned at this point that the most probable implementation of a successful active damper would be based on hydraulic fluid even though any type of basic damping mechanism could be used, "including square law fluid throtling. friction, electro-viscous or electro-mechanical implementations" [68]. This is because the damper responds to a commanded force, not a commanded damping value.

An hydraulic active damper is controlled by the modulation of the damping orifice which requires a high bandwidth servovalve. In order to reduce the complexity of an hydraulic active damper, Krasnicki [69] proposed the idea of an ON-OFF damper. The premise behind the ON-OFF damper was for the damper to operate as a conventional passive damper during a portion of the vibration cycle whilst shutting off during that interval of time when a passive damper would be accelerating the mass. The control law for the ON-OFF damper is identical to the skyhook damper with the exception that instead of trying to track a particular damping force, the damper is instead commanded 
to a predetermined damping coefficient acconding to the following control law:

$$
\begin{gathered}
F_{d}=c(\dot{y}-\dot{x}), \text { if } \dot{y}(\dot{y}-\dot{x})>0 \\
F_{d}=0, i f y(\dot{y}-\dot{x})<0
\end{gathered}
$$

If the product of the relative velocity and absolute velocity is positive the damper is switched to a discrete predetermined setting. Otherwise, the damper is switched off. Kamopp [70] was later to prove that the specific damping coefficient of 0.707 was "not only intuitively reasor.able, but also formally optimum" for an ON-OFF active damper.

According to Krasnicki's experimental results the ON-OFF damper held the transmissibility ratio to 0.89 at resonance whi.st still maintaining good isolation at high frequency. Margolis [71] was later to show that ON-OFF dampers were susceptible to chatter between the ON and OFF states during certain "dynamic configurations of the system". He proposed a cure which had the additional effect of slightly degrading high frequency response and increasing the complexity of the control algorithm.

\subsubsection{Hardware Limitations:}

One problem associated with the control strategies discussed thus far is the difficulty in obtaining the sprung mass velocity by integrating the acceleration signal. It is very difficult to obtain a drift-free pure integrator. A practical accelerometer requires a low pass filter for integration of the acceleration signal plus a high pass filter to eliminate the steady state bias. Margolis [72] rroposed a transfer function utilizing 
acceleration feedback directly as a means of compensating for the non-ideal velocity measurement.

Another person to investigate the effect of hardware limitations on SA suspensions was Lane Miller of Lond Corporation [73]. Noting it was virtually impossible to achieve a perfect integrator with analogue components, Miller proposed a higher order digital filter with break frequency around $0.1 \mathrm{~Hz}$. Miller argued there was a strong dependence of the system performance on the location of the break frequency and on the sampling interval. His simulation results indicated SA systems performed reasonably well if the following conditions were met:

1. the $\mathrm{ON}$ state damping ratio be 0.707 (a formally optimum value);

2. the OFF state damping ratio should be 0.2 ;

3. the break frequency for the digital filter should be around $0.1 \mathrm{~Hz}$;

4. the valve adjustment time (minimum to maximum) should be less than 0.0148 , otherwise degradation of system performance would begin; and

5. the sampling interval should be less than 0.004 secinds.

One of the interesting results from Millers simulations was the observation that valve response times of 7 milliseconds produced almost ideal theoretical response, suggesting a useful bandwidth goal. Miller also noted that SA systems were inherently stable, unlike active systems which have the porential to cause dangerous instabilities. If the SA system fails, it falls back to a conventional passive mode with damping coefiricient 
of around 0.2 .

\subsubsection{Wheel Hop Control}

The previous discussion has been primarily concemed with vibration isolation. There are actually three major parameters of interest when judging suspension performance, whether they be passive, active or semi-active. The three widely recognized parameters are:

1. vibration isolation - usually measured in terms of the International Standands Organization (ISO) weighted vertical body acceleration [74];

2. dynamic tyre load variation - a measure of the ability to control wheel motion, otherwise known as wheel hop; and

3. relative displacement of the suspension attachment points - otherwise known as rattlespace.

Due to the infinite possible combinations of performance indices, a generally common method of judging competing suspensions is to assign a prescribed rattlespace. However, even this can lead to some ambiguity since some suspensions (notably most active and semi-active) can accrue greater advantage from increased rattlespace than others.

It has been shown that skyhook control is a very good method of providing body control; but up to now no mention has been made of wheel control. A modified control 
strategy that addressed the issue of wheel control was proposed by M. Lizell of the Monroe shock absorber company [75]. Lizell argued a control algorithm can be divided into two objectives:

1. control of the sprung mass (body motion); and

2. control of the unsprung mass (wheel motion).

In regard to body motion, Lizell's control strategy simulates skyhook control as described by Karnopp et.al. Wheel control is based on modulation of the damper settings depending on frequency content of the wheel motion. An important part of this control strategy was the expressed aim at minimizing tire-ground loading variation. Lizell noted there were four distinct operating regions for a passenger car:

1. Region (1) - Sprung mass modes - 1 to $3 \mathrm{~Hz}$;

2. Region (2) - Intermediate ride - 3 to $8 \mathrm{~Hz}$;

3. Region (3) - Wheel hop mode - 8 to $20 \mathrm{~Hz}$; and

4. Region (4) - Ride harshness - above $20 \mathrm{~Hz}$.

Lizell argued that optimum damping was frequency dependent and proposed the following settings for an ON-OFF damper:

1. Region (1) - FIRM;

2. Region (2) - SOFT;

3. Region (3) - FIRM; and

4. Region (4) - SOFT. 
Lizell's strategy was to assign a FIRM damper setting in the region of the two natural frequencies (sprung and unsprung mass) and go to a SOFT damper setting in al other cases. The damping coefficient for the FIRM setting was the optimally chosen 0.707 whilst Lizell proposed a SOFT setting of 0.1 to 0.2 for conditions away from resonance.

To control the body motion, absolute velocity using an integrated accelerometer signal was used in conjunction with the skyhook principle. This control strategy was to be implemented only in Region (1). This was effected by incorporating dead band threshold limits that limited switching to excursions of the absolute velocity beyond upper and lower limits.

The control of the unsprung mass was based on a Discrete Fourier Transform (DFI) that calculated the weighted square of the wheel amplitude at the wheel natural frequency. If this value exceeded a certain threshold, the damper was switched to FIRM. In addition the damper was switched to FIRM above certain suspension velocities to avoid bottoming of the suspension components. The control objective using the DFT was to maximize road holding by minimizing tyre load variation.

Although the control strategies for the body and wheel motion act simultaneously, Lizell was careful to point out that wheel control had priority. The results for this combined control strategy were reported to be a smooth ride quality with good rosd 
handling.

\subsubsection{Relative Feedback Control Strategies:}

As previously mentioned, one of the problems with skyhook control is the requirement to feedback an estimate of the absolute velocity to the control unit. Alanoly and Sankar [76], and Jolly and Miller [77] have proposed control strategies utilizing the feedback of relative displacement and relative velocity signals instead of integrating the absolute acceleration of the sprung mass. Alanoly's and Sankar's control strategy can be expressed as:

$$
\begin{gathered}
F_{d}=-\alpha \omega_{n}^{2}(y-x),(\dot{y}-\dot{x})(y-x)<0 \\
F_{d}=0,(\dot{y}-\dot{x})(y-x)>0
\end{gathered}
$$

where $\alpha=$ gain

$\omega_{\mathbf{1}}=$ undamped natural frequency

According to the above control law, when the spring force and damper force act in opposite directions the damping coefficient is set 10 some value in accondance with equation (80). When the spring force and the damper force act in the same direction the damping is set to zero. The relative control strategy described above can also be easily derived for a two DOF system by re-arranging the equations of motion: 


$$
\begin{aligned}
& C_{d}=\frac{-k_{d}(z-y)}{z-y}, i \frac{(z-y)}{(z-y)}<0 \\
& \text { alse } C_{d}=C_{-}
\end{aligned}
$$

where $C_{d}=$ damping coefficient

$2, i z=$ absolute displacement, velocity of the sprung mass

$y, \dot{y}=$ absolute displacement, velocity of the wheel

$k_{8}=$ spring ate $\left(\mathrm{Nm}^{-1}\right)$

The control described above was termed "continuous control" by the researchers at Carleton University and was employed in conjunction with the apparatus depicted in diagrammatically in Figure 21 and photographically in Figure 22. Another control strategy, similar to the ON-OFF strategy described by Karnopp and Krasnicki, was also used and will be referred as the ON-OFF control. The ON-OFF control and continuous control are very closely related. By inspection of the relative control strategy, it is apparent that the damping coefficient goes 10 infinity, and bence the damper saturates, as the relative velocity term (denominator in the above equation) goes to zero. The damping coefficient also quickly goes to zero as the relative displacement term goes to zero. In fact, for simple harmonic motion the switching condition expressed in equation (82) reduces to $\tan (\omega x)$ which has both positive and negative asymptotes. Consequently, the damper is frequently alternating between conditions of cut-off and saturation. 


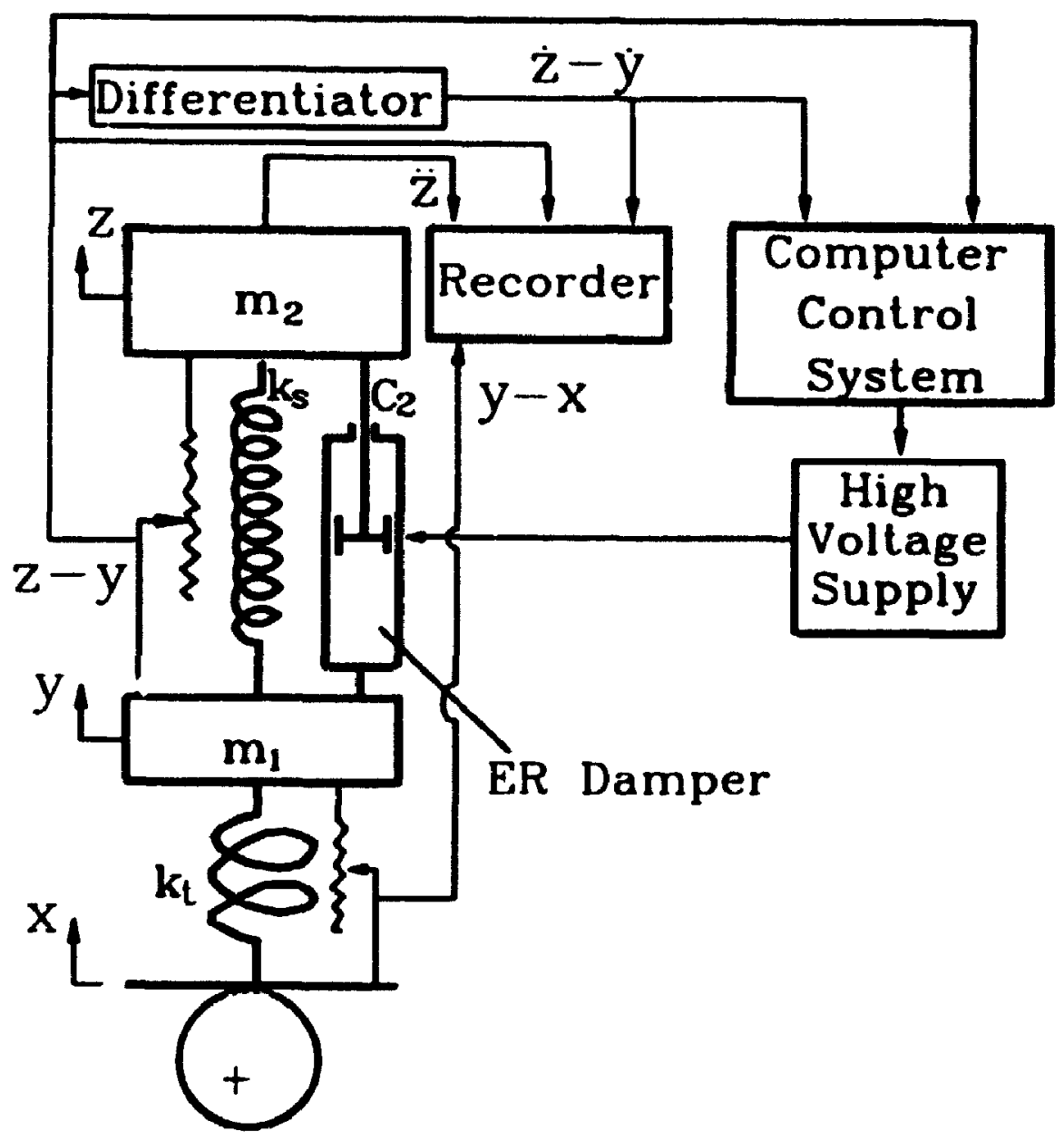

Figure 21: Diagrammatical Sketch of Semi-Active Suspension System

Showing Instrumentation, Sprung Mass, Unsprung Mass and Electrorheological Fluid Damper 


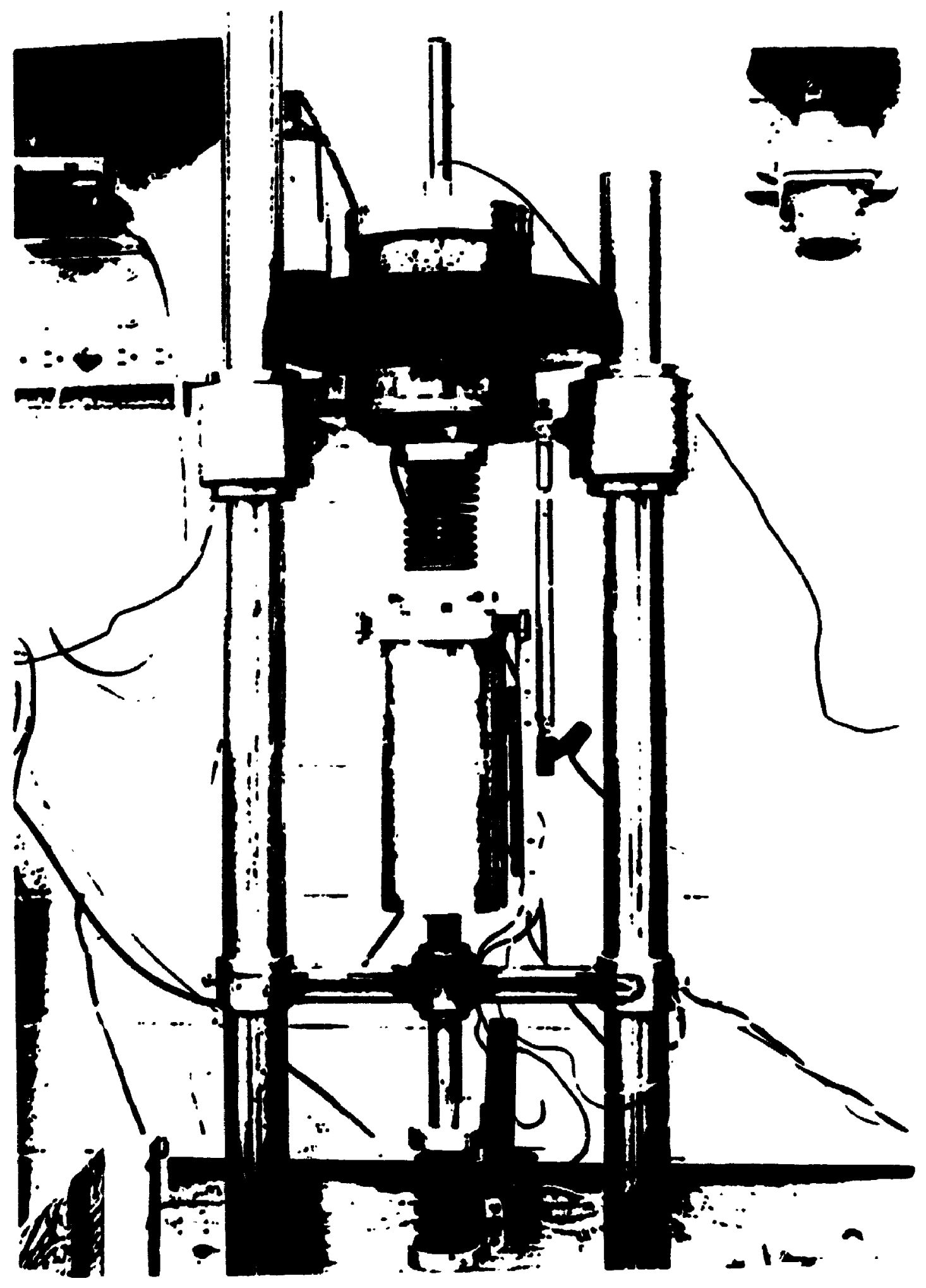

Figure 22: Experimental Semi-Active Suspension System Incorporating Electrorheological Fluid Damper 
An ON-OFF control strategy can produce results very close to that of the continuous control strategy. An ON-OFF control strategy can be implemented using the following two conditions:

$$
\begin{gathered}
C_{d}=C_{\max } \text { if } \frac{z-y}{i-y}<0 ; \\
\text { as well as } \frac{-k_{d}(z-y)}{z-y}>2 \zeta \sqrt{k_{d} m_{s}} \\
\text { else } C_{d}=C_{\text {mb }}
\end{gathered}
$$

where $\zeta=$ a constant value between 0 and 1

The ON-OFF and continuous conurol strategies are discussed in more detail in the next chapter.

\subsubsection{Mechanical versus Electrorheological Dampers:}

In theory, semi-active suspensions can be implemented in a variety of forms using different control strategies and different physical types of valve arrangements. Because the SA damper is commanded to a control force and not to a damping coefficient it may utlize frictional, hydraulic or electro-rheolog:cal elements to vary the damping force.

A recent paper by Hagele et.al. [78] compared, experimentally, the relative merits of mechanical and electro-rheological dampers for what the authors refer to as Rapid Acting Ride Control Systems (RCS). The authors state what they believe to be the basic requirements for adjustable shock absorbers:

1. The maximum achievable shock absorber force should be at least $3000 \mathrm{~N}$; 
2. The ratio of maximum to minimum damping force should be greater than 15 , hence, the minimum damping force should be less than $200 \mathrm{~N}$;

3. The switch over time between minimum and maximum should be less than Sms;

4. The active fluid volume should be less than $500 \mathrm{ml}$;

5. The electrical power consumption should be less than 100W; and

6. The operating range of the device should be between -40 and +120 degrees Celsius.

On the basis of the above requirements, the authors concluded that electrotheological fluids would have to reach a further state of development before they would be practical in a real sense. One of the main drawbacks against ERF dampers, according to the authors, is the complexity of the electrical equipment required to modulate the fluid shear force. The authors also claim to have developed an electro-mechanical damper which is continuously adjustable over a broad damping range with a switch-over time less than $5 \mathrm{~ms}$.

It is true that there are certain fluid lis $-{ }^{-}$ons, especially with regard to the limiterl operating temperature range, which mitigate against the use of ERF dampers. However, it is the purpose of this report to repudiate the claim that the electronic switchgear required to modulate ERF dampers reed be complex. On the contrary, it is the inherent simplicity of ERF dampers, and tueir associated controllers, which renders 
them attractive. The next chapter describes the vibration apparatus, ERF damper and sensor hardware used to build and test an experimental semi-active suspension system. 


\section{CHAPTER V}

\section{EXPERIMENTAL APPARATUS and TEST PROCEDURES}

\subsection{Quarter-Car-Model Test Rig}

The ERF damper, together with the high voltage supply unit, were tested in a quarter-car model test rig shown diagrammatically in Figure 21 and photographically in Figure 22. The test rig used in the experiments consisted of two machined verticai snafts fixed firmly to a steel base plate. The sprung and unsprung masses were constrained to move in the vertical direction by ball bushings running along the shafts. A cam driven by a DC electric motor excited the unsprung mass sinusoidally, at a frequency determined by the speed of the motor. The entire set-up was made to represent a two-degree-offreedom quarter car model. The total sprung mass was $44.2 \mathrm{~kg}$ while the total unsprung mass was $6.2 \mathrm{~kg}$. The spring (representing the suspension spring) located between the sprung and unsprung mass had a spring rate, $b_{\text {, }}$ of $2867 \mathrm{~N} / \mathrm{m}$ while the spring representing the tire had a stiffness, $k_{1}$ of $26460 \mathrm{~N} / \mathrm{m}$.

\subsection{Sensors}

The three criteria for evaluating vehicle suspension performance are vibration isolation, tire dynamic load variation and rattlespace. In order to evaluate vibration isolation the $\mathrm{ms}$ acceleration of the sprung mass was measured by a calibrated accelerometer fixed to the sprung mass. Tire dynamic load variation was tracked with a rectilinear potentiometer fitted across the spring representing the tire. Similarly, a second identical potentiometer was fitted between the sprung and unsprung mass to 
monitor the relative displacement between them. An operational-amplifier differentiator was then used to produce a signal representative of their relative velocity. The relative displacement and relative velocity signals were then input to the computer via a data acquisition board for controlling the damper.

\subsection{Control Strategy}

The so-called "skyhook" damping control strategy which is based upon measurement of the absolute velocity of the sprung mass, is difficult, if not impossible. to implement for a moving vehicle in practice. Therefore, the two control strategies used in this investigation were based on the relative displacement and relative velocity between the sprung and unsprung mass as discussed in Chapter 4. They are intended to achieve good vibration isolation.

The first strategy is for the continuous control of the damping force and may be described as follows:

$$
\begin{aligned}
& C_{d}=\frac{-k_{d}(z-y)}{(\dot{z}-\dot{y})} \text {, if } \frac{(z-y)}{(\dot{z}-\dot{y})}<0 \\
& \text { else } C_{d}=C_{d}
\end{aligned}
$$

Where $C_{d}$ is the desired damping coefficient for the damper, $z$ and $y$ are the displacements of the sprung and unsprung mass, respectively, $\dot{z}$ and $\dot{y}$ are the velocities of the sprung and unsprung mass, respectively, and $k_{3}$ is the suspension spring rate. This control strategy is based upon the consideration that if the spring force and damping force exerted on the sprung mass are in the same direction, then to reduce the sprung mass 
acceleration, the damping force should be a minimum. On the other hand, if they are in the opposite direction, then the damping force should be adjusted in such a way that it will be equal to the spring force in magnitude in onder to produce zero acceleration for the sprung mass.

The second control strategy implemented on the experimental apparatus was an ONOFF control strategy which can be implemented using the following two conditions:

$$
\begin{gathered}
C_{d}=C_{\text {mex }} \text { if } \frac{z-y}{i-\dot{y}}<0 \\
\text { as well as } \frac{-k_{g}(z-y)}{\dot{z}-\dot{y}}>2 \zeta_{\sqrt{k_{d} m_{s}}} \\
\text { elsec } C_{d}=C_{\text {min }}
\end{gathered}
$$

where $\zeta=a$ constant value between 0 and 1

The first condition in the above equation defines the quadrants of operation for the damper. If the relative velocity and relative displacement across the damper are of opposite sign then damping is required and necessary to reduce the acceleration of the sprung mass. The second condition defines a threshold limit, or switchover point as to when the damper should switch from maximum to minimum damping.

The value of $\zeta$ determines the switch-over point when the damper ceases to operate at maximum damping and switches to zero (or minimum) damping. It corresponds to a passive damping coefficient. If the value of $\zeta$ was zero the damper would stay on for an infinitely short period of time, whereas if the value was 1 the damper would remain full- 
on, at maximum damping, for exactly one-half of a vibration cycle. The value of $\zeta$ was chosen by a trial and error procedure to obtain good performance from the apparatus. The ERF damper, high voltage supply unit, sensors and ECU will all have limitations in operating speed, resolution and so forth. Interestingly, the value of $\zeta$ chosen for the ONOFF damper was 0.3 which is a realistic value for a passive damping coefficient.

For ease of software coding, the ON-OFF control strategy was manipulated into the following simpler form:

$$
\begin{aligned}
& C_{d}=C_{\max } \text { if } \frac{i-\dot{y}}{z-y} \leq-\frac{\sqrt{k J m_{d}}}{2 \zeta} \\
& \text { else } C_{d}=C_{\text {min }}
\end{aligned}
$$

As previously mentioned, the ON-OFF damper alternates between saturation and cutoff. Conversely, the continuous damper saturates for approximately $50 \%$ of the ON time before it decays to zero. Figure 23 shows a representative series of output signals for a real-time control sequence of the experimental damper and vibration test rig. The damper is alternately operating between saturation and cutoff. Figure 24 shows a similar series of output signals for the continuous control. The continuous controller also saturates for a finite time, then gradually decreases in magnitude.

\subsection{Tests and Procedures}

The primary purpose of the experiments was to determine whether the ERF damper with the high voltage supply unit developed could control the vibration of the sprung 
mass by modulating its damping force. The two control strategies described above were used. The frequency of excitation was varied in steps from 0.4 to $12 \mathrm{~Hz}$. During the tests recordings were made of the sprung mass acceleration, dynamic deflection of the spring representing the tire, and relative displacement (rattlespace) between the sprung and unsprung mass.

The next chapter discusses the results obtained from the vibration apparatus and ERF damper control equipment. 


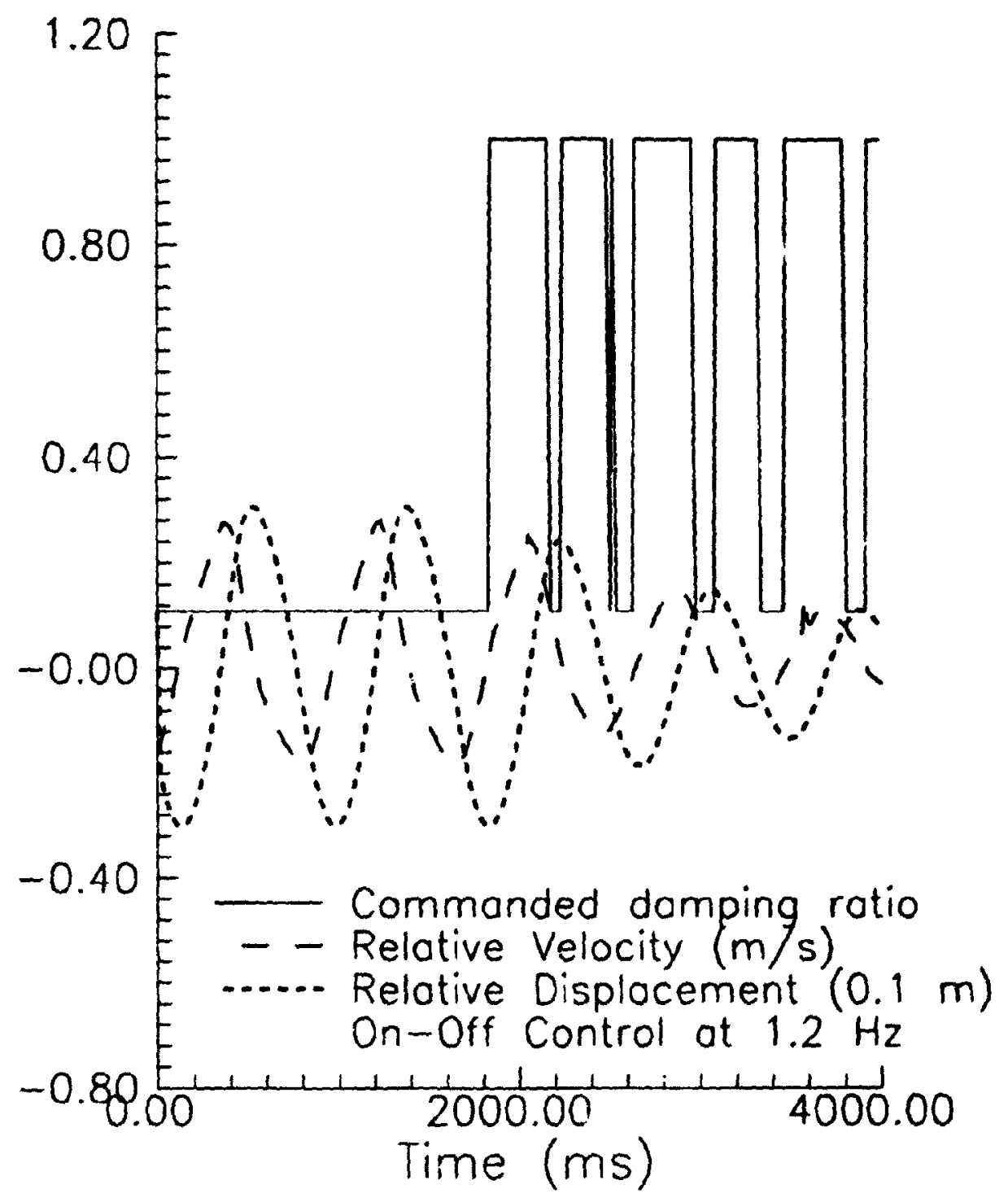

Figure 23: Relative Displacement and Relative Velocity of Semi-Active Suspension System, and Commanded Damping Ratio, Before and After Application of On-Off Semi-Active Control 


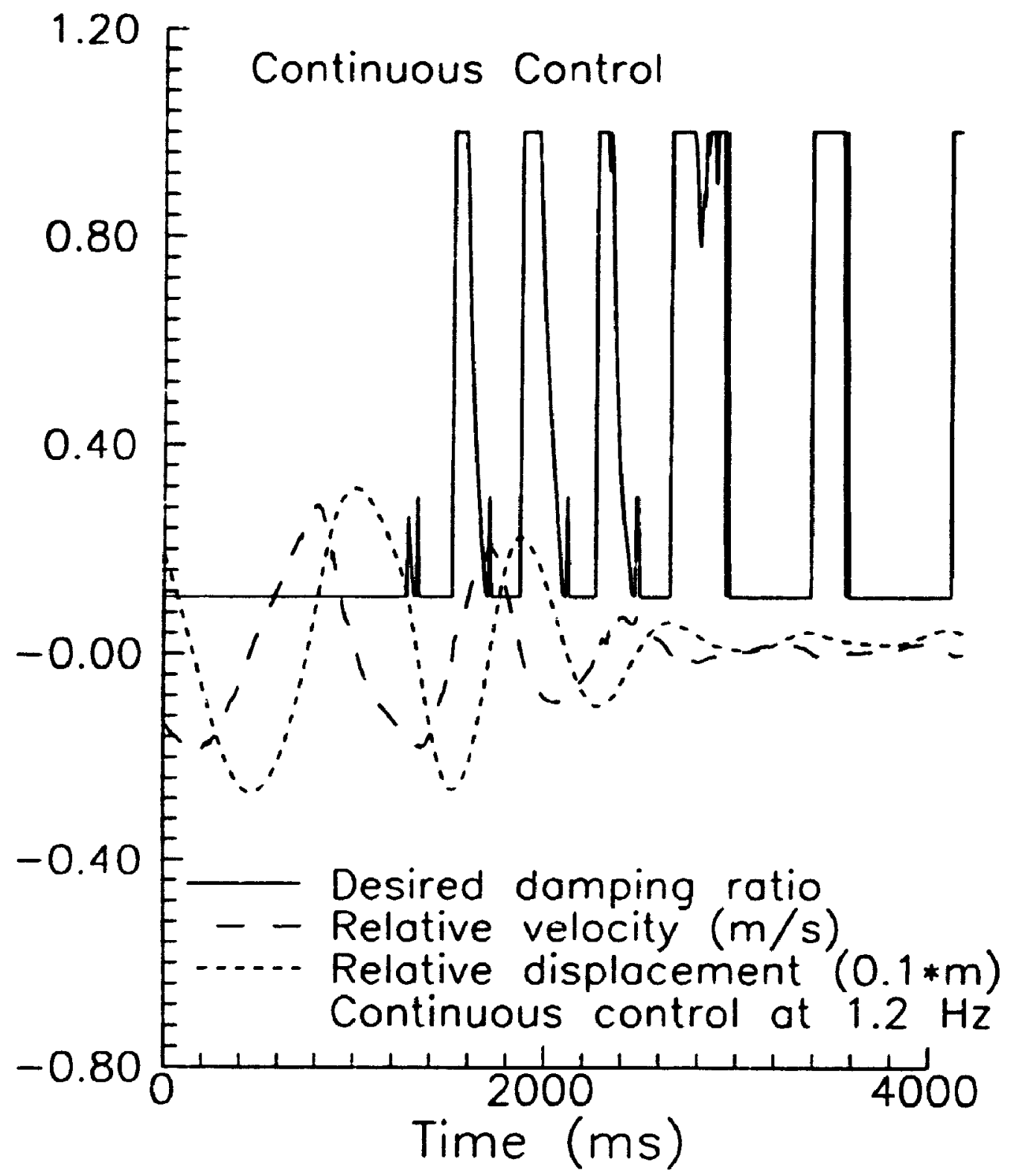

Figure 24: Relative Displacement and Relative Velocity of Semi-Active Suspension System, and Commanded Damping Ratio, Before and After Application of Continuous Semi-Active Control 


\section{CHAPIER VI}

\section{RESULTS and DISCUSSION}

\subsection{ERF Damper}

Figure 25 shows the damping chancteristics of the ERF damper at the first resonant frequency ( $=1.2 \mathrm{~Hz}$.) of the test rig with ERF ' $\mathrm{A}^{\prime}$ as the working fluid. In the figure the damping force $(\mathrm{N})$ is plotted against the relative velocity of the damper attachment points (ie. the relative velocity between the piston and the cylinder). The damping force was measured from a load cell located between the piston and the piston rod-end. The inner loop which varies between $\pm 0.3 \mathrm{~ms}^{-1}$ on the relative velocity axis is the daniping force produced when the voluage is set to zero. When the voltage is off the damping force is seen to vary between $\pm 20 \mathrm{~N}$. The large loop shows the sudden increase in damping force when the voltage is suddenly switched on. The damping force near the instant of turn-on varies between $\pm 80 \mathrm{~N}$. The damping force ratio between minimum and maximum damping in this region of shear rate is approximately four. After the voltage is switched on, the movement of the sprung mass is quickly attenuated; hence the collapse of both the force versus velocity curve about the origin. After a period of time the curve settles into a nearly straight line parallel to the force axis (zero velocity) at the origin, indicating the damper has virtually "locked-up."

The asymmetrical nature of the force versus velocity graph in Figure 25 is due to the non-linearity of the damper. An ideal viscous damper would exhibit a straight line passing through the origin. 


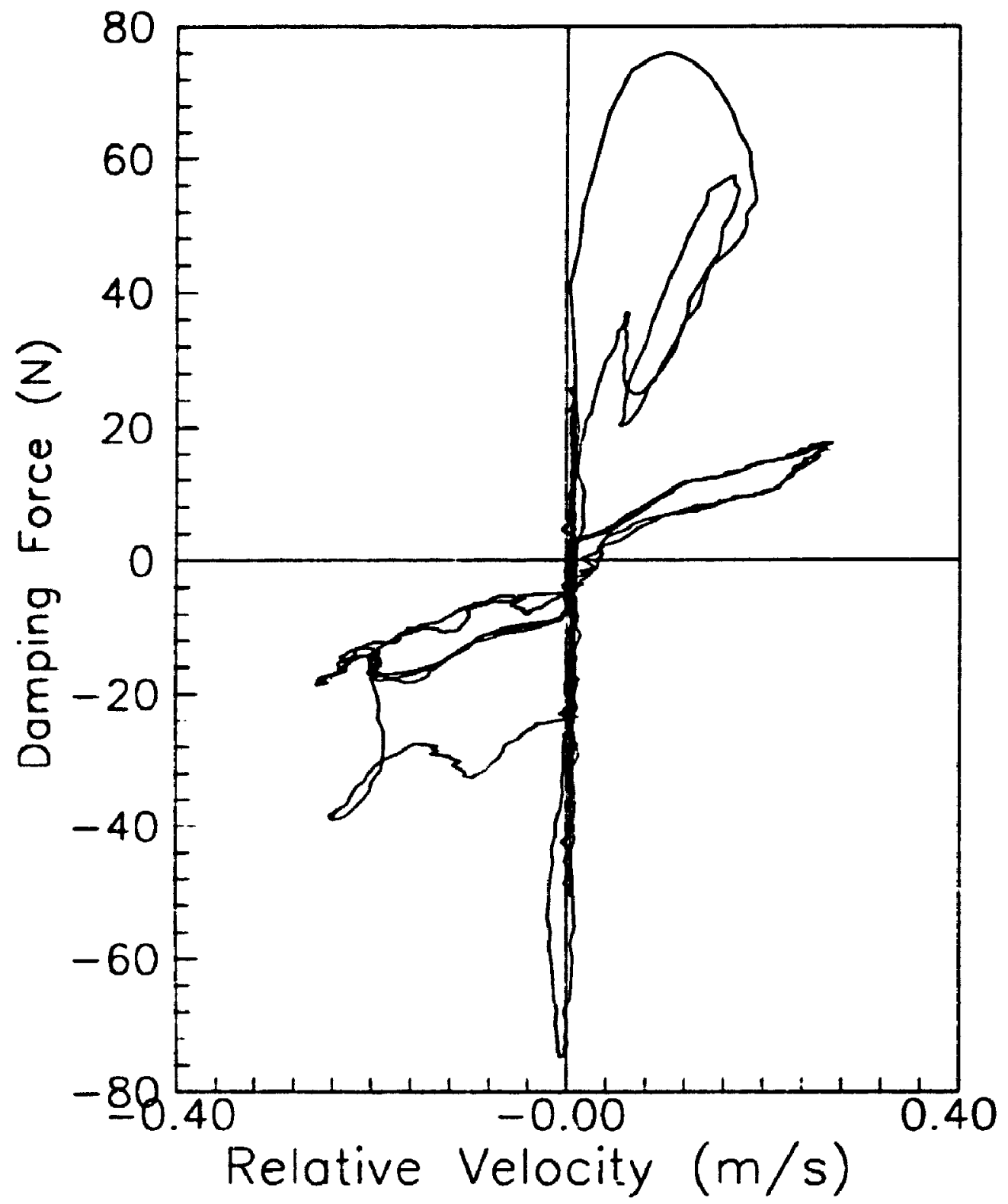

Figure 25: Damping Force versus Relative Velocity Showing Variation of Damping Force Before and After Application of High Voltage (Passive Control) 
Damping. in general, is a complex phenomenon, and linear viscous damping oecurs only for laminar flow conditions. Figure 25 is also not representative of a real situation since a vehicle would never operate at a resonant frequency with with minimum damping. However, as an experimental figle, it shows the maximum damping force ratio is approximately four. The force ratio actually becomes progressively smaller as the frequency increases. As the relative velocity between the piston and cylinder increases. so the shear rate of the working ER fluid between the electrodes also increases. Because the damper was designed with the ratio of blockage area to working fluid area approximately equal to four, the actual relative velocity of the fluid and electrodes is many times the relative velocity between piston and cylinder. Due to the possibility of plug flow, the situation is even worse, with the fluid actually being squeezed through an outer shell of solidified ER material. The result is the fluid having a peak centre velocity perhaps ten times the relative velocity between the piston and cylinder. The shear rate (assuming the case of a linear velocity profile) can be estimated by:

$$
\dot{\boldsymbol{y}}=\frac{V_{\mathrm{mal}}}{G}
$$

where $\dot{\gamma}=$ shear rate $\left(s^{-1}\right)$

$$
\begin{aligned}
& V_{\text {nel }}=\text { relative velocity of the fluid }\left(\mathrm{ms}^{-1}\right) \\
& G \text { = gap width }(m)
\end{aligned}
$$

The above equation is simplified and applies only to a shear mode type of now behaviour. At a vibration frequency of $10 \mathrm{~Hz}$, the shear rate was estimated between 2500 
and $3000 \mathrm{~s}^{-1}$. The high shear rates are due mainly to the design of the damper which had a large blockage area. As a result of the large blockage area, the relative velocity of the fluid through the annular gaps was much higher than the relative velocity of the piston itself. For ERF 'A', at high shear rates the actual amount of electric field enhanced damping force diminishes drastically. The result being no apparent difference between minimum and maximum damping levels. Hence, even with a constant level of excitation voliage applied (ie. in passive mode), ERF dampers do not necessarily exhibit a constant damping coefficient. The damping characteristics of ERF dampers can be very nonlinear. The implications of the non-linearity of ERF dampers will be discussed with respect to performance in the sections following.

\subsection{High Voltage Supply Unit}

The high voltage supply unit comprising flyback converter and discharge circuit were discussed at length in Chapter 3. The flyback converter was capable of charging up the damper capacitance from full-off to full-on $(8 \mathrm{kV})$ in approximately $5.5 \mathrm{~ms}$. The discharge circuit was able to discharge the damper completely in less than $1.5 \mathrm{~ms}$. Therefore the total switch-over time was approximately $7 \mathrm{~ms}$.

The high voltage supply unit was capable of operating from a 12 volt, 1200 mAh, energy source for approximately 60 minutes, hence the power consumption for the entire system was estimated at 14.4 watts, of which approximately 5 watts was used to power the discharge eircuit. The power delivered to the load (damper) by the flyback 
converter was estimated at 2.4 watts. Hence, the efficiency of the flyback converter was approximately $25 \%$ which is reasonable for this type of design and considering the relative magnitudes of the parasitic components (ie. leakage inductance. shunt capacitance).

The high voltage supply unit was fairly reliable and suffered few breakdowns. The only component that required replacement was the PWM IC regulator. Since replacement parts were relatively inexpensive $(\$ \$ 5.00)$ this was not considered a major concem. The IC utilizes CMOS technology which is vulnerable to electrostatic discharge and voltage transients. A permanent cure to prevent failure of the IC would probably require some form of transient protection.

The flyback convener is ideal for charging a capacitive load to high voltages. Its relative simplicity and low-parts-count makes it inherently ı ugged and inexpensive. A complete flyback converter unit, utilizing an ignition coil for magnetics, can be assembled for less than $\$ 20 \mathrm{Cdn}$. The present ignition coil arrangement is capable of delivering up to 2.5 watts of power (estimated) at a continuous rate without overloading the windings. Despite abuses from the researchers, and despite the absence of any snubber network to dissipate voltage and/or current transients, the coil never broke down. This is probably due to the superior insulation techniques used to encapsulate the ignition coil such as vacuum impregnated transformer oil to prevent arcing and corona discharge. 
Whenever large magnitudes of current and/or voltages are switched at high frequency there is bound to be electromagnetic radiation produced. The flyback conventer is a particularly bad offender in this regard since the switching occurs during periods of peak current build-up in the primary inductance. Some form of EML/RFI shielding will be required to reduce the amount of noise injected into other circuitry. Snubber circuits will also reduce the worst of the transients, with some reduction in the outrui voltage as well. The high output voltage across the secondary is a direct result of the high flyback voltage. Also, the reactive nature of the load (damper) caus، sustained ringing which can affect circuits in the nearby vicinity.

The inherent difficulty associated with controlling ERF devices is they require a high intensity electric field applied across the electrodes to respond with satisfactory force. Reducing the gap width across the electrodes will reduce the associated voltage required to produce an electric field intensity. However, reducing the gap width is counterproductive as it reduces the ratio of damping forces and hence the controllability of the damper. Clearly, some form of compromise between the mechanical and electrical systems is required since their requirements are in almost direct conflict. From the fluid mechanics viewpoint the sparing across the electrodes should be as high as possible within the working range of the fluid. From the power supply viewpoint the gaps should be as small as possible to reduce the voltagi levels required to create the electric field. The flyback converter efficiency diminishes as the turns ratio increases. The turns ratio in the ignition coil is already near its practical limit. ine only practical method to 
increase the voltage output would be to increase the voltage input. If the emf source is a $12 \mathrm{Vdc}$ battery then either a voltage doubling circuit or an additional $\mathrm{dc} / \mathrm{dc}$ conventer stage would be required in order to boost the output voltage.

\subsection{System Performance}

\subsubsection{Passive Control}

Both the ERF damper and the high voltage supply unit were experimental pieces of equipment. One of the problems with analyzing the data obtained from the vibration apparatus was determining the relative effects of the control strategy, the damper, and the high voltage supply unit on the system performance. All of the aforementioned items have limitations. The control strategies are limited to the control of a forie m:chanism which can only generate an action-reaction pair of forces. If the damper exerts an upward force on the sprung mass, then an equal and opposite force is exerted on the wheel axle. The damper also has limitations with respect to response time, maximum achievable damping force, zero field viscosity, and coulomb friction effects. Finally, the output voltage from the high voltage supply unit has a small but finite switch-over time. It is important, therefore, to determine how each component of the system contributes to the overall synergistic output.

Figure 26 shows the tansmissibility for the quarter-car-model plotted as a function of both the theoretical and actual damping coefficients, using Passive Control. The transmissibility was calculated as the ms acceleration of the sprung mass divided ty 
the $\mathrm{ms}$ acceleration of the input. A numerical integration was used to calculate the rms acceleration of the sprung mass over several vibration cycles. The experimental data was generated by fixing the voltage of the ERF damper at a prescribed level, either 0 or $8 \mathrm{kV}$ across a $3 \mathrm{~mm}$. gap. The $0.1,0.5$, and 1.0 damping coefficient curves are the result of numerical simulation and hence idea!. As evident from the figure the $0 \mathrm{kV}$ damper produced a curve very similar to the numerical result produced by a theoretical damping coefficient of 0.1 . Due to the generous gap size $(3 \mathrm{~mm}$ ) the ERF damper was able to minimize the "OFF" or zero field damping force. The result is satisfactory vibration isolation at high frequencies with severe oscillation at the first and second resonant frequencies.

The $2.7 \mathrm{kVmm}^{-3}$ curve shows the effect on transmissibility of the sprung mass acceleration with the voltage set to approximately $8 \mathrm{kV}$. The first resonant point is well controlled, almost critically damped, however the effective damping coefficient gradually diminishes at higher frequencies. Due to the higher shear rates, the ERF damper is unable to maintain linearity between relative velocity and damping force. The damping force tends to flatten out, or saturate, at higher frequencies. This may be satisfactory for control of the sprung mass, but is unsatisfactory for the purposes of wheel control. The saturating characteristic of the ERF damper is primarily due to too much blockage area causing the fluid to flow through the annular gaps at too high a velocity with the result being the fluid is unable to sustain shear forces at the higher shear rates. 


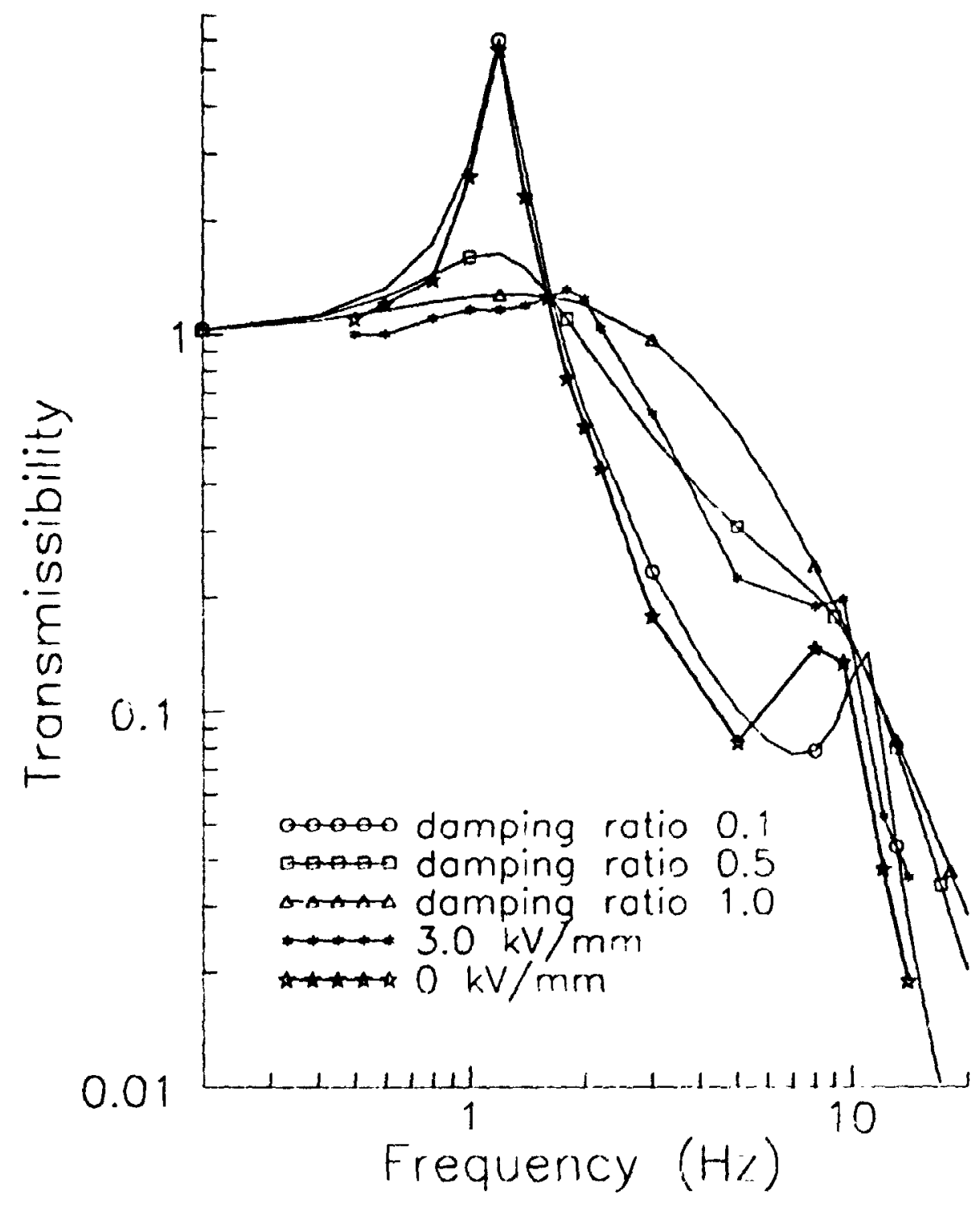

Figure 26: Comparison of Simulated and Experimental Results For the Sprung Mass Transmissibility Using Both Theoretical Levels of Damping Ratio and Experimental Levels of Constant Applied Voltage 


\subsubsection{Semi-Active Control}

Figure 27 shows the transmissibility of the sprung mass versus frequency for various control strategies. Both the continuous and ON-OFF control strategies are effective at controlling body movement whilst maintaining good vibration isolation at frequencies above the first resonant point. There is little discernible difference between the passive $0 \mathrm{kV}$, continuous control, and ON-OFF control curves in the mid-band freyuency range. At the second resonant point the passive $3 \mathrm{kV}$ curve is only slightly higher than the other curves. Hence, the ERF damper, operating under either continuous or ON-OFF control is able to control body movement at the resonant frequency without impairing high frequency isolation.

Figure 28 shows dynamic tire deflection versus frequency for both passive and semi-active control. The main result evident from the graph is the inability to control axle oscillations at the second resonant point. The best strategy in this narrow frequency band is to set the damper to full-on. However, even with $3 \mathrm{kVmm}^{-1}$ applied across the damper, some wheel hop is still in c dence. Thompson [79] has shown that even active suspensions act to increase axle oscillations. Hence, as Litzell pointed out, perhaps the best strategy for wheel control is to apply firm dumper settings at wheel hop frequencies. The problem, of course, is determining the actual frequency content of the suspension vibration in order to determine when to apply wheel control, which may or may not be achievable with the use of Fourier Transform techniques, depending upon the accuracy and availability of sensor information. The application of the Fast Fourier Transform 
(FFT) to wheel control would make an interesting experimental topic. In any event, it is likely that distinctly separate body and wheel control strategies will have to be combined for a real application. 


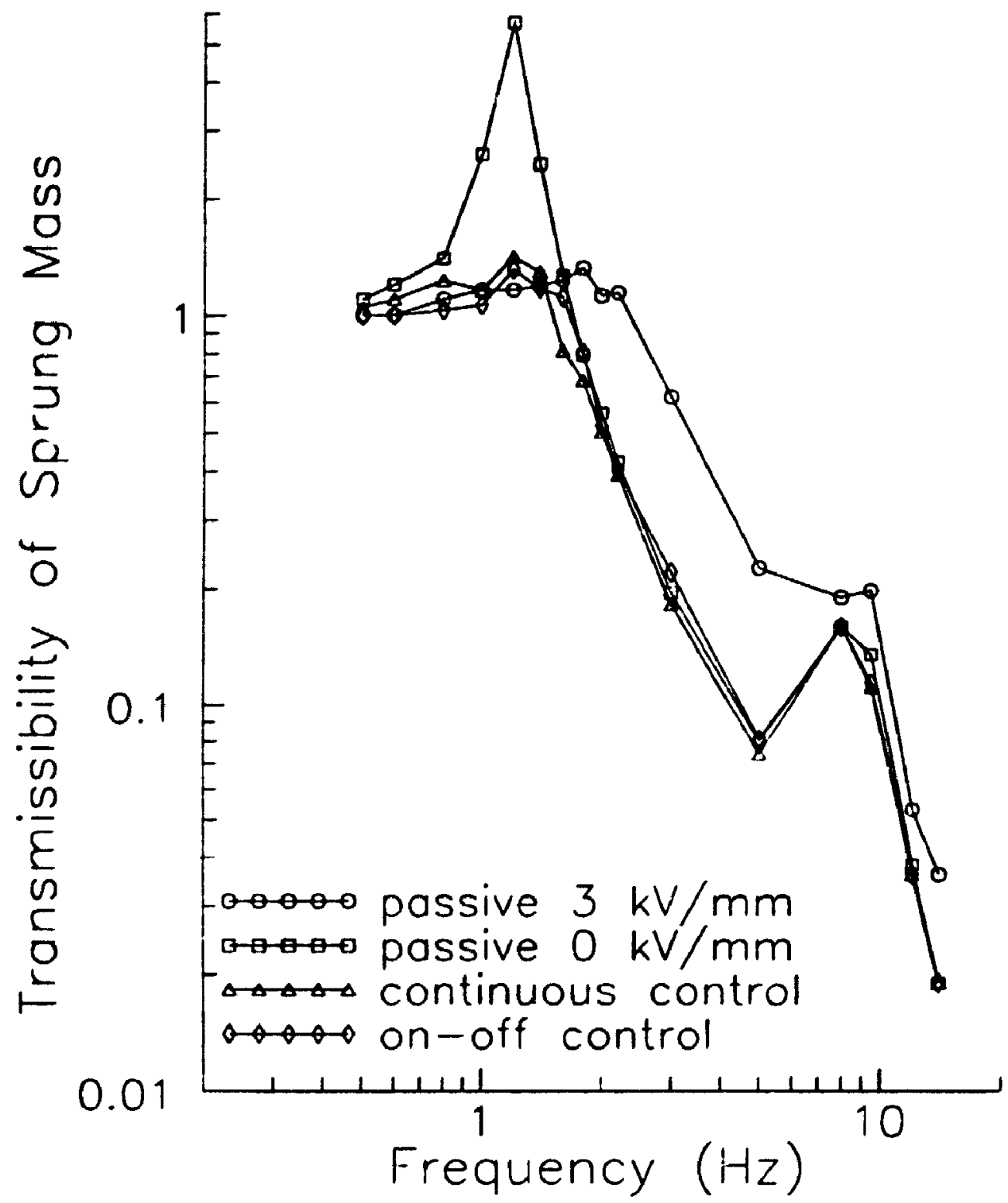

Figure 27: Experimental Results of the Transmissibility of the Spiung Mass Using Both Passive (Fixed Voltage) and Semi-Active Control Including ON-OFF and Continuous Semi-Active Control 


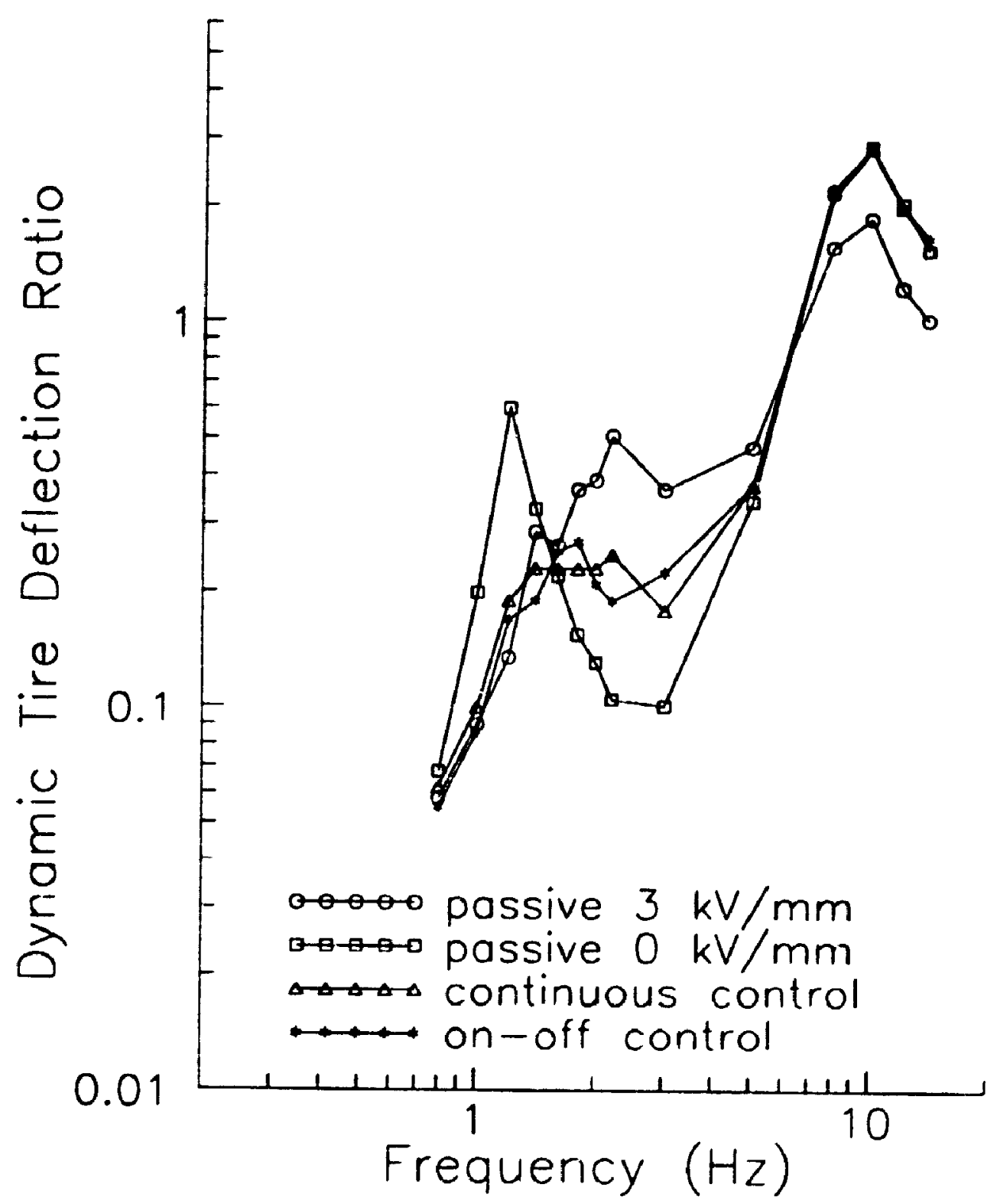

Figure 28: Experimental Results of the Dynamic Tire Deflection Using Both Passive (Fixed Voltage) and Semi-Active Control Including ON-OFF aid Continuous Semi-Active Control 


\section{CHAPTER VI}

\section{CONCLUSIONS}

\section{T.1 ER FLUIDS}

\subsubsection{ERF 'A'}

The starch based ER fluid, which was used throughout the vibration tests, was adequate for laboratory use but was unsatisfactory for vehicular use for a number of reasons:

1. the settling time of the particles was exceedingly short, in the order of minutes, even seconds;

2. the maximum shear stress that could be generated with a $3 \mathrm{~mm}$ gap and approximately 1 litre of fluid was only 300 Newtons;

3. the operating temperature range was only from $0^{\circ} \mathrm{C}$ to $50^{\circ} \mathrm{C}$; and

4. the shear stress dependended considerably on shear rate.

The starch tased fluid, however, did have advantages, which included:

1. starch particles were readily available in small diameter $(25 \mu \mathrm{m})$ size and relatively inexpensive; and

2. the shear ratio of the starch based ER fluid was quite high, approximately 5 at a shear rate of $250 \mathrm{~s}^{-1}$.

It is doubtful whether a commercial ER fluid would ever be based upon starch particles as there are now synthetic polymers and even zeolite materials which show 
signficantly increased ER activity over starch based particles.

\subsubsection{ERF 'B'}

The proprietary fluid obtained from an independent researcher was found through experimentation to be unsuitable for either vehicular or laboratory use because of its relatively large zero field viscosity and small shear ratio. Its salient properties could be summarized as follows:

1. thick, paste like consistency with no electric field applied;

2. maximum shear ratio (or control ratio) of only 2 approximately;

3. good resistance to settling;

4. shear stress in the order of 800 Newtons (at $3000 \mathrm{~s}^{-1}$ ); and

5. shear stress almost linearly dependent upon shear rate.

\subsubsection{Alternative ER Fluids}

There are currently being developed ER fluids which reportedly are capable of generating high shear stress $(4 \mathrm{kPa})$ over a reasonable temperature range $\left(0^{\circ}\right.$ to $\left.80^{\circ} \mathrm{C}\right)$ but their cost is still prohibitively expensive for vehicular applications. Many research centres are actively investigating zeolite materials and synthesized polymers which may or may not be substantially free of water and its attendant problems. When it is considered that a practical ER fluid must be chemically stable, electrically insulating, have low rero field viscosity, be non-corrosive and non-abrasive in addition to demonstra:ing significant ER activity, it is not surprising that the "perfect" ER fluid has not yet been developed. Since 
no pure liquid has demonstrated sufficient ER activity, the problem is compounded by the fact any ER fluid will invariably consist of two separate phases; a continuous phase and 2 dispersed particulate phase. There will therefore probably never be a "perfect" ER fluid which can meet all of the requirements expected. More probably, researchers will devise means with which to circumvent or accomodate the "imperfections".

\subsection{ERF Damper}

The experimental damper used for these experiments had a large blockage area which resulted in excessive shear rates. The high shear rates resulted in the damper saturating at even moderate frequencies ( $>2 \mathrm{~Hz}$.). The damper had a gap : $: z e$ of $3 \mathrm{~mm}$ which was satisfactory for the purpose. A larger gap size would have required higher exciting voltages which in turn would have increased the voltage stresses in the wiring. A smaller gap size would have increased the zero field shear stress and hence reduced the overall shear (or control) ratio.

A new damper should be designed with iess blockage area to reduce the shear rate within the active area of the damper. One possible design method would be to employ concentric cylinders fixed to the damper body through which the ER fluid is squeezed by means of a conventional piston and cylinder situated at the centre of the ERF damper. The ER "valve" configuration would eliminate the problems associated with high voltage electrodes moving relative to the damper body and would simplify the design of the piston considerably. 
It has been shown that for a given volume of ER fluid suspended between concentric, annular electrodes. and for a given electric field intensity, the electrostatic energy stored between the electrodes is practically constant no matter what the gap size. The consequence of this interesting fact is the power requirements will also remain practically constant since power is simply the time derivative of work and energy. Therefore, an ERF damper can be designed for optimality without concem for minimizing the power consumption. The caveat to this statement is that for a given electric field strength, the electric potential across the electrodes increases in direct proportion to the gap size. Increasing the potential across the electrodes increases the voltage stresses in the output wiring of the high voltage generator and within the high voltage generator itself. Increasing the electric potential across the etectrodes also requires a proportional increase in the turns ratio of the converter transformer which has practical limits. Transformers generally decrease in efficiency as the turns, ratio increases. There is also the problem of corgna discharge to contend with. For vehicular applications, the problem of coron, discharge in humid conditions becomes acute. As a guidelize, the upper limit fór an ERF damper excitation voltage slıould be $10 \mathrm{kV}$.

\subsection{High Voltage Supply Unit}

The high voltage supply unit operated satisfactorily iti controlling the ERF damper. The rise time of about $5.5 \mathrm{~ms}$ was within the requirements for switch-over cited by many researchers. The decay time was approximately $1 \mathrm{~ms}$. The deficiencies in the system performance are more likely attributable to the ERF damper and the ER fluid itself 
rather than the high voltage supply unit. There was some problems associated with EMLRFI radiation that must be addressed for practical applications. The flyback converter offers a simple and reliable method with which to energize the ERF damper. There was little discemible difference in effect on the damper between the pulsed dc signals and the ripple free de output from the laboratory power supply. The ignition coil performed satisfactorily, however a coil with a lower primary inductance and less shunt capacitance would allow for a higher, and consequently less audible, switching frequency. The power consumption of the flyback converter was esrimated at 10 watts with an efficiency of $25 \%$.

\subsection{Control Strategies and System Performance}

Both the continuous and ON-OFF control strategies were successful in reducing the transmissibility of the sprung mass over that of a passive system. The ON-OFF control strategy has the advantage of being easier to implement, possibly by analogue control only. In theory, both control strategies could be implemented with a single transducer, a potentiometer across the damper fixing points. Long-life potentiometers are currently being used for throttle positon and EGR valve position sensing on automobiles. Electronic control units for fivel management and wheel spin control are already standard equipment on many models. Therefore, the technical infrastructure for a real-time automatic suspension system already exists. 
The ERF damper used in the vibration tests had a number of limitations which nontheless degraded the system performance. The most serious of those was the dependence of shear stress on shear rate. Figure 29 shows the equivalent damping coefficient of the ERF damper as a function of frequency. At low frequencies $(<1.5 \mathrm{~Hz})$ the damper was able to become very stiff when excited by high voltage and a large control ratio results (as depicted by the difference between the zero field and applied field curves). At higher frequencies the applied field shear damping ratio decreased and eventually approached the zero field curve. Consequently, at very high frequencies the damper is effectively "off" even when excited by the maximum allowable voltage. In physical terms, the fluid is being agitated so rapidly it can not form a cohesive structure. Mainly, this was due to the excessive blockage are, in the pis:on which in turn resulted in excessive shear rates. Consequently, the damper was incapable of generating sufficient force to effectively control wheel hop. Thus, if a wheel hop strategy had been implemented, the damper would not have been able to attenuate the "tire" vibrations satisfactorily. For ride comfort purposes, the diminished control ratio at high frequencies presents no real problem since a "soft" setring is desirable anyways. Modifications to the damper are necessary to provide an adequate control ratio over a broader band of frequencies. Reducing the shear rate within the damper would address this problem. 

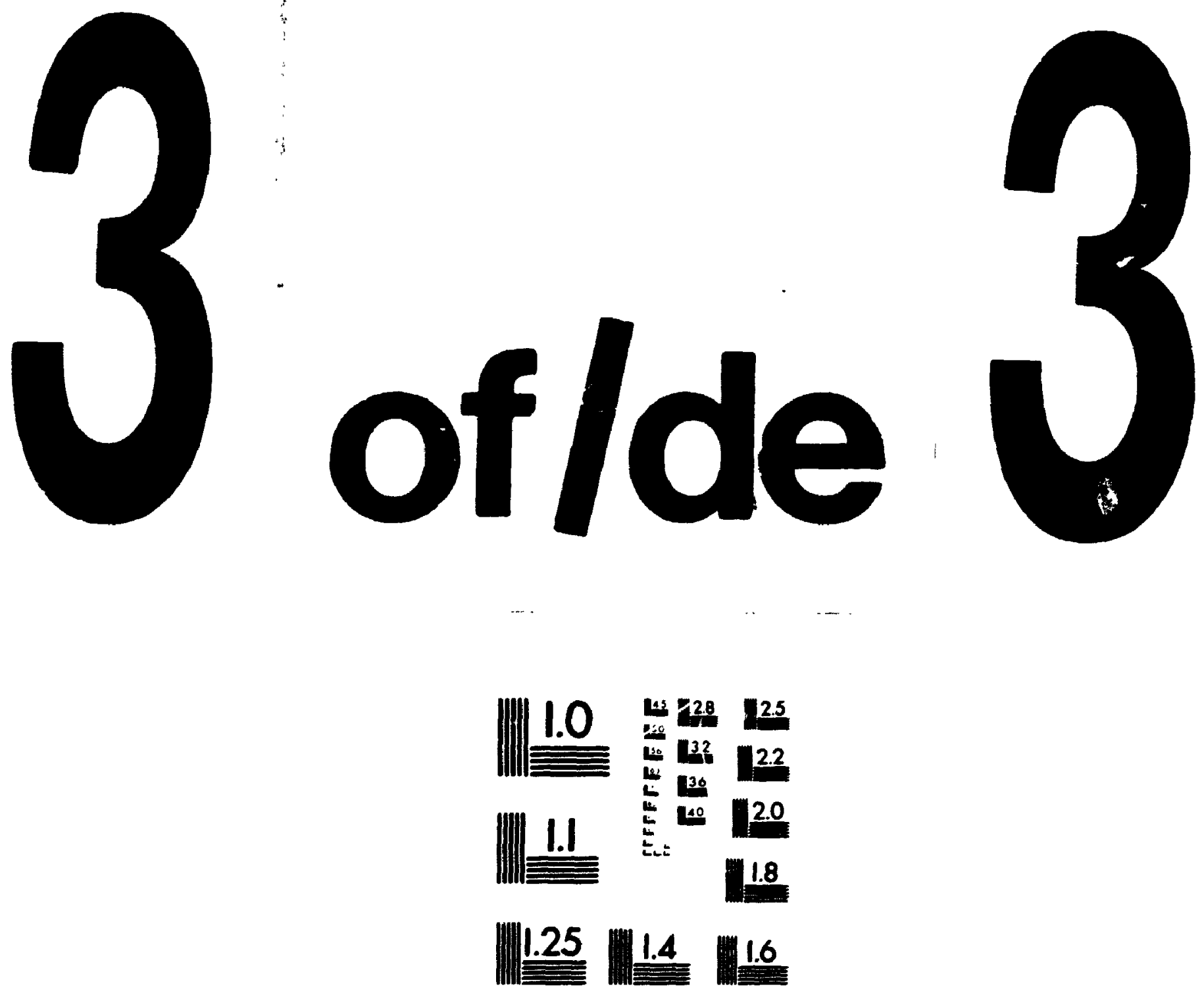

\author{
MICROCOPY RESCLUTION TEST CHART \\ NATIONAL BUAEAU OF STANDARDS \\ STANDARO REFERENCE MATERIAL 1010 \\ (ANSI and ISO TEST CHART No 2)
}




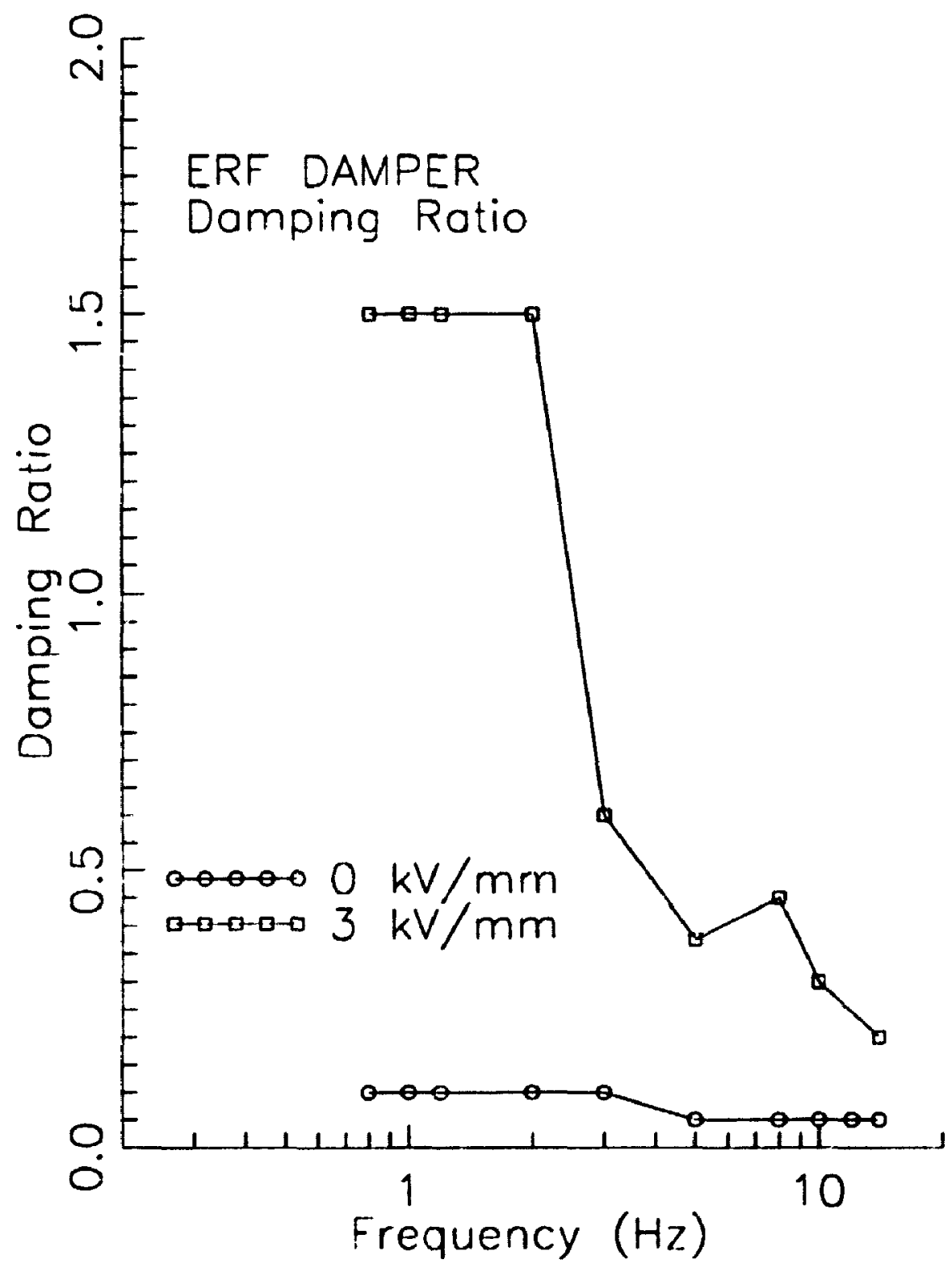

Figure 29: Effective Damping Ratio For the Electrorheological Fluid Damper versus Frecjuency 


\section{CHAPTER VII \\ RECOMMENDATIONS}

\subsection{ERF Damper}

The ERF damper needs to be re-designed with less blockage area, better sealing, and less overall size in order to fully exploit the potential of the ER fluid. An optimization procedure should be carried out in onder to determine the optimum number of cylinders, the gap size, and the length. A computer design program would be essential for optimizing the many conflicting requirements.

Better ERF fluid must be developed or procured for a full-size damper. The ER fluids tested thusfar cannot generate sufficient shear stress for a practical application. Zeolite material shows promise as a base for a practical ER fluid. Since the exact mechanism of the ER effect is still not completely understood, a great deal of research into the basic properties of ER "active" particles is still required.

\subsection{High Voltage Supply Unit}

The switch-over time of the high voltage supply unit could be shortened with some significant improvements in system performance. The reduction of transmitted EML/sFI also requires attention. Shielding, snubber circuits or a combination of both should be investigated. Improvements in the magnetic components could also be made, especially the reduction in shunt and leakage inductance, and shunt capacitance. A lower voltage across the damper would ease the requirements on the power supply; however any 
reduction in output voltage should not compromise the mechanical response of the damper.

\subsection{Control Strategies}

Both the ON-OFF and continuous control strategies demonstrated significant performance increases over the passive suspension. Wheel hop control still needs be addressed however. The possibility of applying some form of Fourier Analysis in the detection of wheel hop frequency content should be investigated. ON-OFF control offers considerable savings in system complexity over continuous control. A more detailed investigation into the relative merits of ON-OFF versus continuous control should be made.

\subsection{Summary}

The vibration tests have proved that ER fluids in conjunction with a semi-active control strategy can provide significant performance increases over passive suspension systems. Moreover, it has been proved that relatively inexpensive equipment can be used to excite the ER fluid. There is no fundamental reason why an ER damper could not be fitted to an existing automobile and provide superior ride performance. 


\section{REFERENCES}

1. Stangroom, J.E.,"Electrorheological Fluids," Physics Technol.,Vol. 14,pp.290-296 (1983)

2. Korobko, E.V., Shulman, Z.P.,"Viscoelastic Behaviour of Electrorheological Fluids," Proceedings of The Second International Conference On ER Fuids,Raleigh, N.C.,pp.3-12 (1989)

3. Bullough, W.A., "A Rheological Semiconductor," Advanced Materials For Optics And Electronics, Vol I, pp.159-171 (1992)

4. Coulter, J.P., Duclos, T.G., "Applications of Electrorheological Materials in Vibration Control," Proc. Second International Conference on Electrorheological Fluids, Raleigh N.C..pp.300-323, (1989)

5. Brooks, D.A., "Devices Using Electro-Rheological Fluids," Proc. Second Intemational Conference on Electrorheological Fluids, Raleigh N.C.,pp.371-401, (1989)

6. Gorodkin, R.G. et al., "Applications of the Electrorheological Effect in Engineering Practice," Fluid Mechanics-Soviet Research, Vol.8, No.4,pp.48-61 (1979)

7. Wu, X.M., Stanway, R. and Sproston, J.L., "Electro-Rheological Fluids And Their Applications In Active Suspension And Power Transmussion," 22nd Int. Symposium on Automotive Technology and Automation, Florence, Italy, pp.823-830 (1990)

8. Bullough, W.A., Peel, D.J., "Progress Towards a Hydraulic Semiconductor for Vehicle Application," SAE Transaction 881786 (1988) 
9. Bullough, W.A. et.al., "Fast Pick-Up and Drop Load Performance of a Low Electrical and Mechanical Time Constant, Electro-Rheologically Based Clutch," Mechatronic Systems Engineering 1, Kluwer Academic Publishers, Netherlands, pp.315-327 (1992)

10. Carlson, J.D., Duclos, T.G., "ER Fluid Clutches and Brater-Fluid Property and Mechanical Design Considerations," Proc. Second International Conference on Electrorheological Fluids, Raleigh N.C.,pp.353-367, (1989)

11. Wong, J.Y. et.al., "On The Applications Of Electro-Rheological Fluids To The Development Of Semi-Active Suspension Systems For Ground Vehicles," Proc. CSME Fonum "Transport 1992" Montreal, Vol.1, pp.186-191 (1992)

12. Konig, W., "Bestimmung einiger Reibungscoefficienten und Verssuche uber den Einfluss der Magnetissirung und Electrisirung auf die Reibung der Flussigkeiten," Ann.Phys.Lpz, Vol.25, pp.618-625 (1885)

13. Sossinski, S., "Effect of an Electric Field on the Viscosity of Liquids," Nature, Vol.144, p.117 (1939)

14. Andrade, E.N., DA C. and Dodd, C., "Effect of an Elecuric Field on the Viscosity of Liquids," Nature, Vol.144, pp.117-118 (1939)

15. Andrade, E.N., DA C. and Dodd, C., "Effect of an Electric Field on the Viscosity of Liquids," Proc. Royal Society, A, Vol.187, pp.296-337 (1946)

16. Winslow, W.M., "Induced Fibration of Suspensions," J. of Applied Physics, Vol.20,pp.1137-1140 (1949) 
17. Winslow, W.M., "Method and Means for Translating Electrical Inupulses into Mechanical Force," U.S. Patent Specification No.2,417,850 (1947)

18. Winslow, W.M., "Field Controlled Hydraulic Devices," U.S. Patent Specification No.2,661,596 (1953)

19. Winslow, W.M., "High Fidelity Slip Control," U.S. Patent Specification No.2,661,825 (1953)

20. Winslow, W.M., "Field Responsive Force Transmitting Compositions," U.S. Patent Specification No.3,047,507 (1962)

21. Klass, D.L. and Martinek, T.W., "Electroviscous Fluids. I. Rheological Properties," J. of Applied Physics, Vol.38, No.1, pp.67-74 (1966)

22. Klass, D.L. and Martinek, T.W., "Electroviscous Fluids. II. Electrical Properties," J. of Applied Physics, Vol.38, No.1, pp.75-80 (1966)

23. Klass, D.L. and Martinek, T.W., "Electric Viscous Field Responsive Shock Absorber," U.S. Patent Specification No.3,207,269 (1965)

24. Klass, D.L., Martinek, T.W. and Brozowski, V., "Electric Field Responsive Fluid and method of Preparation," British Patent Specification No.1,076,754 (1967)

25. Bullough, W.A. and Stringer, J.D., "The Utilisation of the Electroviscous Effect in a Fluid Power System," 3rd Int. Fluid Power Symposium, Turin, Italy (1973)

26. Bullough, W.A. and Stringer, J.D., "Direct Flow Control by Electric Fields," Hydraulic \& Air Engineering, Vol.5, No.4, pp.11-17 (1977) 
27. Bullough, W.A. and Foxon, M.B., "A Proportionate Coulomb and Viscously Damped Isolation System," Jour. Sound and Vibration, Vol.56, No.1, pp.35-44 (1977)

28. Stangroom, J.E., "Improvements in or Reiating to Electric Field Responsive Fluids," British Patent Specification No.1,501,635 (1978)

29. Stangroom, J.E., "Improvements in or Relating to Apparatus For the Controlled Hydration of Solids," British Patent Specification No.1,534,170 (1978)

30. Stangroom, J.E., "Improvements in or Relating to Electric Field Responsive Fluids," British Patent Specification No.1,570,234 (1980)

31. Bullough, W.A., "Miscellaneous Electro-Rheological Phenomena, Part III," Proc. Second International Conference on Electrorheological Fluids, Raleigh N.C.,pp.141-157, (1989)

32. Sprecher, A.F., Chen, Y., and Conrad H., "Measurement Of Forces Between Particles In A Model ER Fluid," Proc. Second International Conference on Electrorheological Fluids, Raleigh N.C.pp.82-92 (1989)

33. Jordan, T.C., Shaw, M.T., "Structure In Electrorheological Fluids," Proc. Second International Conference on Electrotheological Fluids, Raleigh N.C.pp.231-251 (1989)

34. Van Vlack, L.H., "Elements of Material Science and Engineering," publ.AddisonWesley,pp.348-360.

35. Jordan, T.C., Shaw, M.T., "Electrorheology," I.E.E.E. Transactions on Electrical Insulation, Vol.24 No.5,pp.849-89 (1989)

36. Block, H., Kelly, J.P., "Electrorheology," J.Phys.D:Appl.Phys 21,pp.1661-1677 (1988)

37. Block, H., Kelly, J.P., U.S. Patent No. 4687589 (1987) 
38. Inoue, A., "Study of New Electrorheological Fluid," Proc. Second International Conference on Electrorheological Fluids, Raleigh N.C.pp.176-183 (1989)

39. Philips, R.W., "Engineering applications of fluids with a variable yield stress," Ph.D.Thesis, University of California at Berkely, March 1969.

40. Stangroom, J.E., "The Bingham Plastic Model of ER Fluids and Its Implications," Proc. Second Intemational Conference on Electrorheological Fluids, Raleigh N.C.,pp.199-206 (1989)

41. Bares, J.E., Carlson, J.D., "Electrorheological Fluid Design: An Overview," Proc. Second International Conference on Electrorheological Fluids, Raleigh N.C.pp.93-114 (1989)

42. Lingard, S., Bullough, W.A., "Tribological Aspects Of Electromeological Fluid Behaviour With Respect To Non-Polar Base Liquids," Proc. Second International Conference on Electrorheological Fluids, Raleigh N.C.pp.93-114 (1989)

43. Frood, D.G., "Preliminary Measurement of I-V Characteristics in Starch Based ER Fluids," Proc. Second International Conference on Electrorheological Fluids, Raleigh N.C.pp.265-286 (1989)

44. Kraus, J.D., "Electromagnetics," pub. McGraw-Hill Inc., pp438-439, (1992)

45. Walker, P.M.B., Ed., "Cambridge Dictionary Of Science And Technology," pub. Cambridge University Press, pp.663 (1988)

46. Block, H., Kelly, J.P., "Dielectric Properties Of Fluids And Their Relation To ElectroRheology," IEEE Colloquim on Electrically Active Fluids, (1985) 
47. Van Vlack, L.H., "Elements Of Material Science And Engineering," pub. AddisonWesley, pp.354 (1984)

48. Stevens, N.G., Sproston, J.L., and Stanway, R., "The Influence Of Pulsed D.C. Input Signals On Electrorheological Fluids," Journal of Electrostatics, 17, pp.181-191 (1985)

49. Jordan, T.C., Shaw, M.T., "Electiorheology," I.E.E.E. Transqctions on Electrical Insulation, Vol.24 No.5,pp.849-89 (1989)

50. Hagele, K.H., Engelsdorf, K., Mettner, M., Panther, M., Ngoc, Q., Tran, E. Rubel, E., "Continously Adjustable Shock Absorbers for Rapid-Acting Ride Control Systems (RCS). SAE Transactions, 905125, pp.37-46 (1990)

51. Stevens, N.G., Sproston, J.L., and Stanway, R., "The Influence Of Pulsed D.C. Input Signals On Electrorheological Fluids," Journal of Electrostatics, 17, pp.181-191 (1985)

52. Coulter, J.P., Duclos, T.G., "Applications of Electrotheological Materials in Vibration Control," Proc. Second International Conference on Electrorheological Fluids, Raleigh N.C., pp.300-323 (1989)

53. Hnatek, E.R., "Design Of Solid State Power Supplies," pub. Van Nostrand Reinhold, New York (1989)

54. Smith, S., "Magnetic Components," pub. Van Nostrand Reinhold, New York (1989)

55. Sum, K., "Switchmode Power Conversion," pub. Marcel Dekker. Inc. (1984)

56. Flanagan, W.M., "Handbook Of Transformer Applications," pub. McGraw-Hill Book Company (1986) 
57. Weber, H., "Electronic Breakeriess Inductive Storage Ignition," pub. Automotive Electronics (SAE 740021) pp.245-255 (1974)

58. Frungel, F., "High Speed Pulse Technology," Vol.I, pub.Academic Press, New York (1965)

59. Gottlieb, I.M., "Power Supplies, Switching Regulators, Inverters \& Converters," pub. McGraw-Hill Book Corapany (1984).

60. Decker, H. et.al., "A Practical Approach Towards Advanced Semi-Active Suspension Systems," International Conference on Advanced Suspensions, London, 1988.

61. Sherman, D., "Rjiding On Electrons," Popular Science, Sept. 1990.

62. Crosby, M.J., Karnopp, D.C., "The Active Damper - is New Concept For Shock And Vibration Control," The Shock And Vibration Bulletin, Vol.43, Washington, 1973.

63. Bender, E.K., Karnopp. D.C., and Paul, I.L., "On the Optimization of Vehicle Suspensions Using Random Process Theory," ASME no.67 Trans-12, 1967.

64. Krasnicki, E.J., "The Experimental Performance Of An 'ON-OFF' Active Damper," The Shock and Vibration Bulletin, Vol.51, 1981.

65. Kamopp, D., "Theoretical Limitations In Active Vehicle Suspensions," Vehicle System Dynamics, 15, 1986, pp41-54.

66. Crolla, D.A., Aboul Nour, A.M.A., "Theoretical Comparisons Of Various Active Suspension Systems In Terms Of Performance And Power Requirements," Intemational Conference on Advanced Suspensions, London, 1988. 
67. Sharp, R.S., Hassan, S.A., "The Relative Performance Capabilities of Passive, Active and Semi-Active Car Suspension Systems," Proc.Institute Mech.Engr. Vol. 200, 1986.

68. Crosby, M.J., Karnopp, D.C., "The Active Damper - A New Concept For Shock And Vibration Control," The Shock And Vibration Bulletin, Vol.43, Washington, 1973.

69. Krasnicki, E.J., "The Experimental Performance Of An 'ON-OFF' Active Damper," The Shock and Vibration Bulletin, Vol.51, 1981.

70. Kamopp, D.C., "Active Damping In Road Vehicle Suspension Systems," Vehicle System Dynamics, Vol.12, 1983, pp291-316.

71. Margolis, D., "The Chatter of Semi-Active On-Off Suspension and its Cure," Vehicle System Dynamics, Vol.13,1984, pp.129-144.

72. Thomson, W.T., "Theory of Vibration With Applications," Prentice Hall, New Jersey, 1988, p.78.

73. Margolis, D., "The Response of Active And Semi-Active Suspensions To Realistic Feedback Signals," Vehicle System Dynamics, Vol.11, 1982, pp.267-282.

74. Miller, L.R., "The Effect of Hardware Limitations On An On-Off Semi-Active Suspension," Int.Conf.Advanced Suspensions, London, 1988.

75. Wong, J.Y., "Theory Of Ground Vehicles," John Wiley \& Sons Inc., New York, 1978. pp286.

76. Lizell, M., "Semi-Active Damping," Int.Conf.Advanced Suspensions, London, 1988. 
77. Jolly, M.R., Miller, L.R., "The Control of Semi-Active Dampers Using Relative Feedback Signals," SAE TRANS. 892483.

78. Hagele, K.H. et.al., "Continously Adjustable Shock Absorbers for Rapid Acting Ride Control Systems (RCS)," 23rd FISITA Congress, Torino, Italy, 1990.

79. Thompson, A.G., "An Active Suspension with Optimal Linear State Feedback, Vehicle System Dynamics, Vol.5, pp.187-203,1976. 

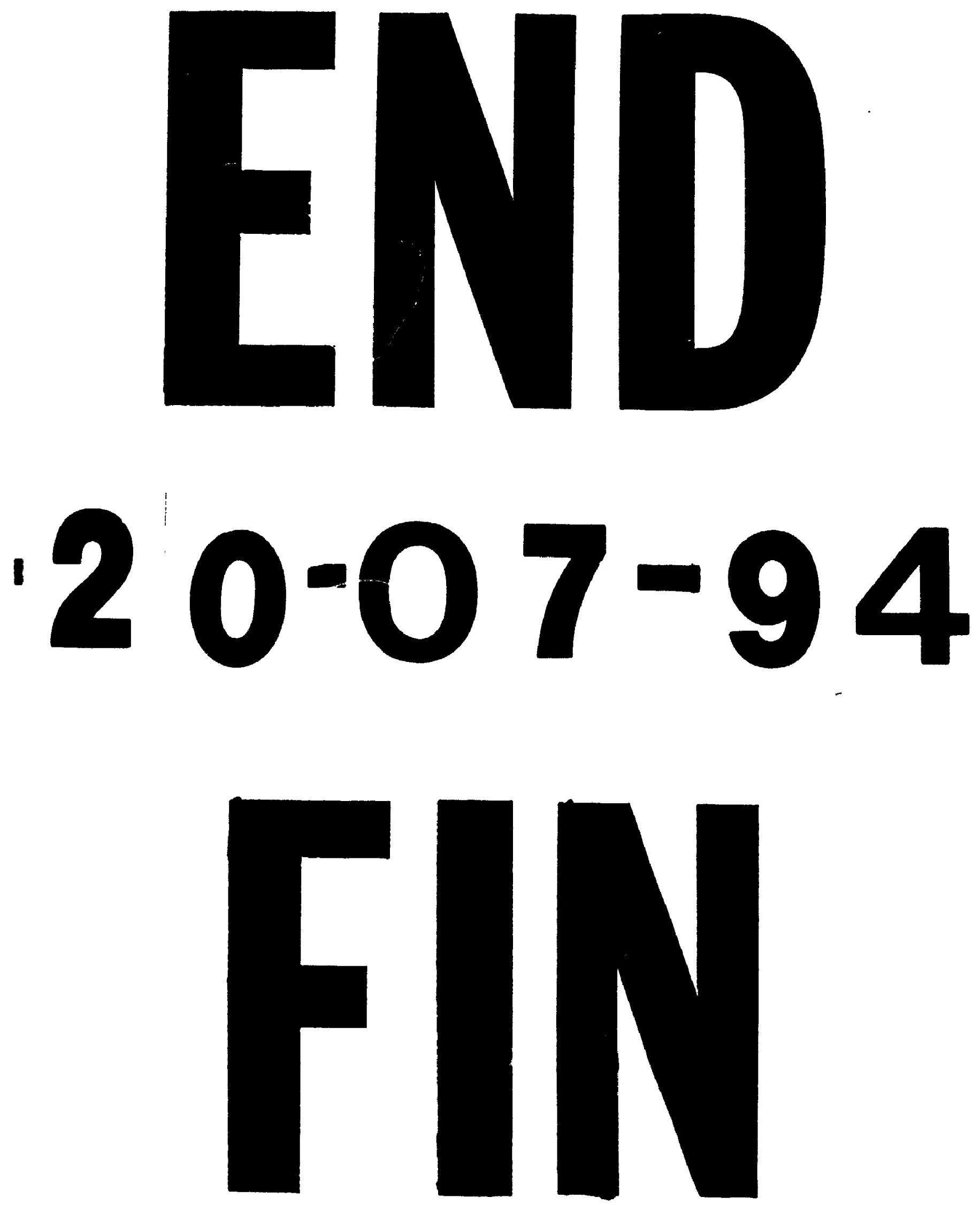